\title{
Vibration Sensitivity in Earthworms: Surfacing Responses to Seismic Vibrations in Florida and Ontario
}

\author{
By \\ Ombor Mitra \\ A dissertation submitted to the Faculty of Graduate Studies and Research in partial \\ fulfillment of the requirements for the degree of Master of Science in Biology \\ Carleton University \\ Ottawa, Ontario
}

\author{
Ombor Mitra \\ Carleton University \\ Supervisor: Dr. Jayne Yack
}

(c) Ombor Mitra 2009 


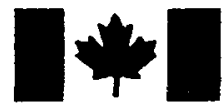

\author{
Library and Archives \\ Canada \\ Published Heritage \\ Branch \\ 395 Wellington Street \\ Ottawa ON K1A ON4 \\ Canada
}

Bibliothèque et

Archives Canada

Direction du

Patrimoine de l'édition

395 , rue Wellington

Ottawa ON K1A ON4

Canada
Your file Votre référence
ISBN: $978-0-494-68612-6$
Our file Notre référence
ISBN: $978-0-494-68612-6$
NOTICE:

The author has granted a nonexclusive license allowing Library and Archives Canada to reproduce, publish, archive, preserve, conserve, communicate to the public by telecommunication or on the Internet, loan, distribute and sell theses worldwide, for commercial or noncommercial purposes, in microform, paper, electronic and/or any other formats.

The author retains copyright ownership and moral rights in this thesis. Neither the thesis nor substantial extracts from it may be printed or otherwise reproduced without the author's permission.
AVIS:

L'auteur a accordé une licence non exclusive permettant à la Bibliothèque et Archives Canada de reproduire, publier, archiver, sauvegarder, conserver, transmettre au public par télécommunication ou par l'Internet, prêter, distribuer et vendre des thèses partout dans le monde, à des fins commerciales ou autres, sur support microforme, papier, électronique et/ou autres formats.

L'auteur conserve la propriété du droit d'auteur et des droits moraux qui protège cette thèse. Ni la thèse ni des extraits substantiels de celle-ci ne doivent être imprimés ou autrement reproduits sans son autorisation.
In compliance with the Canadian Privacy Act some supporting forms may have been removed from this thesis.

While these forms may be included in the document page count, their removal does not represent any loss of content from the thesis.
Conformément à la loi canadienne sur la protection de la vie privée, quelques formulaires secondaires ont été enlevés de cette thèse.

Bien que ces formulaires aient inclus dans la pagination, il n'y aura aucun contenu manquant.

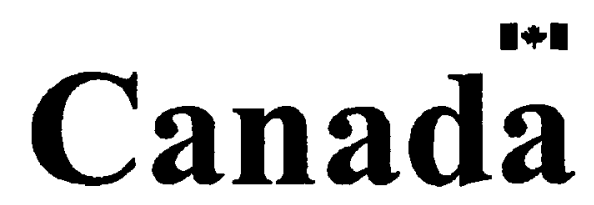




\begin{abstract}
:
The various anecdotal reports of earthworms surfacing in response to soil-borne vibration have never been formally tested. My thesis objectives included testing the effectiveness of this phenomenon, characterizing the soil vibrations involved, and identifying responding species. Trials conducted using traditional earthworm harvesting methods (a wooden stake scraped with a metal bar, and a hand-vibrated pitchfork) showed that Diplocardia earthworms in Florida responded to stake vibrations (the pitchfork was not tested there), and various species in Ontario responded to pitchfork vibrations, but not the stake. Both techniques produced broadband low frequency vibrations below $500 \mathrm{~Hz}$ (peaking between 60 to $100 \mathrm{~Hz}$ ). The number of surfacing earthworms was significantly greater than controls, and was correlated to seismic signal strength. Preliminary anatomical descriptions of possible sensory organs implicated ciliated sensory organs in vibration reception, and functional significance of surfacing responses is discussed. Surfacing may be an escape response used against burrowing predatory moles.
\end{abstract}




\section{Acknowledgements}

My thanks go first and foremost to my supervisor Dr. Jayne Yack for her guidance, experience, patience, and critical direction with which she contributed heavily to this work, and to my committee members Dr. Jeff Dawson and Dr. John Lewis. Special acknowledgements are deserved by Dr. Mac Callaham, Dr. John Reynolds, and Dr. Myron Smith, as the field work done in Florida would not have been possible without the help of Dr. Callaham and Dr. Smith, while the field work and earthworm identification in Ontario would have been equally impossible without the expertise of Dr. Reynolds. Special acknowledgement must also be given to Dr. Jeff Dawson, who helped with many technical aspects of this research, especially the assembly of the geophone soil sensors. I would also like to thank Jianqun Wang for his assistance with electron microscopy.

All of my colleagues from the Yack lab from 2008 to 2009 deserve acknowledgements as well: Alan Fleming, J-P Fournier, Veronica Bura, Sarah Bond, Jackie Scott, Katie Lucas, Jenn Mongrain, and Sen Sivalingam. Their friendship, support, and advice were all instrumental in the success of this thesis. Special thanks goes to AJ, JP, Sarah, and Jenn, as they provided critical assistance with transportation and experimentation during the Ontario field trials. I would also like to thank my friends and family for their support and advice during this time, since without the help of Tara Best, Ian Chardine, Shyamal, Chaitali, and Sharoni Mitra, this work would have been impossible to complete.

The Apalachicola National Forest, United States Department of Agriculture's Forest Service, the National Capital Commission, and Carleton University must also be recognized for their willingness to allow research to be undertaken on their properties. 
The fieldwork conducted on their land was the foundation of my research. A very special thanks goes to the Irene Ethel Cockburn Bursary I received in 2008. I am extremely grateful for the assistance I needed and received from that bursary. I would also like to thank the CFI New Opportunities and NSERC Discovery (JEY) programs for funding, as well as the friendly residents of Sopchoppy, Florida, for their kind assistance at the Sopchoppy Worm Gruntin' Festival. 


\section{Table of Contents}

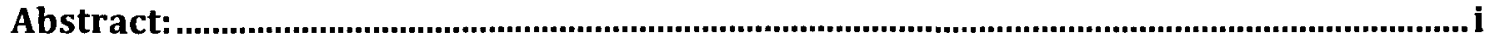

Acknowledgements .......................................................................................................................

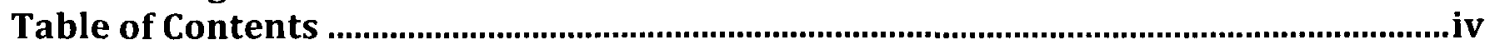

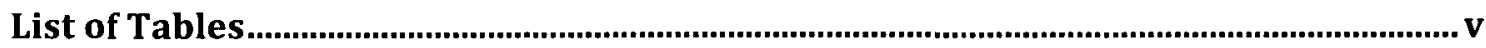

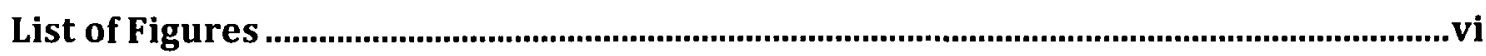

Chapter 1 General Introduction............................................................................ 1

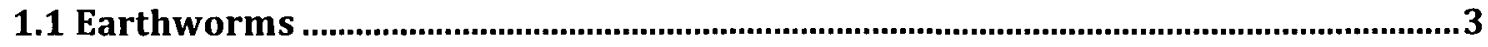

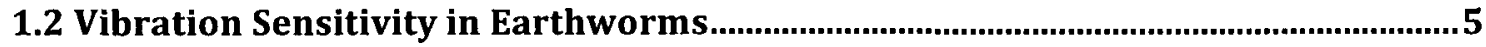

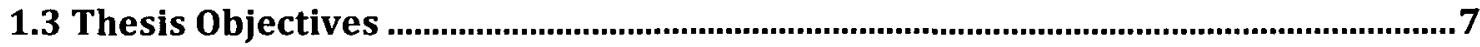

Chapter 2 Behavioural Responses to Vibrations in Worms From Florida and

Ontario ............................................................................................................................. 8

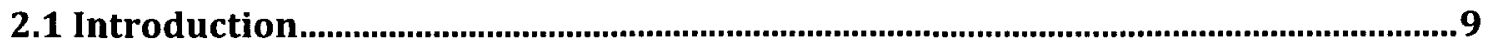

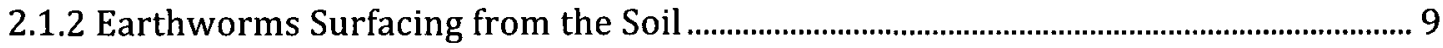

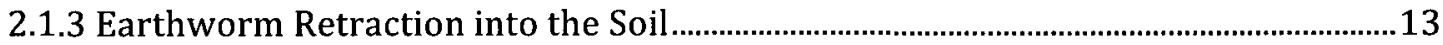

2.1.4 Other Earthworm Responses to Vibration ........................................................................14

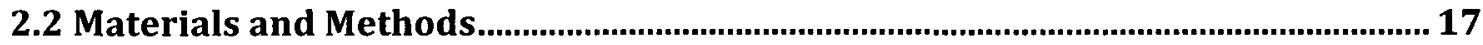

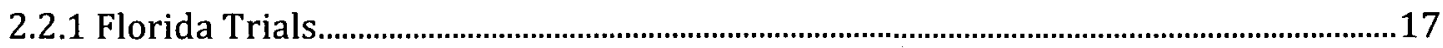

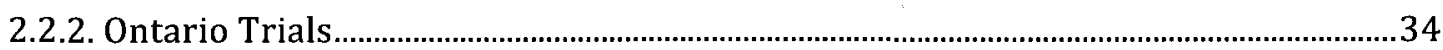

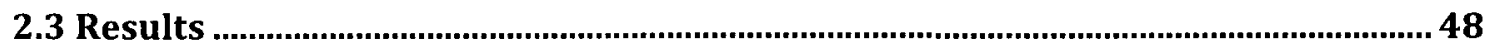

2.3.1 Earthworm Responses to Vibration in Florida .................................................................48

2.3.2 Earthworm Responses to Vibration in the Ottawa Region of Canada .........................63

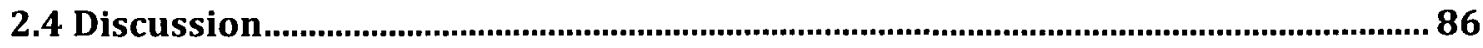

Chapter 3 Anatomy: Nervous system and Sensory Organs............................... 107

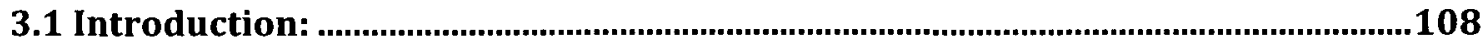

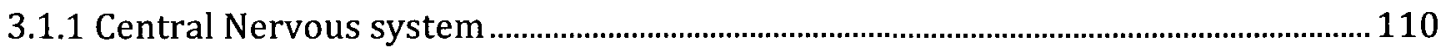

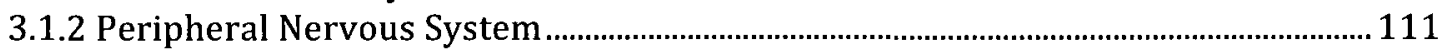

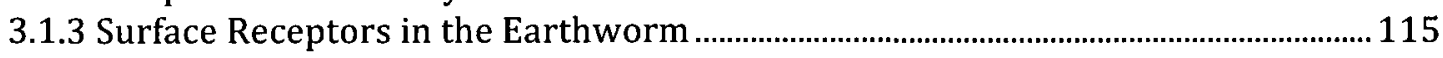

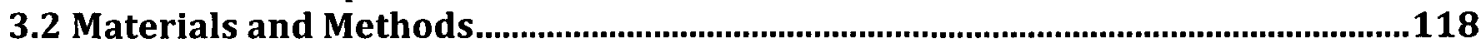

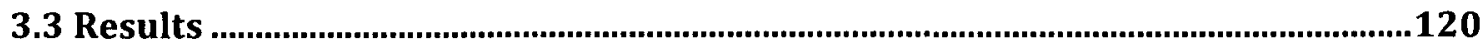

3.3.1 Internal Anatomy of the Nervous System .................................................................. 120

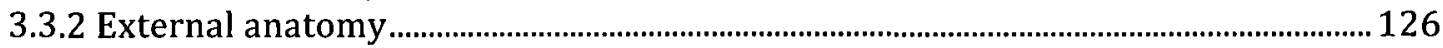

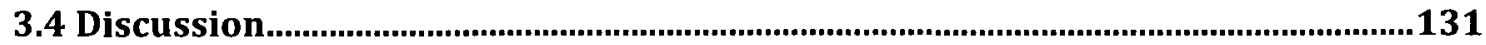

Chapter 4 General Discussion........................................................................................ 138

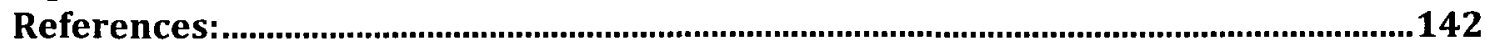

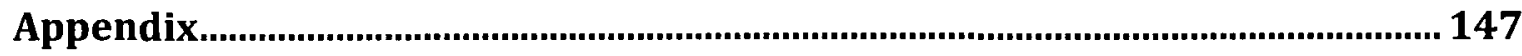




\section{List of Tables}

Table 2.1 Anecdotal Reports of Worm Grunting and Worm Charming Phenomena................... 10

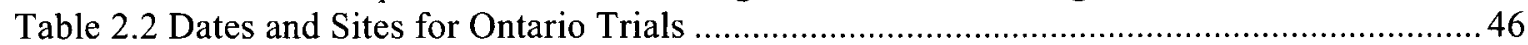

Table 2.3 Earthworm Abundance Data for Fresh and Old Trial Sites....................................... 83

Table 2.4 Environmental Factors During Ontario Trials ........................................................ 87 


\section{List of Figure Captions}

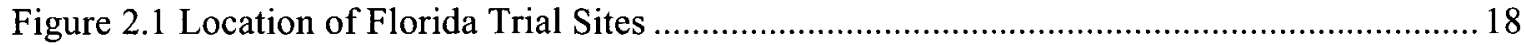

Figure 2.2 Natural Habitat of Diplocardia Earthworms in the Apalachicola National Forest...... 21

Figure 2.3 Ground Cover in the Apalachicola National Forest after a Prescribed Burn.............. 23

Figure 2.4 Florida Worm Grunting Apparatus and Method ................................................... 25

Figure 2.5 Schematics of the Different Geophone Arrays ..................................................... 28

Figure 2.6 Experimental Field Setup used in Florida ......................................................... 32

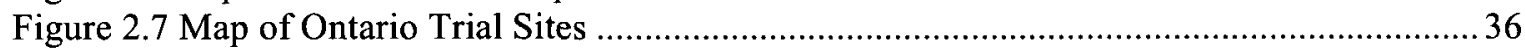

Figure 2.8 Primary Trial Site: Carleton University's Land at Herbert's Corners......................... 38

Figure 2.9 Primary Trial Site: Mer Bleu Conservation Area............................................. 40

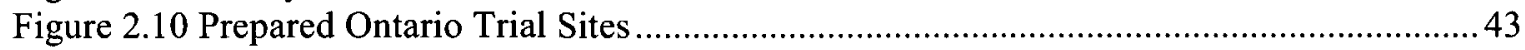

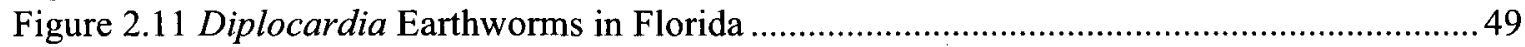

Figure 2.12 Oscillogram and Spectrogram of Vibrations from Florida Worm Grunting...............51

Figure 2.13 Vibration Measurements in Florida from all Sensors ...........................................5 54

Figure 2.14 Attenuation of Soil Vibration over Distance in Florida ........................................56

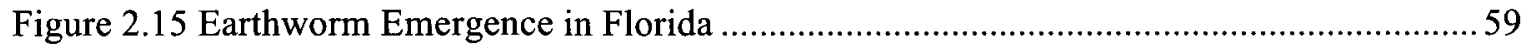

Figure 2.16 Earthworm Emergence as a Function of Distance and Surface Area in Florida........ 61

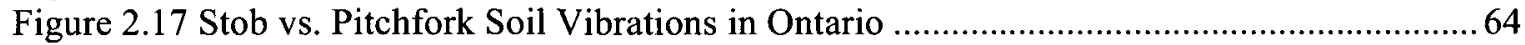

Figure 2.18 Attenuation of Soil Vibrations in Stob and Pitchfork Trials .....................................68

Figure 2.19 Earthworm Emergence During Pitchfork Trials in Ontario ..................................... 71

Figure 2.20 Sliding Window Analysis of Earthworm Emergence over Distance During

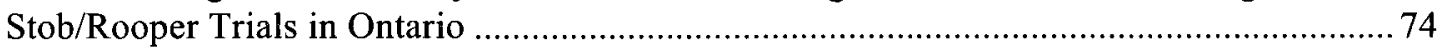

Figure 2.21 Sliding Window Analysis of Earthworm Emergence over Distance During Pitchfork

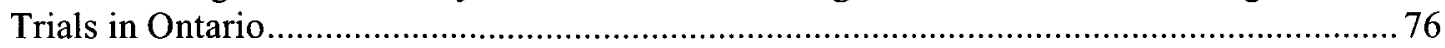

Figure 2.22 Earthworm Emergence and Abundance Comparisons for the Stob and Pitchfork Trials

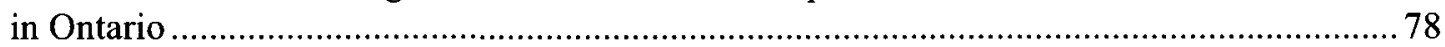

Figure 3.1 Diagram of the Central Nervous System of the Earthworm Lumbricus terrestris...... 112

Figure 3.2 Cephalic Region of the Nervous System in Diplocardia mississipiensis. ................. 121

Figure 3.3 Schematic of the Central Nervous System of Diplocardia mississipiensis. ............... 124

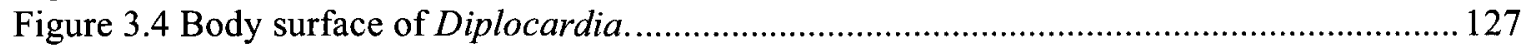

Figure 3.5 Arrangement of Sensory Organs in Lumbricus rubellus...................................... 129 
Chapter 1

General Introduction 
Animals interact with their world using a wide variety of senses that can respond to many different types of physical phenomena. Their sensory systems can detect and respond to many different types of stimuli, including visual, auditory, chemical, tactile, and even electric and magnetic field stimuli, and the information gathered through these diverse sensory modalities can be advantageous to the organism. The information an organism gathers through its senses can result in behavioural responses to sensory stimulation, which can create complex interactions between a species and the biotic and abiotic components of its environment. The most studied senses are those close to our own, such as vision, touch, and hearing. However, different kinds of animals have different kinds of sensory systems based on which sensory modalities are appropriate for their environment. Over the past several decades increasing awareness and research on novel sensory modalities and modes of communication have occurred, and understanding these sensory modalities allows us to better understand animal behaviour and the complex interactions between a given species and its environment. One of these novel sensory pathways is substrate vibration (Hill, 2001; Cocroft and Rodriguez, 2005; Hill, 2008).

Vibrations occur as mechanical oscillations in a given medium, and the most familiar of these is acoustic vibration transmitted through the air. Mechanical vibrations and pressure waves transmitted by air molecules create what we call "sound" when animals capable of hearing detect them. However, many animals have now been shown to be able to detect vibrations transmitted through other media such as water, plant stems and leaves, and soil (Hill, 2001; Cocroft and Rodriguez, 2005; Hill, 2008). There is a growing body of evidence demonstrating that vibrations transmitted directly through the 
soil can be an important avenue of information and communication for a variety of different animals. For example, elephants, mole-rats, kangaroo rats, and frogs have all been shown to detect and use soil-borne vibrations in some way (Hill, 2001; 2008). There is also a growing body of literature describing various invertebrates that respond to soil vibrations, including crickets, ants, stink bugs, scorpions, spiders, and many insect groups, although some of these organisms detect and use vibrations only from the surface of the soil (Brownell, 1977; Baroni-Urbani et al., 1988; Hill and Shadley, 2001; VirantDoberlet and Cokl, 2004; Quirici and Costa, 2005; Elias et al., 2006, Hill, 2008). But what about the various invertebrates living in visually restricted environments such as wood or soil? Detection of vibrations transmitted through these media could be very important in these situations. For example, seismic vibrations are used as courtship signals in some species of tarantula that burrow beneath the soil (Quirici and Costa, 2005). Seismic vibrations are also used by termites as alarm signals (Rosengaus et al., 1999), and similarly, substrate vibration is also used by competing weevil larvae that burrow within beans (Thanthianga and Mitchell, 1987). One important example of an invertebrate living in a visually restricted environment for which there is abundant anecdotal, but little experimental evidence for vibration sensitivity is the earthworm.

\subsection{Earthworms}

Earthworms are an abundant group of organisms familiar to most people. They are members of the class Oligochaeta, which is part of the phylum Annelida, which in turn contains various types of segmented worm-like invertebrates such as bristle worms and leeches (Reynolds, 1977; Edwards and Bohlen, 1996). There are an estimated 7000 
species of earthworm (Hendrix et al., 2008), most of which play critical roles in ecological systems that include regulating nutrient dynamics and the breakdown of organic matter, affecting the abundance and dispersal of microorganisms, altering the physical properties of soil, and improving soil fertility (Edwards and Bohlen, 1996). The diverse types of earthworms demonstrate a rich repertoire of behaviours and specialization as they pursue different ecological strategies and niches. Although there are different methods of categorizing these various lifestyles, one commonly accepted system is to place the worms into one of three major ecological groups termed: epigeic, endogeic, or anecic (Wallwork, 1983; Edwards and Bohlen, 1996). The epigeic worms are small and uniformly coloured litter dwellers that live only on the soil surface or upper soil layers. They do not normally burrow and tend to have high reproductive rates and grow rapidly. Epigeic worm species include Lumbricus rubellus, Lumbricus castaneus, and Eisenia fetida, the last of which is frequently used in vermiculture (Wallwork, 1983; Edwards and Bohlen, 1996). The endogeic earthworms vary in size and may be large or small. They construct branching horizontal burrows in the organo-mineral layer of the soil, and include the species Allolobophora caliginosa. In contrast, the anecic worms include larger deep burrowing species that construct permanent or semi-permanent vertical burrows. These burrows are open at the surface and can extend to depths of over 1 meter. Worms from this group often emerge at night to cast and feed, and will sometimes pull food material back into their burrow (Wallwork, 1983; Edwards and Bohlen, 1996). The anecic worms include Lumbricus terrestris. 


\subsection{Vibration Sensitivity in Earthworms}

Although earthworms demonstrate a variety of different lifestyles, all earthworms could potentially benefit from being able to detect and respond to soil vibrations for a variety of reasons. Sensitivity to substrate vibration could be useful for predator detection as well as communication between conspecifics, and many different organisms do use soil-vibration for these purposes (Mason and Narins, 2001; Cocroft and Rodriquez, 2005; Hill, 2008). Since earthworms live in a subterranean environment that can restrict some sensory modalities (such as vision), the ability to detect and respond to soil vibration could be a particularly advantageous evolutionary adaptation. Subterranean predators such as moles do frequently prey upon earthworms (Edwards and Bohlen, 1996), and the digging/foraging behaviour of these types of predators may produce vibrational signals that the worms can detect. However, very little has been studied in earthworms regarding their ability to detect and respond to soil vibration. There is some evidence for both behavioural and physiological responses to vibrations in earthworms. The behavioural responses have been observed in worms of various species, and these appear to respond in three general ways: by coming out of the ground, retracting into the ground, or displaying various other behaviours in response to vibrations in a laboratory setting. Additionally, there is physiological evidence showing that the nervous system of worms is sensitive to vibrational stimuli.

The first of these behavioural response types (surfacing out of the soil) has been observed in a variety of contexts and geographic areas. Earthworms are made to come out of the soil using a variety of man-made vibration mediated methods. These methods will be elaborated on in chapter 2, but in brief, these techniques are widespread in certain 
areas and go by various names including worm grunting, or worm charming (Vail, 1972;

Edwards and Bohlen, 1996). Some animals including the wood turtle (Clemmys insculpta) and some species of birds also appear to use very similar methods to make earthworms exit the soil (Darwin, 1881; Tinbergen, 1960; Kaufmann, 1986, 1989; Edwards and Bohlen, 1996). It is thought that there may be an adaptive significance to these surfacing behaviours (possibly as an escape response to underground predators, or a surfacing response to rainfall), but despite ample anecdotal evidence for vibration mediated surfacing behaviours, these phenomena have never been directly examined experimentally.

The second response to soil vibration was observed by Charles Darwin, who found that earthworms on the soil surface would react to vibrations from a piano by retracting back into the soil (Darwin, 1881). Darwin's experiment will be elaborated on in chapter 2 , but these behaviours were never observed in nature, and this type of experiment has not been subsequently replicated.

Finally, a collection of behavioural responses to vibration have been observed in laboratory settings. While many conditioning studies have demonstrated that worms can detect and learn to respond to vibrations (Ratner and Miller, 1959; Peeke et al., 1965; Herz et al., 1967), unlearned and "innate" responses to vibrations such as lengthening or contracting the body, as well as a tail flattening response have been described very rarely (Herz et al., 1967). These behavioural responses to vibration are supplemented by physiological evidence that has shown that the nervous systems of whole organisms as well as dissected earthworm preparations do respond to vibration (Collier, 1939; O'Gara et al., 2006). These laboratory experiments will be discussed in further detail in chapter 2. 


\subsection{Thesis Objectives}

The broad goal of my thesis is to experimentally determine if earthworms do surface in the presence of seismic vibrations, thus experimentally testing for the first time the many anecdotal reports that earthworms surface in response to soil vibration. Although previous work has established the ability of earthworms to detect vibrations in general, the questions of what natural responses to vibration might exist, as well as how and why such a sensory modality might be used by the organism have not been examined. I will attempt to answer these questions solely with respect to the vibration mediated surfacing behaviours of earthworms, because these are the only supposedly vibration-mediated behaviours in earthworms that have been observed in nature. A behavioural approach will examine worm "grunting" and "charming" techniques in the field. Specific thesis objectives include:

1) Measuring and characterizing the soil vibrations involved in worm grunting and charming (chapter 2)

2) Characterizing the behavioural responses of various earthworms to these vibrations (chapter 2)

3) Preliminary investigation of the nervous system and sensory receptors in earthworms (chapter 3) 


\section{Chapter 2}

\section{Behavioural Responses to Vibrations in Worms From Florida and Ontario}

Part of the subsequently described data has been published in Mitra et al. 2009:

Mitra O., Callaham M. A., Smith M. L., Yack J. E. (2009). Grunting for Worms: Seismic Vibrations Cause Diplocardia Earthworms to Emerge from the Soil. Biology Letters. 5, 16-19. 


\subsection{Introduction}

It appears that there are three different but possibly related behavioural responses to vibrations that have been observed in earthworms: exiting the ground, going into the ground, and tail-flattening and/or extending and contracting the body. The most common

response described anecdotally (through various written accounts, websites, and personal communications) is that of worms exiting the soil in response to vibration, and this response will be the primary focus of this thesis. This is because the phenomenon is relatively widespread (it occurs in North America and Europe), and unlike the other vibration responses, it is known to occur in nature and may have an adaptive function.

\subsubsection{Earthworms Surfacing from the Soil}

Earthworms responding to vibrations by coming out of the ground have been observed in a variety of diverse geographic locations. There are various reports of earthworms being collected by a variety of seemingly vibration mediated harvesting techniques, and while many of the sources of this information are anecdotal, it appears that earthworms have been harvested using vibrations in England, the United States, and Canada. Specific states and provinces in North America where such techniques are said to work include Illinois, Georgia, Florida, Arkansas, Washington, Ontario, and Nova Scotia (Reynolds. 1977; Edwards and Bohlen. 1996; various personal communications and websites (Table 2.1). The techniques used are diverse and vary according to the geographic area involved. Most American methods usually involve driving a wooden stick or stake (often called a stob) into the soil and then vibrating the stick with a metal object such as a dull saw or old leaf-spring from a vehicle (often called a rooper). 
Table 2.1 Anecdotal Reports of Worm Grunting and Worm Charming Phenomena

\section{Method}

Rubbing a metal bar against a wood stake

Rubbing a metal bar against a wood stake

Manually vibrating a garden fork England

Manually vibrating a garden fork England

Pounding on trees, or using a garden fork

Motors vibrating the ground

Manually vibrating a spade
Location

Florida, U.S.A.

Florida, U.S.A.

Washington, U.S.A.

Iowa, U.S. A.

Holland
Source

Worm Digest:

http://www.wormdigest.org/content/view/393/2/

Language Log: Worm Grunting

http://itre.cis.upenn.edu/ myl/languagelog/archive s/002996.html

The World Worm Charming Chmpionships:

http://www.wormcharming.com/

The Telegraph:

http://www.telegraph.co.uk/news/newstopics/howa boutthat/5664058/The-charms-of-worm-

charming.html

As a youth ( 50 years ago) we would capture large

"night crawlers" on the Olympic Peninsula near Forks, Washington by pounding on the sides of small trees. Large night crawlers would immediately start crawling out of the ground. We would use them in fishing for trout. My cousin used a similar technique to capture smaller earth worms near Bothell, Washington (Seattle suburb) by sticking a pitch fork into the lawn and moving it rapidly back and forth. The worms would crawl quickly to the surface and we used them for fishing. The lawn was also frequented by numerous moles, to the consternation of my aunt. (Tom Richards, via email)

Yes, I have witnessed this phenomena [worm grunting], mostly by accident, with say a rough running motor on a lawn mower or a car or near a rototiller. We have several Diplocardia species in Iowa south of Interstate 80 . (Bert Swalla, via email)

When I was around eight (in the late 60's) I went to Holland with my family. My cousins wanted to take me fishing and when I asked about where we would get bait one of them pulled a spade out from a shed. She stuck it into the ground and started to move it back and forth. Within minutes worms starting popping out of the ground and we soon had all the bait we needed. I was amazed at how fast they came out of the ground. I can to this day still see them popping out of the ground. Several months later I was back home and wanted to go fishing (I grew up in Collingwood) and we needed bait. Everyone was about to head out and turn stones and logs to find worms but I told them to stop. I said to my friends, "Watch this!" I got a shovel and stuck into my front lawn and started moving it back and forth. Nothing. I tried another spot. Nothing. I tried several more spots and every time: Nothing! My friends thought I was an idiot. I couldn't figure it out why it didn't work. (Frank Van Keeken, via email) 
Table 2.1 (continued)

Vibrating a rod

Various vibration mehods

General ground vibrations, and birds

Worm grunting

Worm grunting
U.S.A.

Southern U.S.A. Vibration methods, or mechanical extraction, are currently limited to the south-eastern United States. Various modifications of thie technique ("grunting" in Florida and Georgia, and "fiddling" in Arkansas) are employedby fish bait collectors and yield earthworms in amazing quantities. Mechanical stimulation by vibrations seems to have very little effect on on the Lumbricidae but it is extremely successful for some Acanthodrilidae and some Megascolecidae. (Reynolds, 1977)

Ireland, and unknown

Florida, U.S.A

Worm grunting, by which vibrations produced by rubbing a piece of metal (i.e. a tire iron or axe head) over a piece of wood (staub) driven into the ground cause the worms to come to the surface where they are easily gathered. The vibrations create a sound similar to a pig's grunt. (Vail, 1972).

Florida, U.S.A. Earthworms are harvested in mass by baiters who use a technique called "grunting", in which a wooden stake driven into the soil is vibrated with a flat piece of metal. Earthworms emerging onto the soil surface are collected and the process is repeated at approximately 5-10 m intervals across the forest floor. (Hendrix et al., 1994). 
There are many variations of this technique; often a young tree already growing in the soil is substituted for the stob, and sometimes this is simplified further and a garden fork is thrust into the ground and merely vibrated by hand. The latter method is especially common in England, where worms are "charmed" out of the ground by "twanging" the handle of a garden fork, the tongs of which are inserted into the soil (Edwards and Bohlen, 1996; Table 2.1). Vibrations may also be generated by using motors (from vehicles or chain saws), and even footsteps may be sufficient to cause earthworms to surface (Darwin, 1881; Kaufmann, 1989; Table 2.1).

Interestingly, it appears that some animals may also "grunt" for worms. Birds such as the Peewit (Tringa vanellus) and various gulls as well as the Wood Turtle (Clemmys insculpta) have been observed collecting worms using soil vibrations. These animals typically stomp the ground with their feet in a rhythmic fashion to make worms surface so they can be eaten, although some birds have been observed pecking hard at stones to make worms surface (Darwin, 1881; Tinbergen, 1960; Kaufmann, 1986, 1989; Edwards and Bohlen, 1996). Regardless of the "grunting" species and exact methods involved in forcing earthworms to surface, it appears that soil vibration is the unifying mechanism among all of these phenomena, although this has not yet been formally tested. In the Southeastern USA worm "grunting" by humans is particularly widespread, probably because it is normally used to collect and sell earthworms for fish bait. This can become a profitable business due to the large numbers of worms that can be harvested in this way, and this makes worm grunting both economically and ecologically important in localized regions. Although appreciable income can be generated by collecting large quantities of worms, this can result in negative effects on earthworm populations and 
their associated benefits to plant nutrition (Hendrix et al., 1994; Callaham and Hendrix, 1998). Significant reductions in earthworm biomass due to bait harvest were reported in Florida (Hendrix et al., 1994), and it was noted that during some seasons thousands of earthworms per hectare per day could be harvested via grunting. The typical Florida technique of worm grunting uses a wooden stake or "stob" which is driven into the ground and then typically scraped with a long metal "rooper" (typically an old leaf-spring from a vehicle) until worms come to the soil surface.

Despite their prevalence, worm grunting and similar techniques have not been examined experimentally. The vibrations themselves have never been recorded, and the presumed relationship between vibrations and worm emergence has not been scientifically demonstrated. I plan on characterizing the vibrations being transmitted through the soil using typical worm grunting techniques, and I will test the hypothesis that earthworms surface in response to a soil vibration stimulus. Hypotheses explaining the adaptive significance of earthworms surfacing in response to vibrations will be discussed, and worm grunting will be tested in a variety of habitats and geographic areas (in Florida and Ontario) to examine the prevalence of this response across different earthworm species. These analyses of worm grunting will form the bulk of my thesis.

\subsubsection{Earthworm Retraction into the Soil}

Although I will be focusing on worm grunting responses in the field, it is important to consider some of the existing work that has been done regarding vibration sensitivity in earthworms. Some experimental work has described various physical responses in earthworms to vibration, although these appear to be distinct from the worm 
grunting behaviours. Charles Darwin, who took a great interest in earthworms during his later years, was the first person to report vibration sensitivity in earthworms. His experiments showed that worms would retreat into their underground burrows when presented with a vibration stimulus (Darwin, 1881). He used specimens of Lumbricus terrestris with a piano as his vibration source, and he placed pots of soil containing worms directly on top of the piano to observe the worms' responses to vibration. The earthworms were placed on the soil surface with their tails in their burrows, and when soil borne vibrations were produced by playing notes on the piano it was observed that the worms would move immediately and retreat into their burrows. Darwin described the worms as being "extremely sensitive to vibrations" and found that this response could be elicited by playing a variety of notes at very different frequencies. He claimed that the earthworms responded to vibration frequencies ranging over two octaves, with some of the specific notes he had used possibly corresponding to a frequency range between 130 and either 520 or $780 \mathrm{~Hz}$ (although other unspecified notes and frequencies were also used successfully). He also found that the worms did not respond to airborne acoustic vibrations at all.

\subsubsection{Other Earthworm Responses to Vibration}

In addition to the above responses, earthworms have been observed responding behaviourally to vibrations in different ways in laboratory settings. This has been demonstrated through various learning and conditioning experiments. These studies did not specifically examine vibration sensitivity itself (as they focused on learning and conditioning), but most of these studies used vibrations as a conditioned stimulus and in 
doing so demonstrated that earthworms could detect and eventually learn to respond to vibrations (Ratner and Miller, 1959; Peeke et al., 1965; Herz et al., 1967). These responses typically consisted of contractions of the body, but it is important to note that these responses were learned over the course of the experiment, and the earthworms did not naturally demonstrate such responses to vibration. Body contractions naturally occurred only when these worms were exposed to light (used as an unconditioned stimulus in these experiments), and therefore these experiments only showed that earthworms could learn to contract their bodies when exposed to a vibration stimulus (the conditioned stimulus) that was presented at the same time as the light stimulus. These learned responses to vibration were described in minimal detail, and these experiments did not demonstrate or discuss any unlearned and "innate" responses to vibration. Only one similar study used vibration as an unconditioned stimulus and noted unlearned and pre-existing unconditioned responses in Lumbricus terrestris to vibration (Herz et al., 1967). It was observed in this case that mild vibration would produce sharp contractions of the body, which would habituate with repetition, while a more intense stimulus $(40 \mathrm{c} / \mathrm{s}$ at less than $60 \mathrm{db}$ ) would result in an extension of the anterior portion of the body. While these studies demonstrate some limited sensitivity to vibration in earthworms, they all offer minimal details on the vibration stimuli and vibration responses involved. Most vibration sources used were very non-specific (e.g. a 6V doorbell buzzer used in Ratner and Miller, 1959), and details on the nature of the stimulus itself (e.g. frequencies and amplitude used) were virtually never given. There is, however, one recent experiment (Watanbe et al., 2005) that does provide some details on the vibration stimulus. This conditioning experiment used the earthworm Eisenia fetida (belonging to Lumbricidae), 
and used an 8 second stimulus vibrating at $180 \mathrm{~Hz}$ created by a vibration motor, with a maximum acceleration of $5.7 \mathrm{~m} / \mathrm{s}^{2}$. It should be noted that this frequency $(180 \mathrm{~Hz})$ is within the frequency range used by Darwin in his experiments.

The above experiments do establish some level of vibration sensitivity and responsiveness in the earthworms, but they provide very little specific and concrete data on these topics. They also provide minimal information on any natural biological significance to vibration sensitivity in these organisms. Nevertheless, the fact that they do show that worms can detect and respond to at least some vibrations is consistent with the hypothesis that worm grunting may be vibration-mediated. Furthermore, the observations that worms may contract or extend their body in response to vibration is consistent with the behavioural responses involved in both worm grunting and Darwin's experiments, since these types of body movement could be components of the surfacing or retracting behaviours as well as the peristaltic motion used by earthworms in locomotion.

Of the various responses to vibration documented in earthworms, the phenomena of worm grunting and worm charming appear to be the most robust and widespread behavioural responses to vibration reported in these organisms. It is also the only response observed in the wild, and as a result has the most potential ecological and economic significance out of the various vibration responses. For these reasons, worm grunting and worm charming will be the primary focus of my research into behavioural responses of earthworms to vibration, and my specific goals regarding this research are as follows:

1) Characterizing the soil vibrations involved in worm grunting/charming - examining the frequency composition of the vibration stimulus 
- examining how the vibrations travel and attenuate

2) Characterizing the behavioural responses of earthworms to vibrations

- describing the behaviours observed during vibration-mediated surfacing

- quantifying the relationship between vibration and earthworm emergence

- identifying the earthworm species involved in emergence

\subsection{Materials and Methods}

Worm grunting and related techniques were tested in two distinct geographic areas where anecdotal reports suggest that these techniques may be effective in eliciting surfacing responses: the Apalachicola National Forest in the state of Florida, U.S.A., and the Ottawa region in the province of Ontario, Canada. The following methodology section will deal with these two locations separately.

\subsubsection{Florida Trials}

\section{Purpose}

Experiments conducted in Florida served three primary purposes: 1) to confirm that worm grunting is an effective method for making earthworms surface, 2) to characterize the vibrations that cause earthworms to emerge, and 3) to demonstrate a relationship between the vibration stimuli and earthworm emergence.

\section{Location}

Experiments were conducted in the pine dominated forests of Appalachicola National Forest, in Liberty County, Florida. Compartments 100 and 110 of the forest were used for grunting between 8:00 and 10:00 am, April 14-15, 2008 (Fig. 2.1). This 
Figure 2.1 Location of Florida Trial Sites

A) State of Florida, highlighted on a map of the U.S.A. (source: Wikimedia Commons). B) Location of the Apalachicola National Forest within the state of Florida (credit: US Forest Service). C) Arrows indicate specific compartments used for trials. (credit: US Forest Service). 
Fig. 2.1

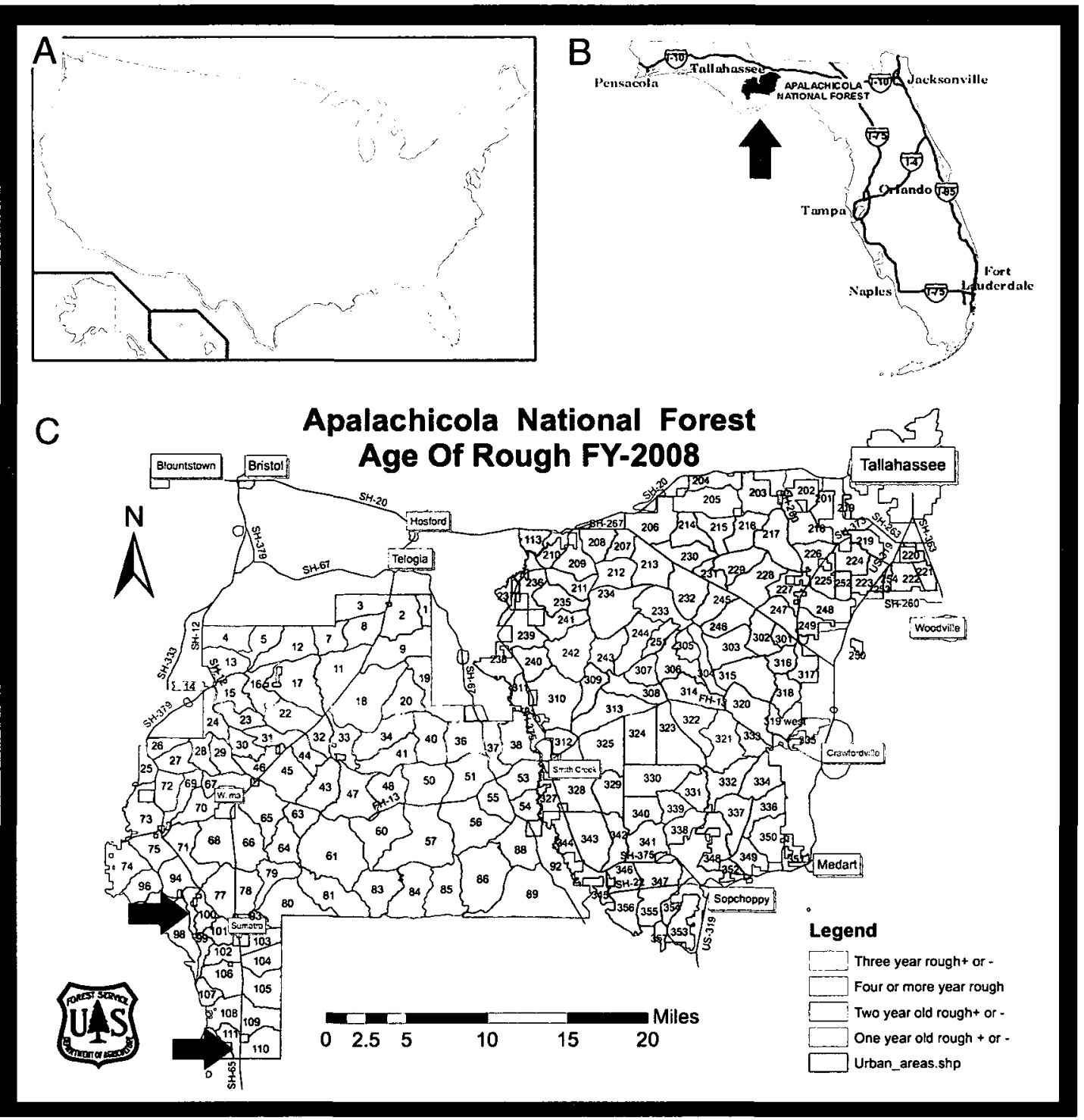


forest is a naturally fire-driven ecosystem that is currently managed with regular prescribed burns. The trees of the forest consist almost entirely of the pine species Pinus palustris and Pinus elliottii (Fig. 2.2 A), while the ground cover consists primarily of wiregrass (Aristida stricta) and saw palmetto (Serenoa repens) (Fig. 2.2 B). Both of the sites used experimentally had recently undergone prescribed burning and had very little emergent vegetation or detritus obscuring the ground surface, making it much easier to find any earthworms on the soil surface (Fig. 2.3). For this reason, recently burned areas are attractive to bait harvesters and are preferentially used to collect worms shortly after prescribed fires have been conducted (Hendrix et al., 1994). It should be noted that evidence of mole activity (in the form of tunnels and burrows) was observed at various trial sites.

\section{Vibration production and analysis}

The worm grunting vibrations were generated by Dr. Mac Callaham of the United States Department of Agriculture's Forest Service, who had previously used this technique to survey for earthworms (Hendrix et al., 1994). Grunting was performed by first hammering a wooden stake (made of swamp tupelo, Nyssa biflora) into the soil to a depth of about $30 \mathrm{~cm}$. The stake was $53 \times 6 \times 3 \mathrm{~cm}$ in size, with its top end flattened and the bottom end sharpened to a point, and vibrations were produced when the top end of the partially buried stake was rubbed in a rhythmical fashion with a long flat metal object (in this case an automobile leaf spring, see Fig. 2.4 A). The rubbing motion was performed rather forcefully using a side-to-side motion in a single direction, similar to the way a bow is used to play a violin (Fig. 2.4 B). The stake and leaf spring were both typical implements used by local worm grunters, and in the vernacular of local worm 
Figure 2.2 Natural Habitat of Diplocardia Earthworms in the Apalachicola National Forest

A) Pine species Pinus palustris and Pinus elliottii endemic to the area. B) Natural ground cover consists of wiregrass (Aristida stricta) and saw palmetto (Serenoa repines) (credit: Ombor Mitra). 

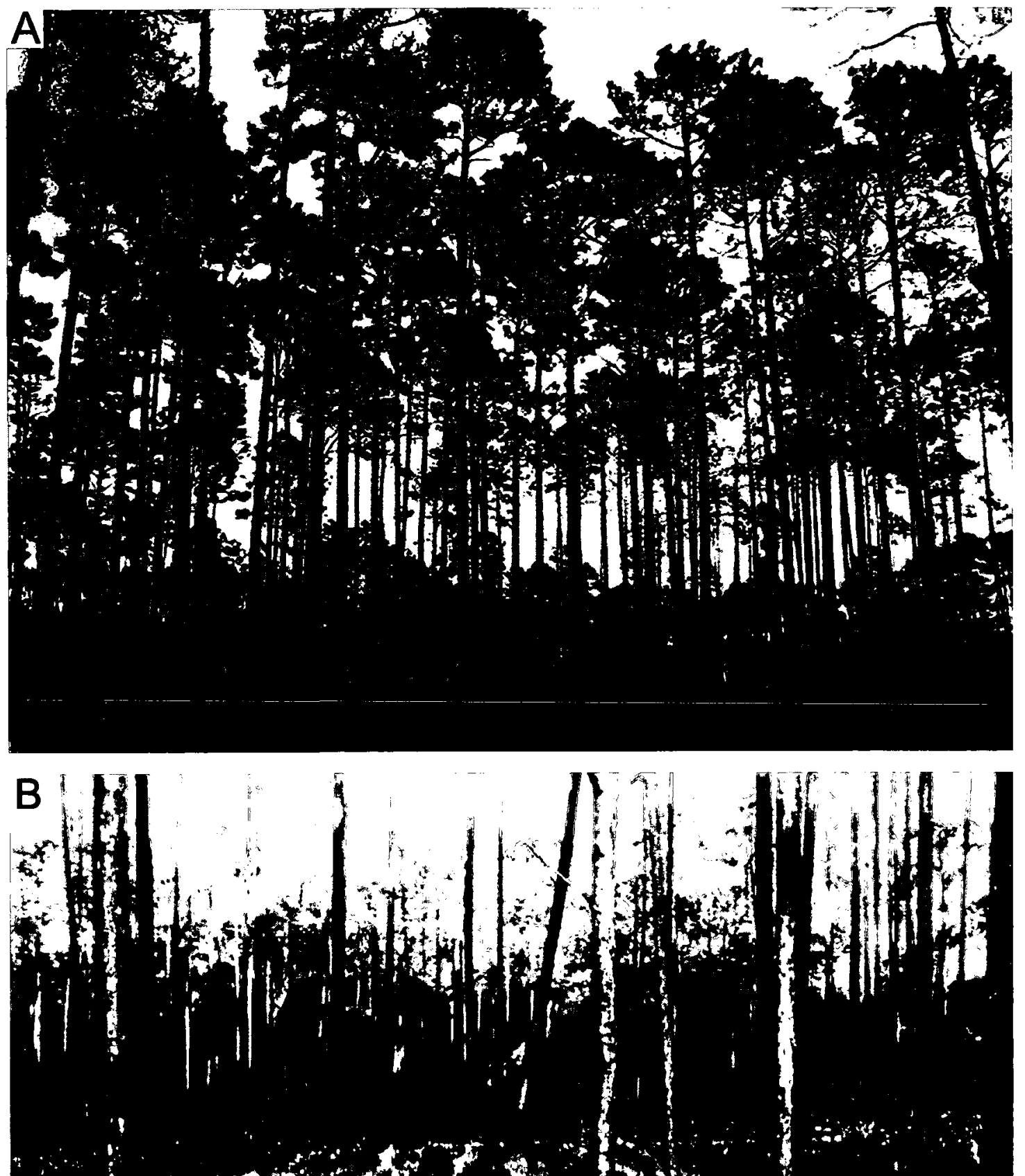

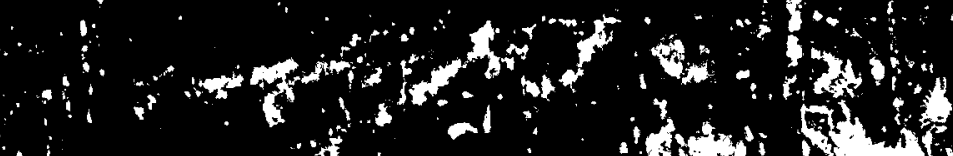

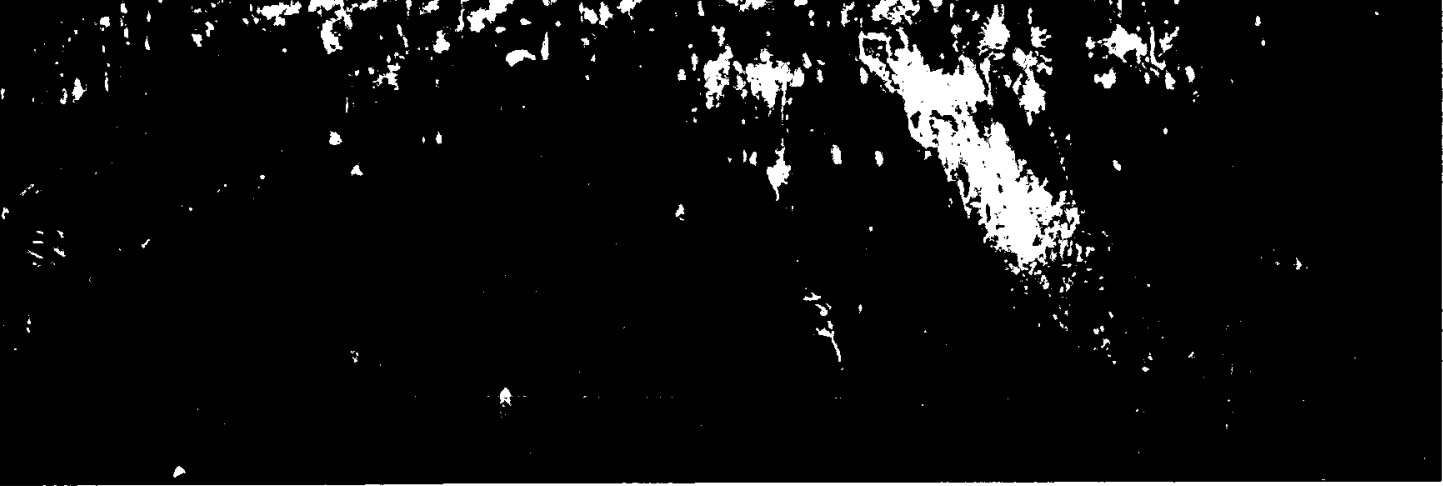


Figure 2.3 Ground Cover in the Apalachicola National Forest after a Prescribed Burn.

A) Larger plants (such as saw palmetto) are pruned back by fire. B) Much of the burnt ground surface is exposed, making surfaced earthworms much more visible. 

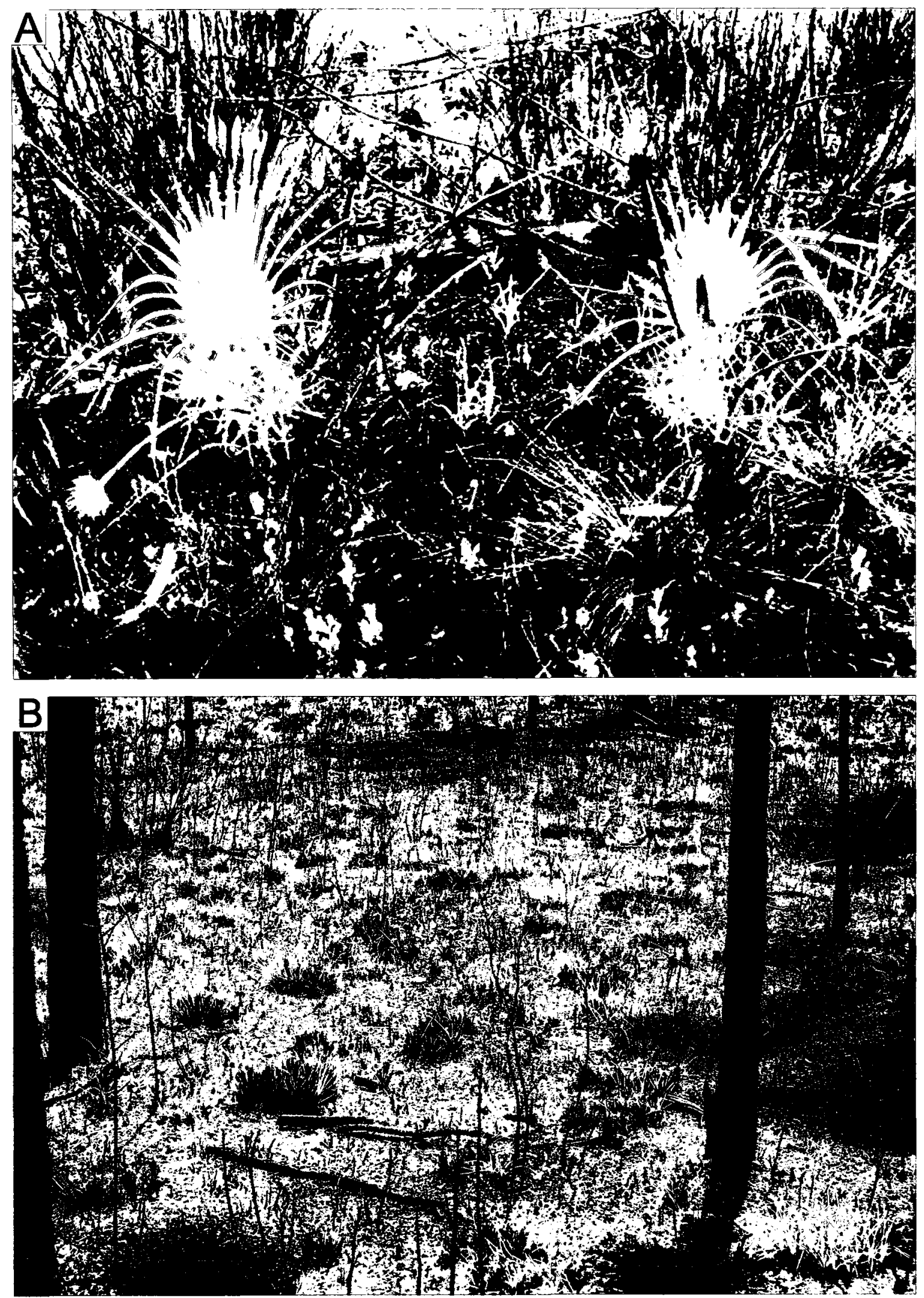
Figure 2.4 Florida Worm Grunting Apparatus and Method

A) Wooden stake ("stob") and metal scraper "rooper" used for worm grunting. Scale bar is $30 \mathrm{~cm}$. B) Mac Callaham worm grunting in the field. The scraper is rhythmically rubbed across the top of the partially buried stake. 
Tig요. 2.64
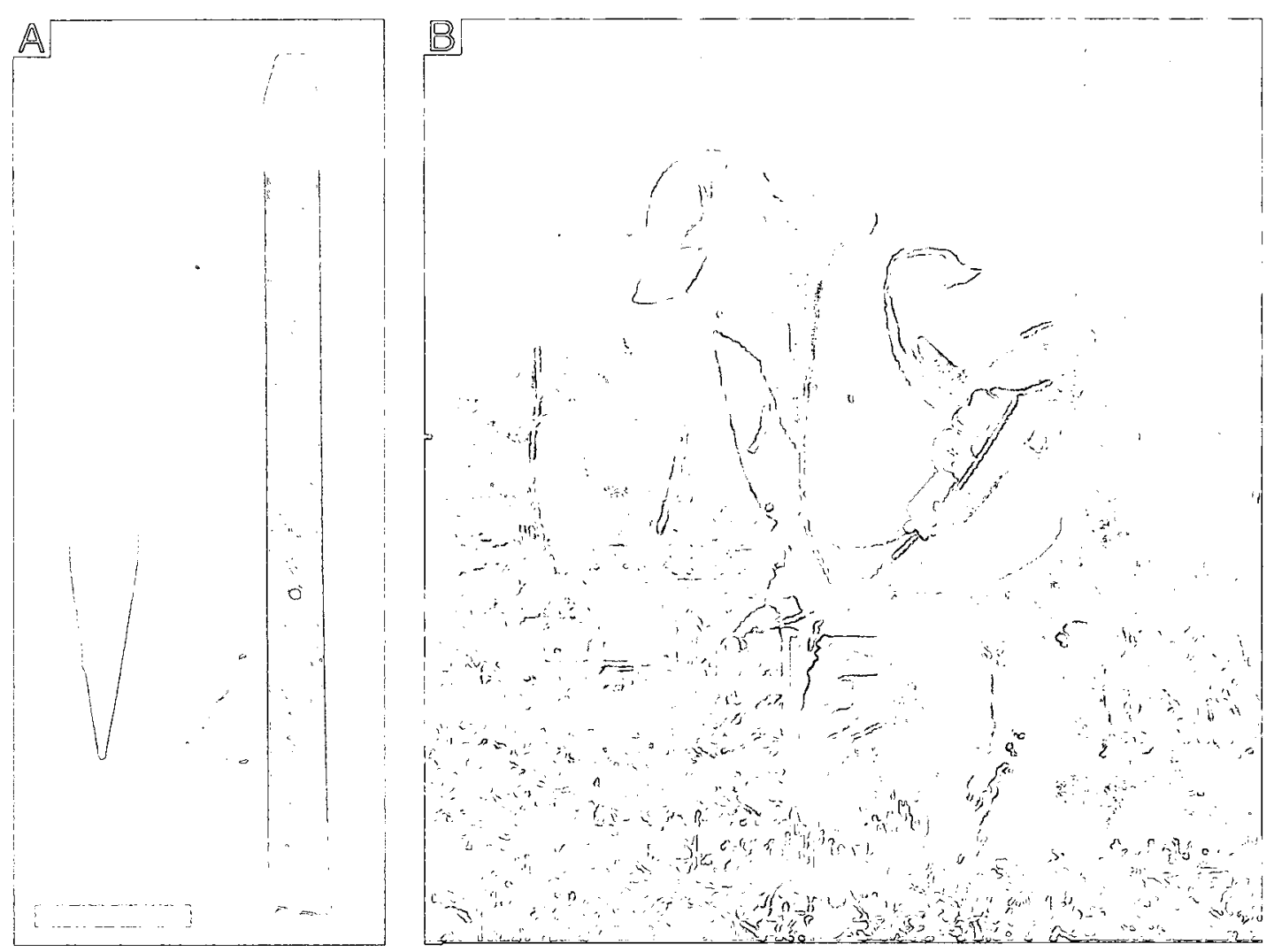
grunters the wooden stake is referred to as a "stob" while the metal object is referred to as a "rooper". I will use the same terms to refer to these objects. Specific locations within each test site were evaluated for the presence or absence of earthworms by conducting brief bouts of worm grunting, and if earthworms were observed to surface we moved a short distance away (approx. $20 \mathrm{~m}$ ) to perform full trials. Visual inspection of the trial areas prior to grunting indicated that no worms were ever initially visible on the soil surface. Five people were typically involved in each trial, with one dedicated worm grunter (who was always Mac Callaham). The other individuals assisted in recording vibrations and collecting earthworms.

Seismic vibrations from grunting were recorded using two setups: linear geophone arrays were used to examine amplitude decay over distance (Fig. $2.5 \mathrm{~A}$ ), while equidistant arrays were used to examine the frequency composition of the vibrations (Fig. $2.5 \mathrm{~B}$ ). Linear arrays consisted of four identical vertical geophones (DT20DX 4.5Hz, Dynamic Tech, Calgary, Canada) buried at a depth of $10 \mathrm{~cm}$, and placed at equal intervals of either 1.8 or 3 meters away from the wooden stake. Geophone signals were amplified (M-10MX, Edirol/Roland) and recorded onto digital data recorders (PMD671, Marantz) using a $44.1 \mathrm{kHz}$ sampling rate. The equidistant arrays consisted of four different sensor types: three geophones including a DT20DX 4.5Hz, a GS-20DM $28 \mathrm{~Hz}$ (Oyo Geospace, Calgary, Canada), a GS-100 100Hz, and one microphone (ATM10a, Audio Technica, 18-20000 Hz). Each sensor was buried at the same depth $(10 \mathrm{~cm})$ and positioned at an equal distance (either 0.9 or $3.6 \mathrm{~m}$ ) away from the stob. All geophones were amplified and recorded as described above, while the microphone was connected directly to the data recorder. Data files were transferred to a laptop computer and 
Figure 2.5 Schematics of the Different Geophone Arrays

A) Linear array, using identical sensor types placed equal intervals apart. B) Equidistant array using different sensor types placed the same distance away from the vibration source. In both diagrams, the circle represents the vibration source (stob), and the squares represent buried seismic sensors. 
Fig. 2.5
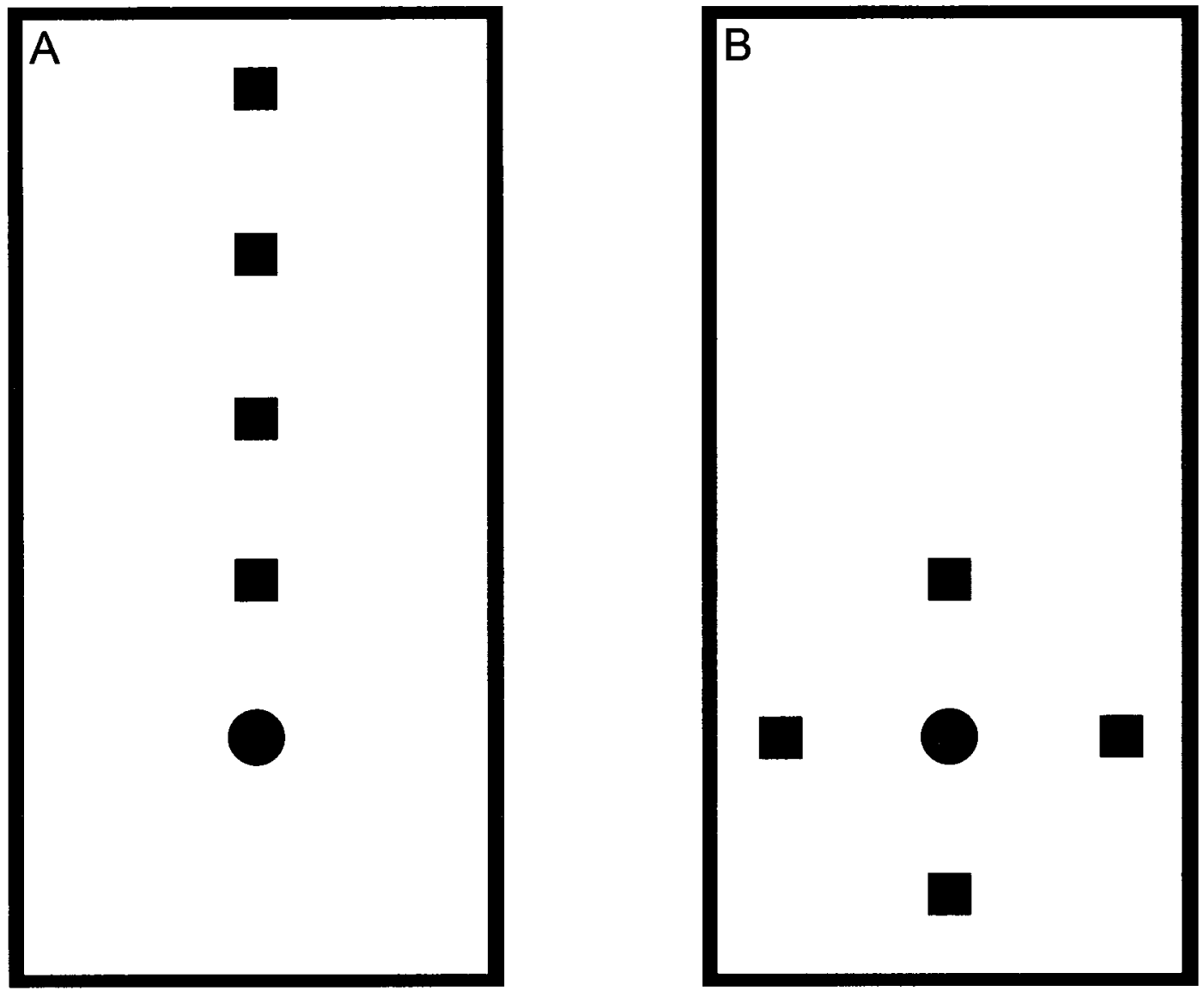
analyzed using the Raven Bioacoustics Research Program (v1.2 and 1.3, Cornell Laboratory of Ornithology).

\section{Collecting and Identification of Earthworms}

Each trial consisted of a harvesting and recording phase. The harvesting phase preceded the recording phase, although all recording equipment was placed in position before the harvesting phase began. Five individuals searched for surfacing earthworms while grunting was performed during the harvesting phase. The location of each emerged worm was marked with a small flag made up of a small sharpened dowel affixed with flagging tape, and all specimens were immediately collected in a container to prevent recounts. All earthworm specimens were identified onsite by Dr. Mac Callaham. After harvesting was complete (when worms ceased to surface), the recording phase began and the worm grunting vibrations were recorded with either a linear or equidistant sensor array. A map of the immediate area was made, indicating the positions of, and distances between worm flags, sensors, and the stob. All experiments were videotaped using a camcorder (DCR-TRV19, Sony). The camera was typically mounted on a stationary tripod to monitor the experiments and to provide temporal data on the latency of earthworm emergence with respect to the onset of worm grunting vibrations. The camera was also hand-held at times and used to videotape the emergence behaviour of individual earthworms during grunting. All video footage was transferred to an iMac computer and viewed with iMovie software (v7.1.4). Emergence latencies were measured by watching the videotaped experiments and manually 
measuring the times between the onset of grunting and the emergence of worms using a stopwatch. Images of the Florida field setup are presented in Fig. 2.6. 
Figure 2.6 Experimental Field Setup used in Florida

A) Setup used to record grunting vibrations. Note the video camera on the left. B) Collecting earthworms while grunting. A collector to the right is marking emergence sites with pink marker flags, which are visible nearby the grunter. 

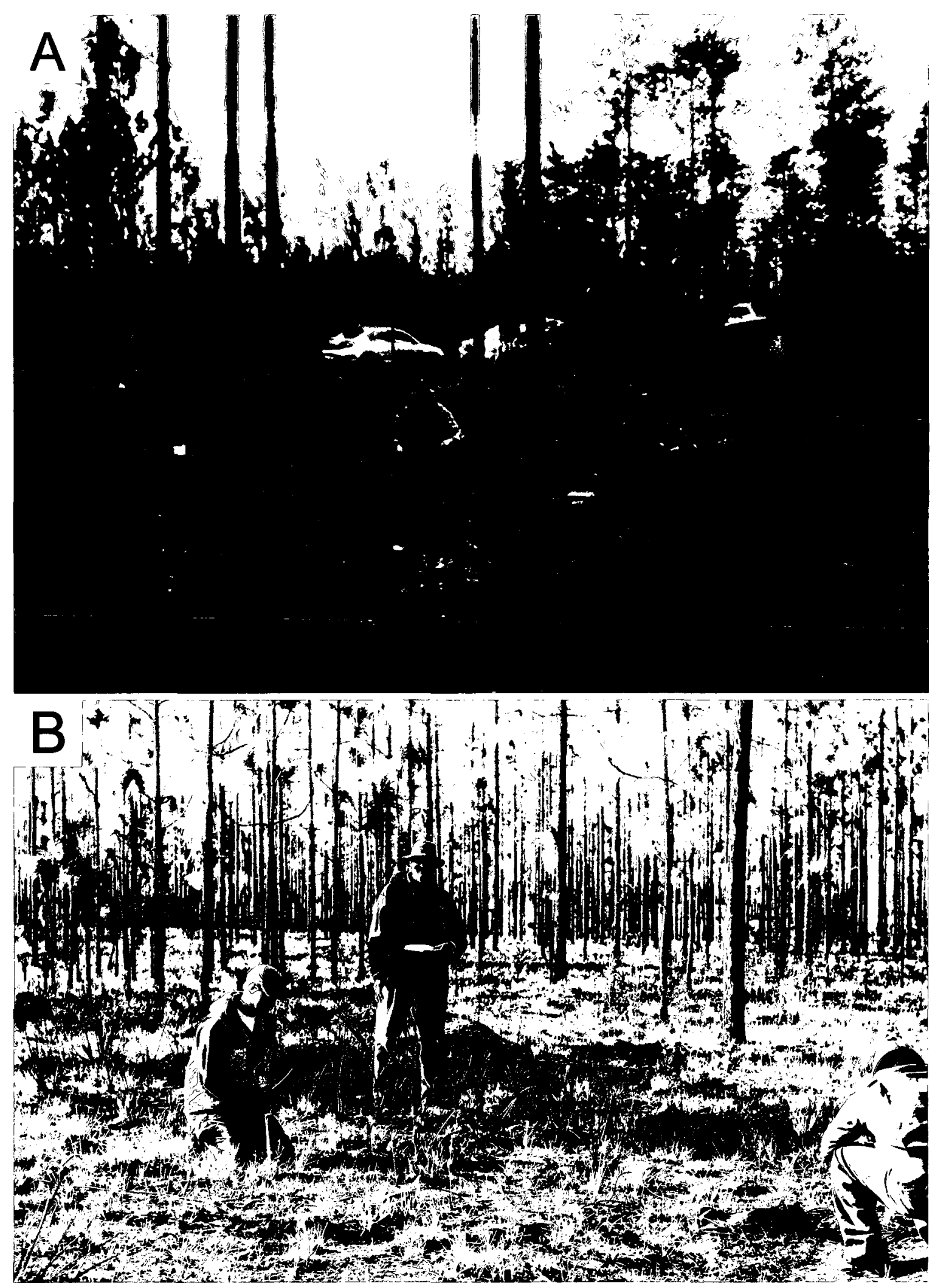


\subsubsection{Ontario Trials}

\section{Purpose}

The worm grunting trials in Ontario differed from those of Florida in a variety of ways. While grunting was known to be effective in specific habitats of Florida, it is generally claimed to be ineffective in Ontario (Reynolds, 1977; personal communications). The anecdotal reports of vibration-mediated earthworm surfacing in Ontario and Canada (Table 2.1) contained very few details about the habitats, earthworm species, and "grunting" techniques involved. As a result, a variety of different habitat types and "grunting" methods were selected in an effort to test the effectiveness of worm grunting in Ontario and to examine any species specificity in the behavioural responses to soil vibrations. Specific goals for the Ontario trials include:

1) Testing two different worm grunting/charming techniques in the Ottawa area

2) Examining the species involved in any emergence responses

3) Comparing the worm "grunting" and "charming" techniques

\section{Sites}

All grunting trials were conducted in the vicinity of the city of Ottawa, Ontario (Canada) between the dates of April 24th to June 18th 2009. Different habitat types were deliberately used in an effort to test grunting on different species of earthworm. This is because some species of earthworm have different preferences for habitat features, although there is considerable overlap in these preferences between species (Reynolds, 1977; Edwards and Bohlen, 1996). Two primary sites were used to test grunting repeatedly during the summer months, while a number of supplementary sites were tested 
more sporadically. The primary grunting sites were located on Herbert Corners road and the Mer Bleu Conservation Area (Fig. 2.7). The first site consisted of property owned by Carleton University at the end of Herbert Corners road and was referred to by the University (on their maps) as "Carleton Land site A". This site was located at latitude 45.2011 and longitude -75.6056 (decimal degrees), and consisted of a mossy field containing a few small plants and shrubs, bordered by a grove of sumac trees and some cedar (Fig. 2.8). The other primary trial site was within deciduous forest located in the Mer Bleu Greenbelt property owned by the National Capital Commission. This specific site was located at latitude 45.3935 and longitude -75.5097 (decimal degrees), and consisted of forested areas near walking paths that were comprised of deciduous trees and only a few smaller plants and shrubs, with the soil being covered in a thick layer of primarily deciduous leaf litter (Fig. 2.9). These primary sites were chosen out of a larger pool of habitats that were all sampled for worms prior to trials, between the dates of April $15^{\text {th }}$ and $24^{\text {th }} 2009$, and these samples indicated that earthworms were prevalent in both locations. Each primary site was also visited the night before trials to prepare the site. If surface vegetation and ground cover were present, a circular area $3 \mathrm{~m}$ in diameter was cut to a very short length to aid in the visual detection of surfaced earthworms. Vegetation was cut with a large pair of garden shears, and all vegetation and leaf litter was removed with a pitchfork.

There were three supplementary sites that were also tested and these consisted of alternative habitats including coniferous and deciduous forests, bare garden soil, and grassy lawns near human habitation. Coniferous forest was tested at the Pinhey Forest Greenbelt property (owned by the National Capital Commission), while deciduous and 
Figure 2.7 Map of Ontario Trial Sites

Circled stars indicate primary trials sites, which are (from top to bottom) the Mer Bleu Conservation Area and Carleton University's Herbert's Corner's property. Un-circled stars indicate secondary trial sites, which are (from top to bottom) the Mongrain property, the Nesbitt property, and the Pinhey Forest property (modified from Google Maps). 
Fig. 2.7

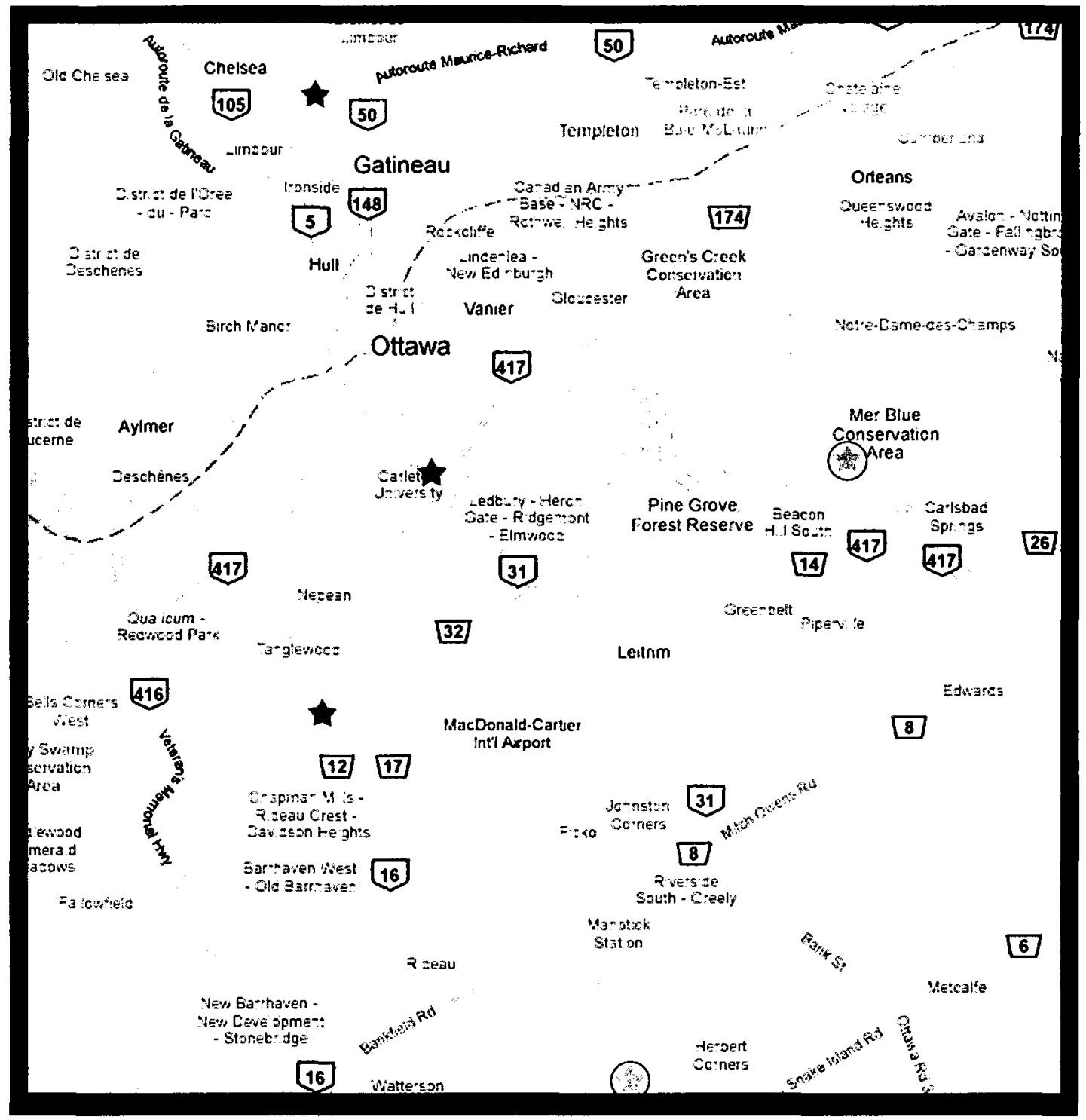


Figure 2.8 Primary Trial Site: Carleton University's Land at Herbert's Corners

A) View of the field and sumac stands. Ground cover consists of sparse grass and shrubs with abundant moss. B) Map indicating precise location of trials (modified from Google Maps) 
Fig. 2.8
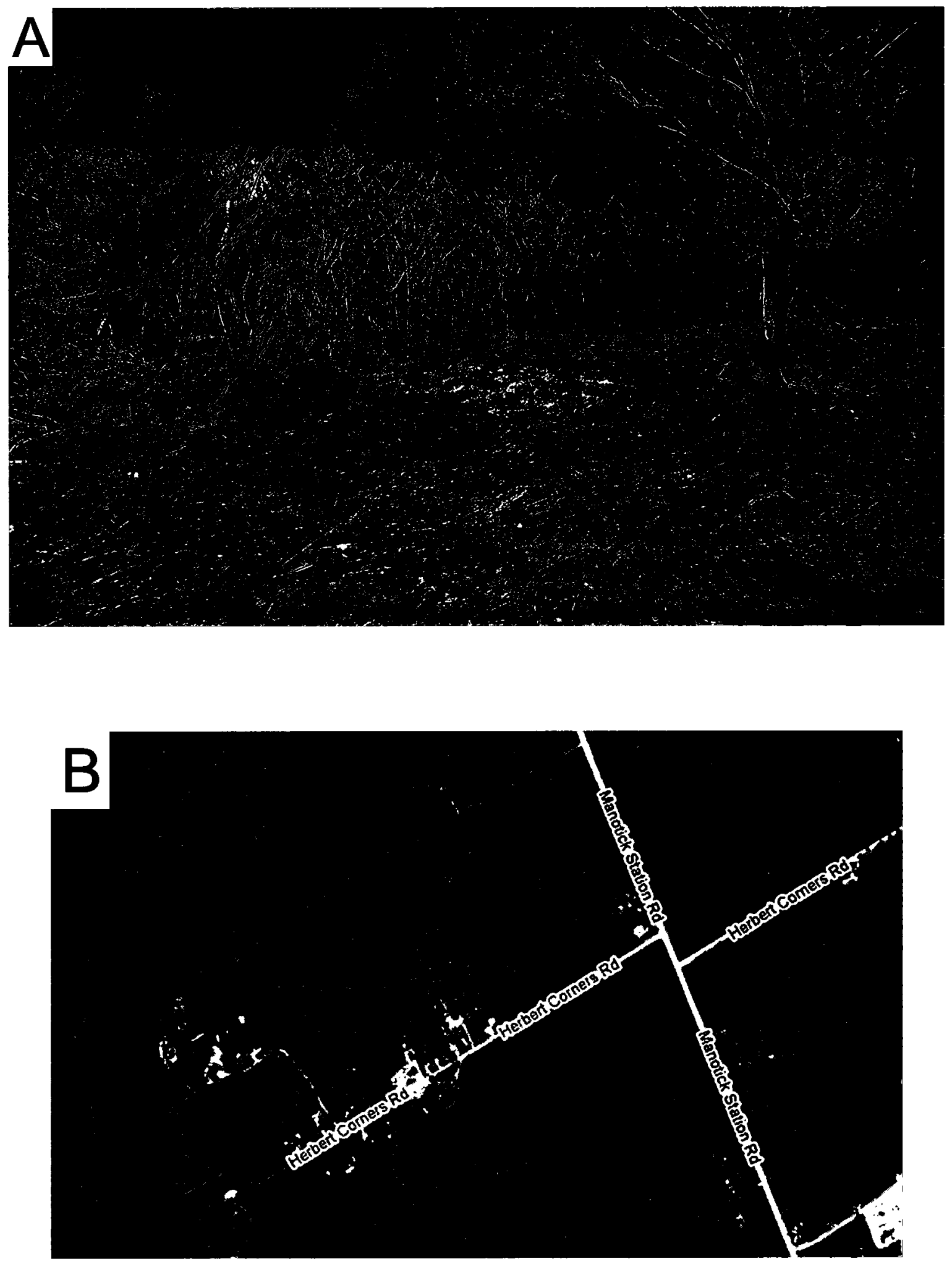
Figure 2.9 Primary Trial Site: Mer Bleu Conservation Area

A) View of the deciduous forest, with ground cover consisting of loose leaf litter. B) Map indicating precise location of trials (modified from Google Maps). 

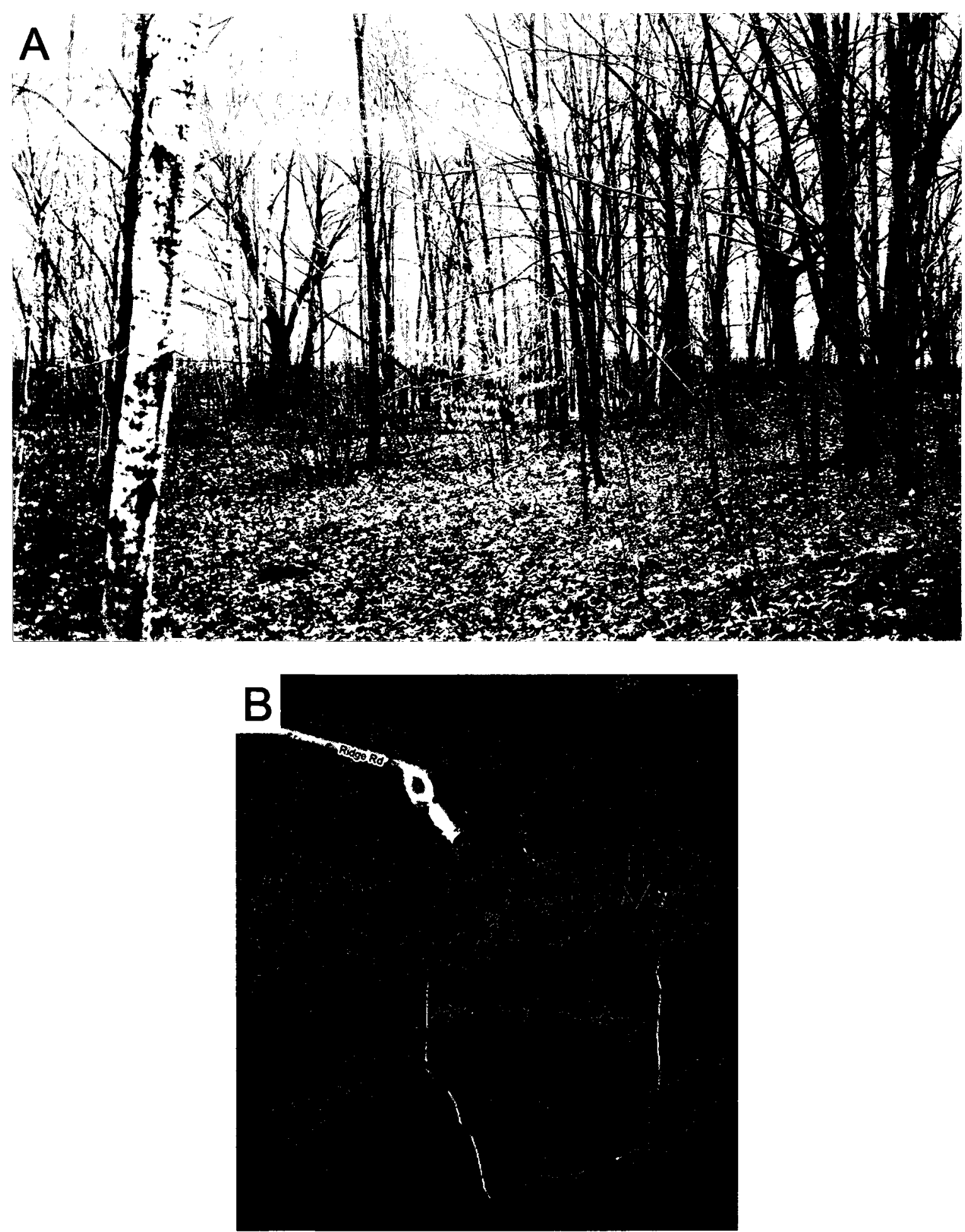
shrubby forest was tested at the Mongrain property (23 rue Lery, Gatineau, QC), and bare soil and grassy lawn was tested near the Nesbitt building of the Carleton University campus (see Fig. 2.7 for precise site locations). Some of these supplementary and sporadically tested sites were cleared of surface debris only prior to the trial itself. This occurred only at sites that were easily and quickly cleared of ground cover (e.g. locations where loose leaf litter and/or mosses obscured the ground), and this ground cover was removed by pulling the loose debris out of the trial area with a pitchfork, while taking care to make minimal contact with the soil itself. Representative images of prepared sites are presented in Fig. 2.10 A and B. Trial sites were also examined for any signs of mole activity (such as tunnels and burrows).

\section{Conditions}

Environmental conditions including the weather conditions and soil properties were assessed for all trials at all sites. Soil composition was evaluated using the OPAL Soil and Earthworm Survey guide from the Imperial College, London (produced by the Field Studies Council). The $\mathrm{pH}$ of the soil was measured by mixing a small quantity of soil with distilled water and testing this mixture with $\mathrm{pH}$-indicator strips $(\mathrm{pH} 2.0-9.0$ colorpHast strips by EMD Chemicals Inc.), while soil temperature was measured by inserting a thermometer $20 \mathrm{~cm}$ into the soil (stainless steel Instant Read Thermometer by Taylor). The soil sample was obtained from a $20 \times 20 \times 20 \mathrm{~cm}$ soil plot dug up immediately after the vibration test was completed. 
Figure 2.10 Prepared Ontario Trial Sites

A) Ground cover cleared around a stob trial site (Mer Bleu). B) Ground cover cleared around a pitchfork site (Herbert's Corners). C) Pitchfork used in the Ontario trials. Scale bar is $30 \mathrm{~cm}$. 


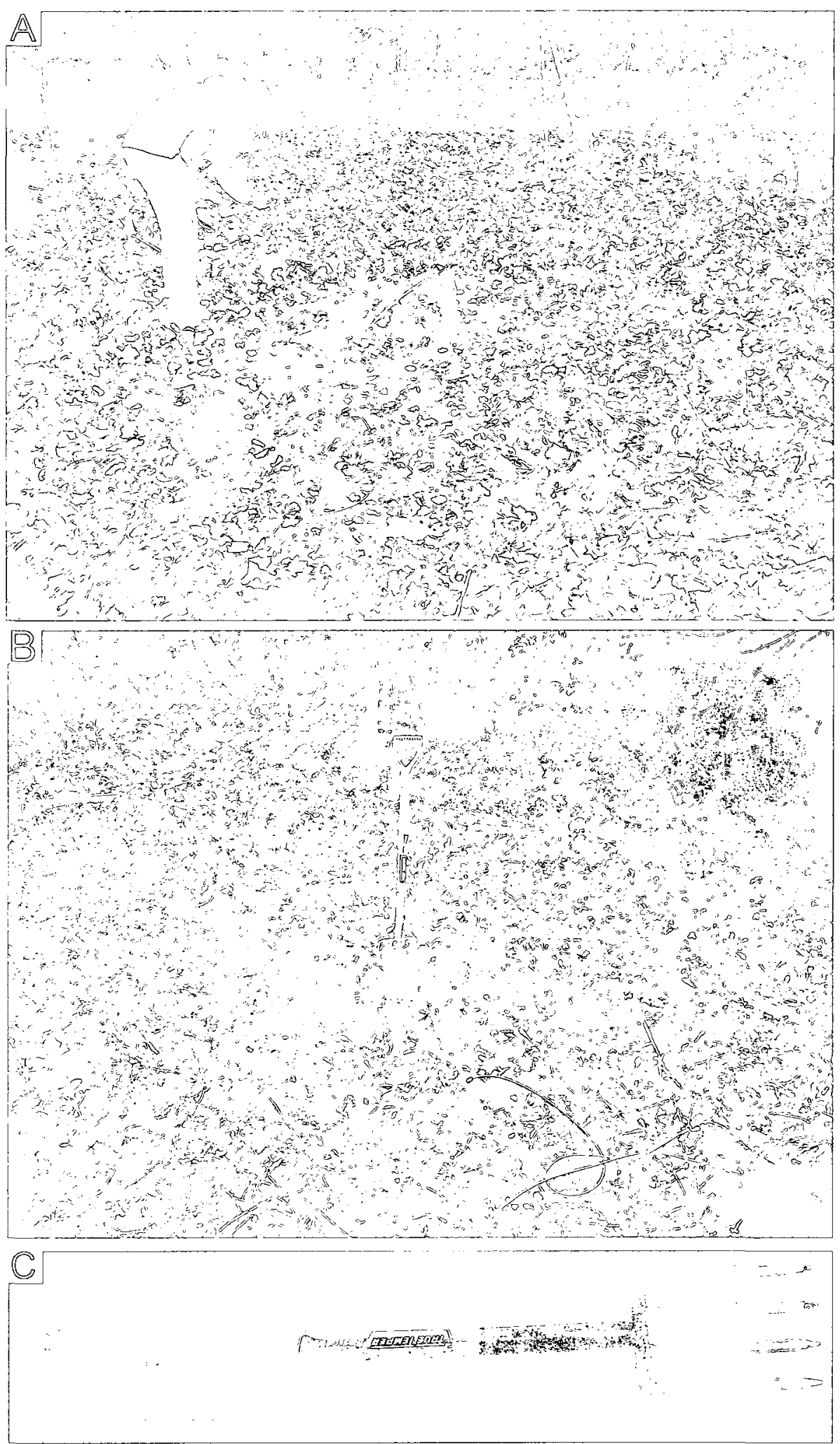




\section{Schedule}

The primary sites were tested on a fairly regular schedule (every $12.7 \pm 5.4$ days on average), while the additional trial sites were tested sporadically (Table 2.2). Trials were typically conducted in the morning around 10 a.m. (as they were in Florida), but some tests were also deliberately done at other times of the day, such as early and late afternoon.

\section{Vibration production and analysis}

Two types of vibration-mediated earthworm harvesting techniques were used at each primary trial site. The first was worm grunting using a stob and rooper, performed in a manner identical to the Florida trials (except in this case the grunting was performed by Ombor Mitra). The second was the pitchfork method often used in England and to a lesser extent the United States. This technique (which will be referred to as "worm charming" in this text) involves inserting a large garden pitchfork (Fig. 2.10 C) about $30 \mathrm{~cm}$ into the ground and then moving it rapidly back and forth. The twanging motion was generated in two ways: by horizontally pulling back and releasing the pitchfork handle (causing the elastic energy of the soil to whip the pitchfork forward and backwards a few times), as well as manually wiggling the pitchfork back and forth. Both motions were performed with regular speeds and consistent levels of force, as per written descriptions and videos of worm twanging performed in the United States and England (Table 2.1).

Vibrations were recorded using the same amplifiers and digital recorders used previously, but all recordings were made using a shorter linear array of two $4.5 \mathrm{~Hz}$ 
Table 2.2 Dates and Sites for Ontario Trials

Primary Sites

Herbert Corners

April 28, 2009

May 7, 2009

May 22, 2009

May 29, 2009

June 10, 2009
Secondary Sites

Mer Bleu

May 6, 2009

May 22, 2009

May 28, 2009

June 18, 2009
May 4, 2009, Pinhey Forest

May 5, 2009, Mongrain Property

May 13, 2009, Mongrain Property

May 15, 2009, Nesbitt Property 
geophones placed at 1 meter intervals from the stob or pitchfork. Recordings were analyzed using the same software (Raven) as the Florida trials. Many trials were also recorded with a hand-held video camera (DCR-TRV19, Sony). This was done to measure the latencies of earthworm emergence, and to record the behaviour of emerging earthworms.

\section{Experimental Trials}

Each trial was comprised of three 3 phases and was typically conducted with at least two individuals (including the grunter/charmer) observing the area for surfaced earthworms. The first phase defined the control conditions of the experiment through a pre-count of worms found on the soil surface prior to the application of vibration stimulus. This pre-count lasted for 5 minutes, and any worms found during these control conditions were collected for subsequent identification. This was followed by the second phase of the trial, which was the application of the vibration stimulus using either the stob or pitchfork. Any worms that surfaced during this vibration phase were also collected, and emergence sites for worms were marked and documented using the same procedures used in Florida (emergence sites were marked with flags and their positions and distances from the vibration source were marked on maps). Grunting or charming was performed continuously for 5 minutes at each site. When this was complete, the third phase of the trial would begin, and the soil surface was again observed for 5 minutes in an attempt to conduct a post-count and find any remaining surfacing worms. When these phases were complete, a $20 \times 20 \times 20 \mathrm{~cm}$ soil sample was taken from the trial location to provide a sample of the earthworms that remained within the soil, as well as a sample of the soil 
itself (used for soil composition analysis). The sample plot was dug in the soil $30 \mathrm{~cm}$ in front of the stob or pitchfork, and worms were collected from this sample by handsorting. These specimens were brought back to the lab and were sacrificed in $70 \%$ ethanol before being preserved in $15 \%$ formalin, and were subsequently identified using the dichotomous keys in Reynolds (1977), while some specimens were also sent to Dr. John Reynolds at his Oligochaetology laboratory (in Kitchener, Ontario) for further identification.

\subsection{Results}

\subsubsection{Earthworm Responses to Vibration in Florida}

Worm grunting with a stob and rooper proved successful at making Diplocardia mississipiensis earthworms surface from the soil at multiple trial sites, and this technique proved to be capable of eliciting surfacing responses in worms some distance away from the stob. Images of surfacing and collected Diplocardia worms (identified by Dr. Mac Callaham) are presented in Fig. 2.11.

\section{Temporal and Frequency Characteristics}

The worm grunting technique generated a train of distinct seismic vibrations that were recorded with all sensor types. This train of vibrations consisted of repetitive rhythmic strokes, each of which was followed by a brief pause. The characteristics of the stimulus were consistent between different trials, and individual strokes were $739.7 \pm$ $96.5 \mathrm{~ms}$ in duration ( $\mathrm{n}=30$, from 3 trials), with a $486.3 \pm 90.0 \mathrm{~ms}$ silent pause between strokes ( $\mathrm{n}=30$, from 3 trials) (Fig. 2.12 A). Each of these strokes consisted of an initial 
Figure 2.11 Diplocardia Earthworms in Florida

A) An earthworm surfacing while the grunting stimulus is applied. B) Earthworms collected during a single trial of worm grunting. Scale bars are $2 \mathrm{~cm}$. 
Fig. 2.11
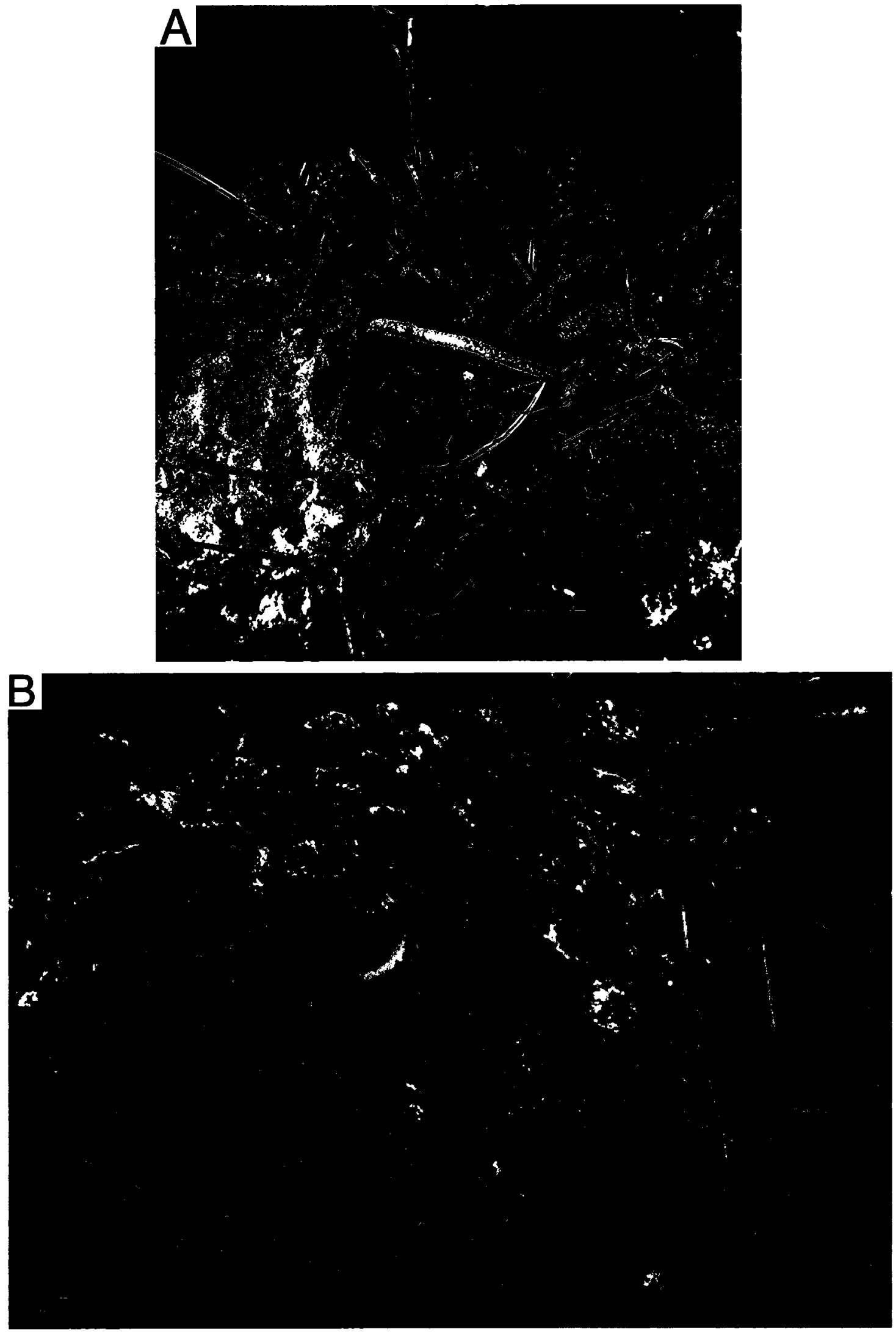
Figure 2.12 Oscillogram and Spectrogram of Vibrations from Florida Worm Grunting

A) The stob and rooper produced a fairly regular train of vibrations, with the dominant frequencies falling below $500 \mathrm{~Hz}$. Scale bar is $2 \mathrm{sec}$. B) Single grunting pulse expanded (first pulse from A). C) Power spectra of 5 individual grunts. The dominant frequency is about $97 \mathrm{~Hz}$, and the spectra labeled " $\mathrm{N}$ " indicates background noise levels. 
Fig. 2.12
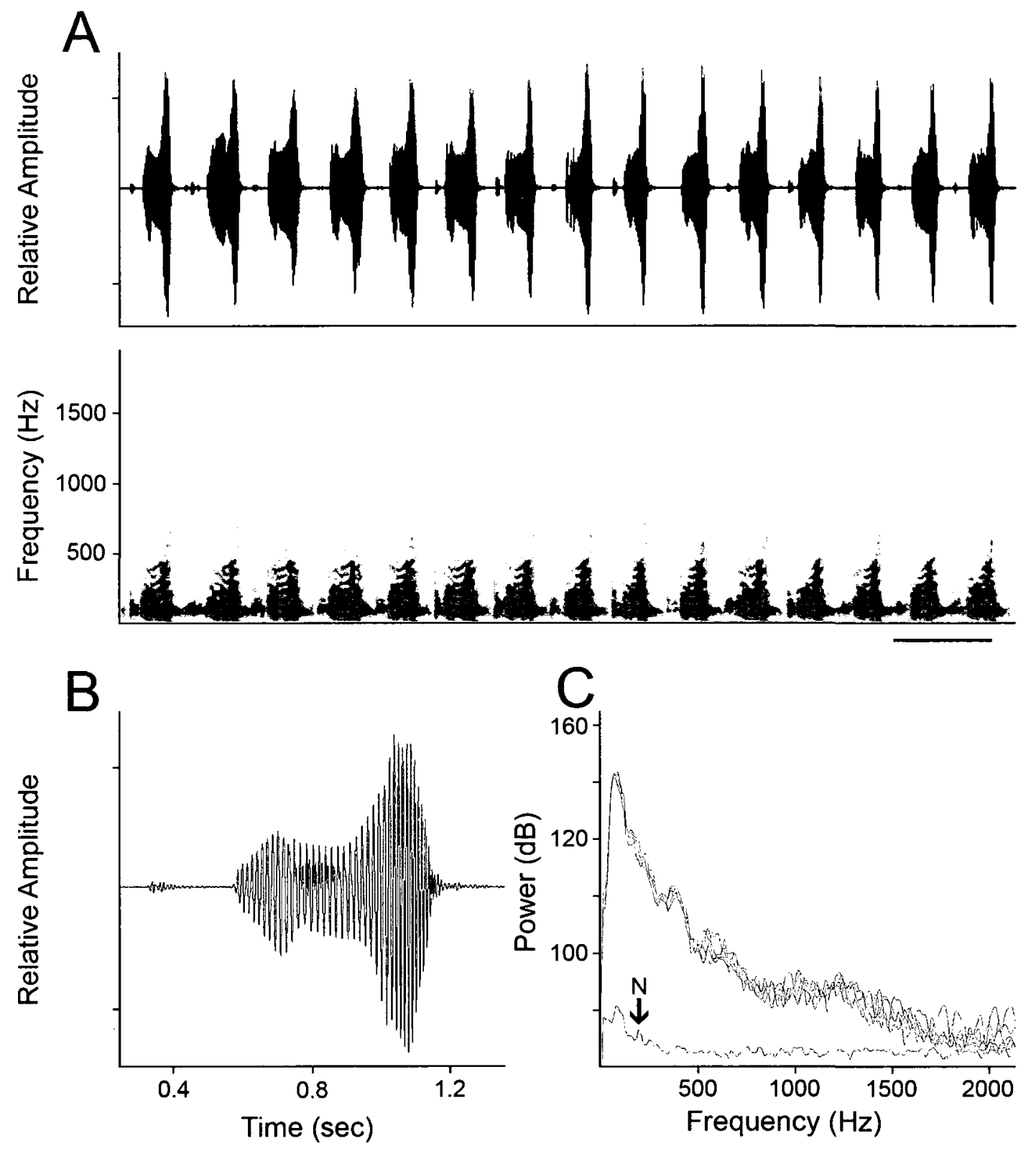
discreet noise (produced by the metal rooper making initial contact with the stake) followed by a broadband "grunt" caused by stroking the metal rooper against the stake (Fig. $2.12 \mathrm{~B})$. The seismic signals generated by this activity were broadband $(0-4 \mathrm{kHz})$ with most of the energy concentrated below $500 \mathrm{~Hz}$ (Fig. 2.12 A), and the dominant frequency was found to be $97.3 \pm 11.7 \mathrm{~Hz}(\mathrm{n}=15)$ (Fig. 2.12 C). The frequencies present in the recordings were fairly consistent between the different sensor types (Fig. 2.13). Soil-borne vibrations were strong enough to be felt through the ground even when standing several meters from the stake. At 1 meter from the vibration source the peak energy was $70 \mathrm{~dB}$ above background levels. Vibrations were still detected by our furthest geophone, which was placed 12 meters away from the stake, but the relative amplitude of the signals decayed markedly beyond a few meters, and spectral changes were also apparent as the distance from the stake increased. While vibrations below $500 \mathrm{~Hz}$ were still quite prominent at our furthest recording distance $(12 \mathrm{~m})$, the frequencies above 1.5 $\mathrm{kHz}$ were typically attenuated beyond $7 \mathrm{~m}$ from the stake. Changes in amplitude and spectral characteristics with distances are presented in Fig. 2.14.

\section{Earthworm Emergence}

Earthworms emerged from the soil after an average of $192 \pm 99 \sec (n=21)$ following the onset of vibration stimuli. Close up videos showed that the worms exited their burrows using slow peristaltic locomotion. Following emergence they continued to crawl across the soil surface and remained on the surface after vibrations ceased (at least until the specimens were collected). Surfaced worms did not show directional preferences, since they were observed moving both away from and towards the stake. 
Figure 2.13 Vibration Measurements in Florida from all Sensors

A) Recordings from a $4.5 \mathrm{~Hz}$ geophone. Lowest amplitude power spectrum indicates background noise levels. B) Recordings from buried microphone. Lowest amplitude power spectrum indicates background noise levels. C) Recordings from $28 \mathrm{~Hz}$ geophone. Lowest amplitude power spectrum indicates background noise levels. D) Recordings from $100 \mathrm{~Hz}$ geophone. Lowest amplitude power spectrum indicates background noise levels. The overall frequency characteristics from all recordings are the same, although the microphone was more sensitive to higher frequencies. Scale bars are all $0.5 \mathrm{sec}$. 

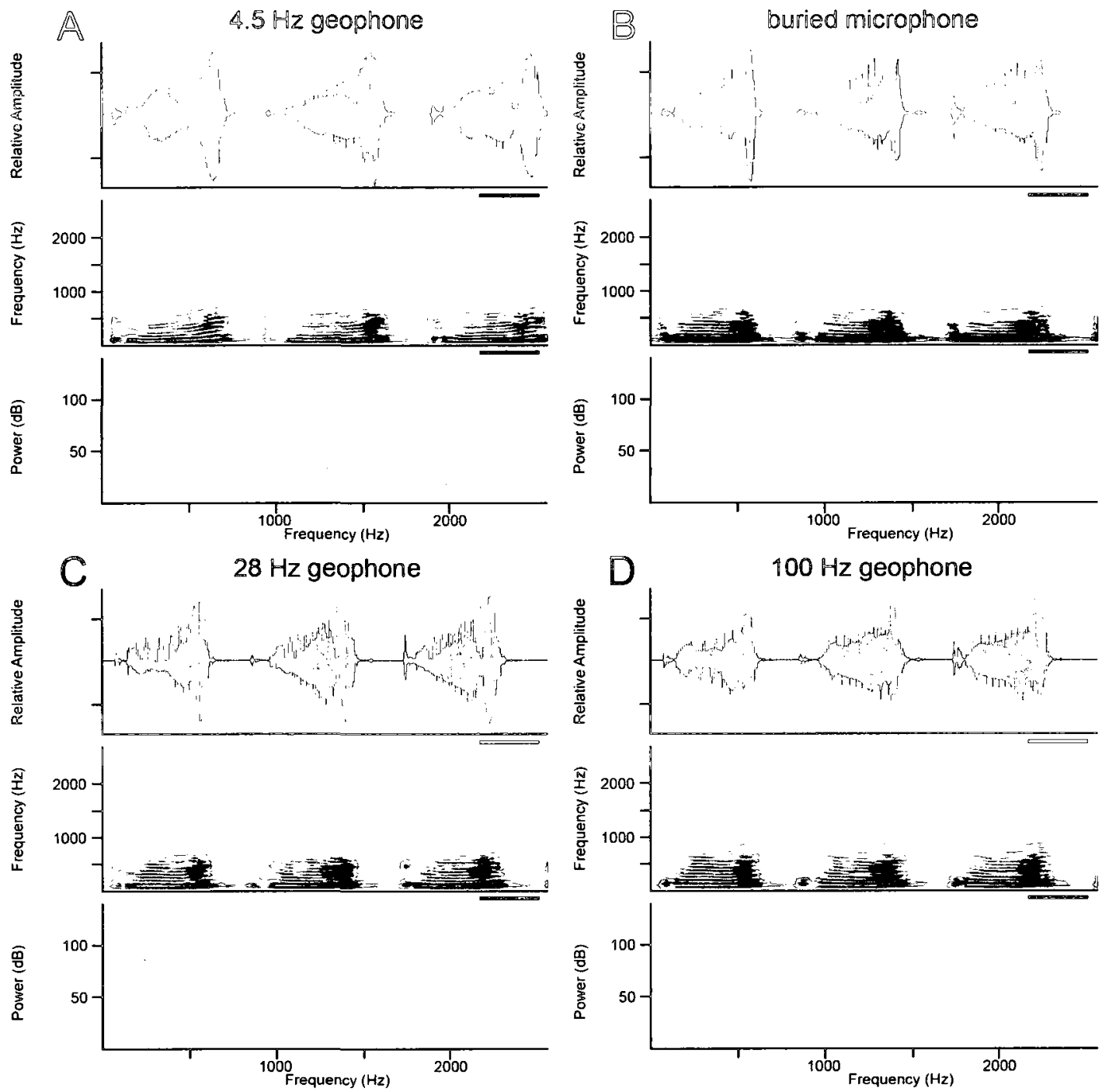
Figure 2.14 Attenuation of Soil Vibration over Distance in Florida

A) Relative amplitude decay of soil vibrations recorded from a linear geophone array. Upper waveform shows grunting vibrations $1.8 \mathrm{~m}$ from the stob, while the lower waveform shows the same vibrations $7.3 \mathrm{~m}$ from the sob. B) Corresponding spectrograms showing changes in frequency composition over distance. Note the disappearance of higher frequency components over this distance, while lower frequencies (e.g. below 400 $\mathrm{Hz}$ ) persist. Scale bar is $0.5 \mathrm{sec}$. 
Fig. 2.14
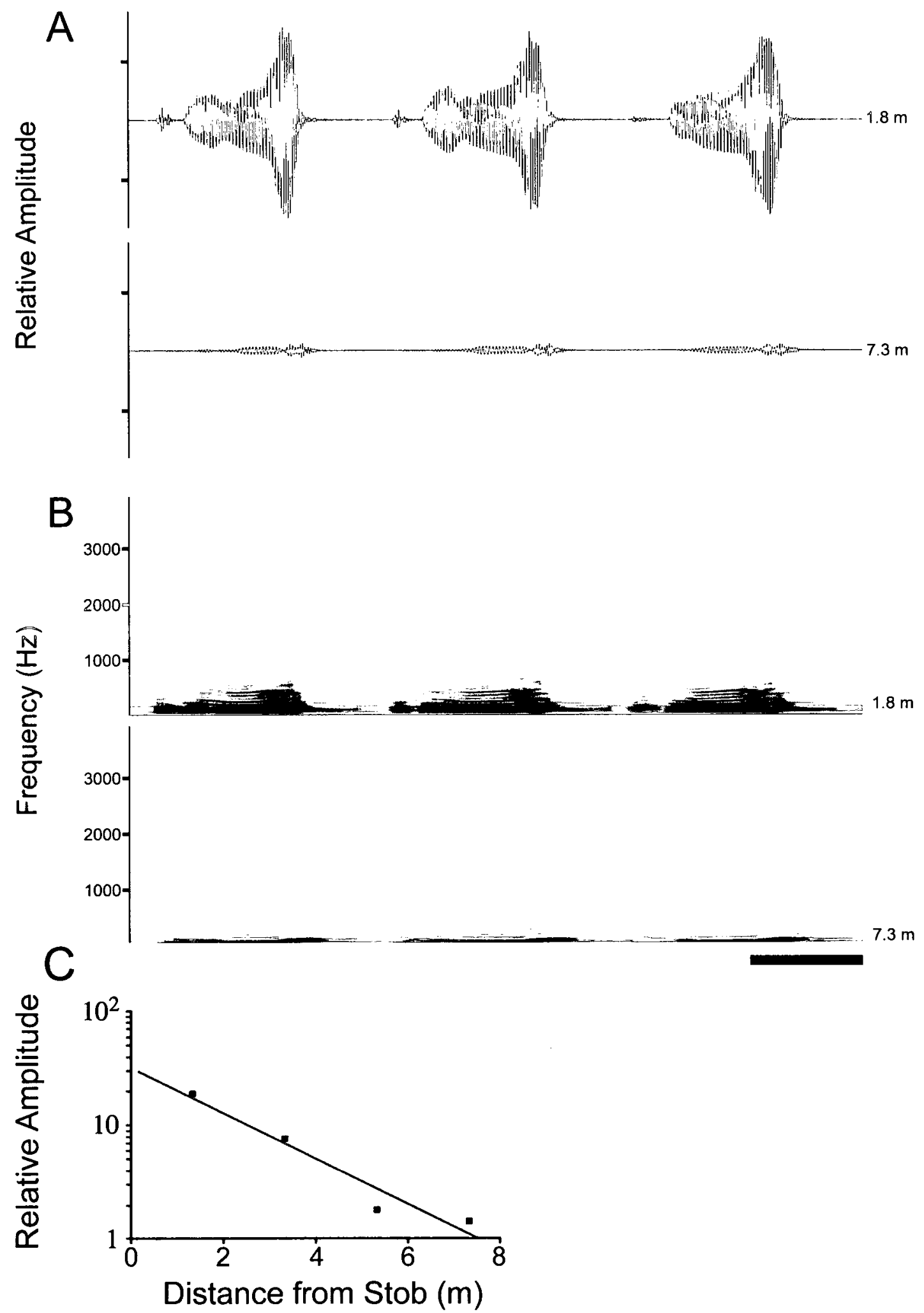
There was also no pattern in the size of the worms that emerged and collected specimens ranged between 7 and $30 \mathrm{~cm}$ in length. All of the collected specimens were identified in the field by Dr. Mac Callaham as belonging to the genus Diplocardia. The largest number of worms surfacing in a single trial was 41 , which occurred during 22 minutes of worm grunting in an area approximately 18 meters in diameter centered on the stob. Earthworms surfaced within a large range of distances from the vibration source. Some specimens emerged from the soil as close as $0.25 \mathrm{~m}$ from the stob, while the furthest specimen surfaced $8.73 \mathrm{~m}$ away (Fig. 2.15). Analysis of the number of worms emerging in the plane of worm grunting (in front of and behind the worm grunter) versus those that emerged perpendicularly to the plane indicated that there was no significant difference in the directionality of earthworm emergence (paired one-tailed t-test, $p=0.43$ ). This was examined by applying 2 equal sized rectangular plots to the trial area, one oriented in the implied plane of vibration (in front of and behind the vibration source), the other oriented perpendicularly to that plane. Plots were sized so that approximately half of the total number of surfaced earthworms would be contained in the area of the plot. Counts were made of the number of surfaced worms observed in each plot per trial, and this data was compared using a paired one-tailed t-test. Data from the spatial distribution of surfaced worms collected from all trials shows that the number of worms surfacing decreases as distance from the vibration source (stob) increases (Fig. 2.16). 
Figure 2.15 Earthworm Emergence in Florida

A composite map indicating the locations of surfaced worms (closed circles) during 4 superimposed trials of worm grunting in Florida. The wooden grunting stob is indicated by the circle and arrow at the centre of the map, with the worm grunter facing the direction of the arrow (towards the left-hand side of the map). Scale bar is $1 \mathrm{~m}$. 
Fig. 2.15

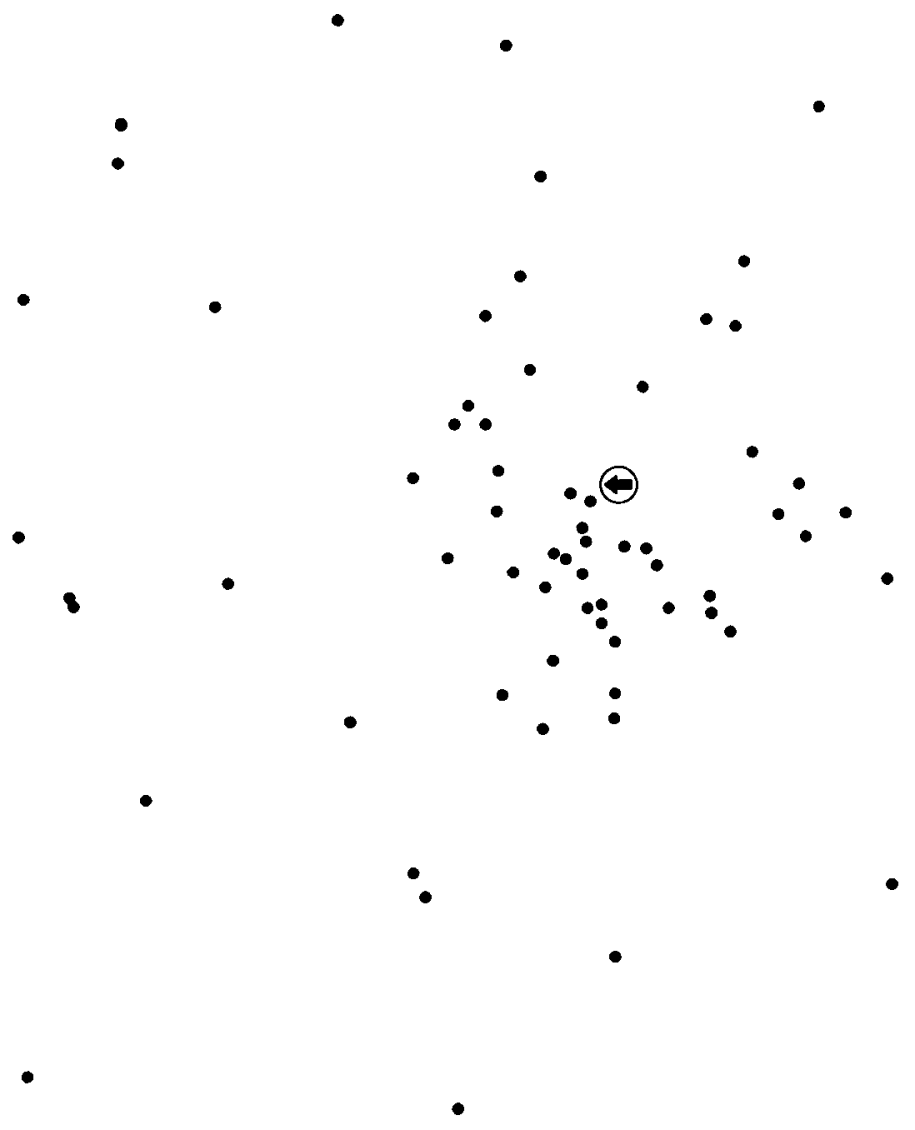


Figure 2.16 Earthworm Emergence as a Function of Distance and Surface Area in Florida

A) Number of worms surfacing as a function of linear distance from the stob. Data are summed from all Florida trials $(\mathrm{n}=5)$ and plotted using sliding window comparisons, using $100 \mathrm{~cm}$ windows with $50 \mathrm{~cm}$ increments. B) Number of worms surfacing as a function of surface area around the stob. Data are summed from all Florida trials $(n=5)$ and plotted using sliding window comparisons, using $50 \mathrm{~m}^{2}$ windows with $25 \mathrm{~m}^{2}$ increments. 
Fig. 2.16

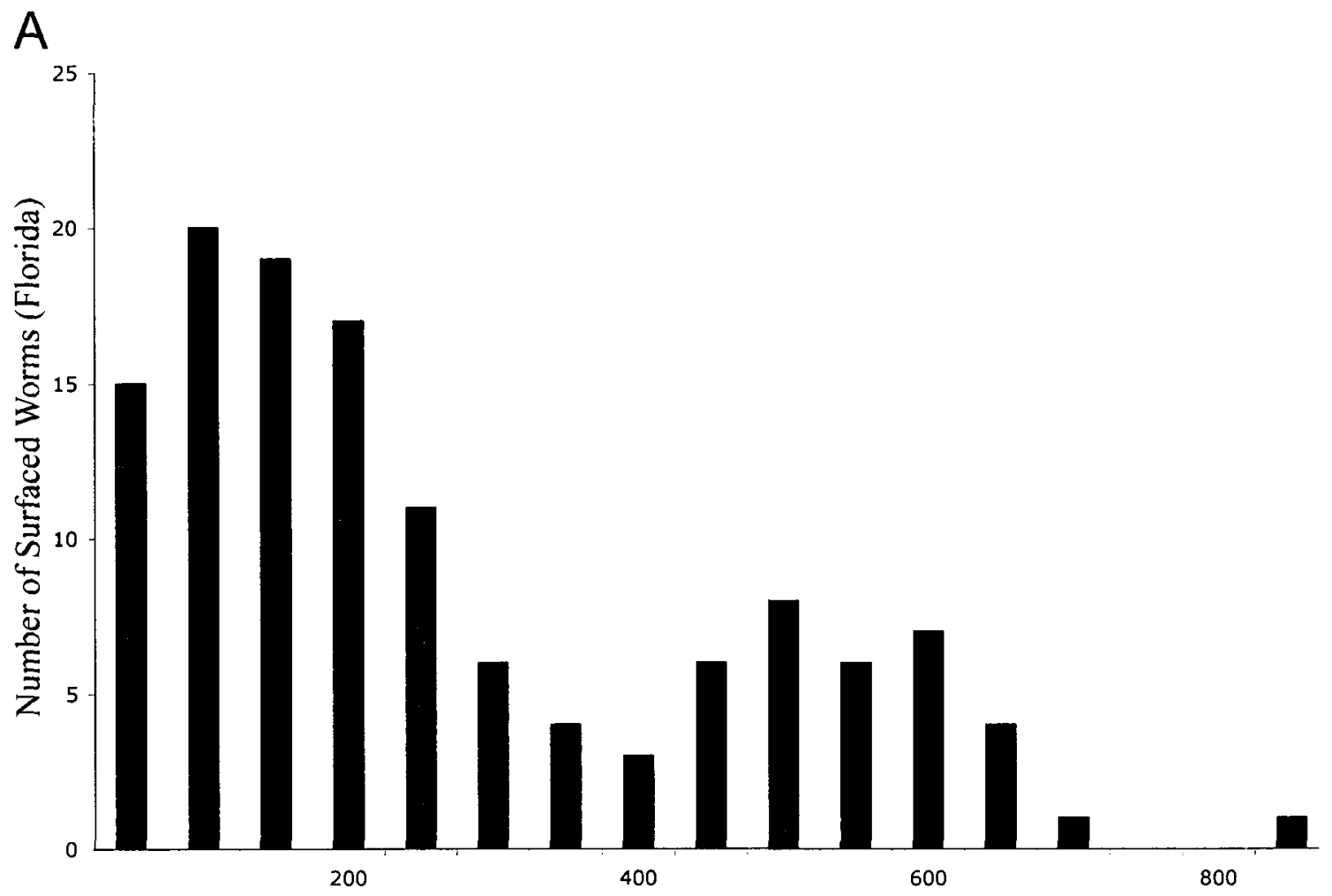

B

Distance Intervals (from Stob) in $\mathrm{cm}$

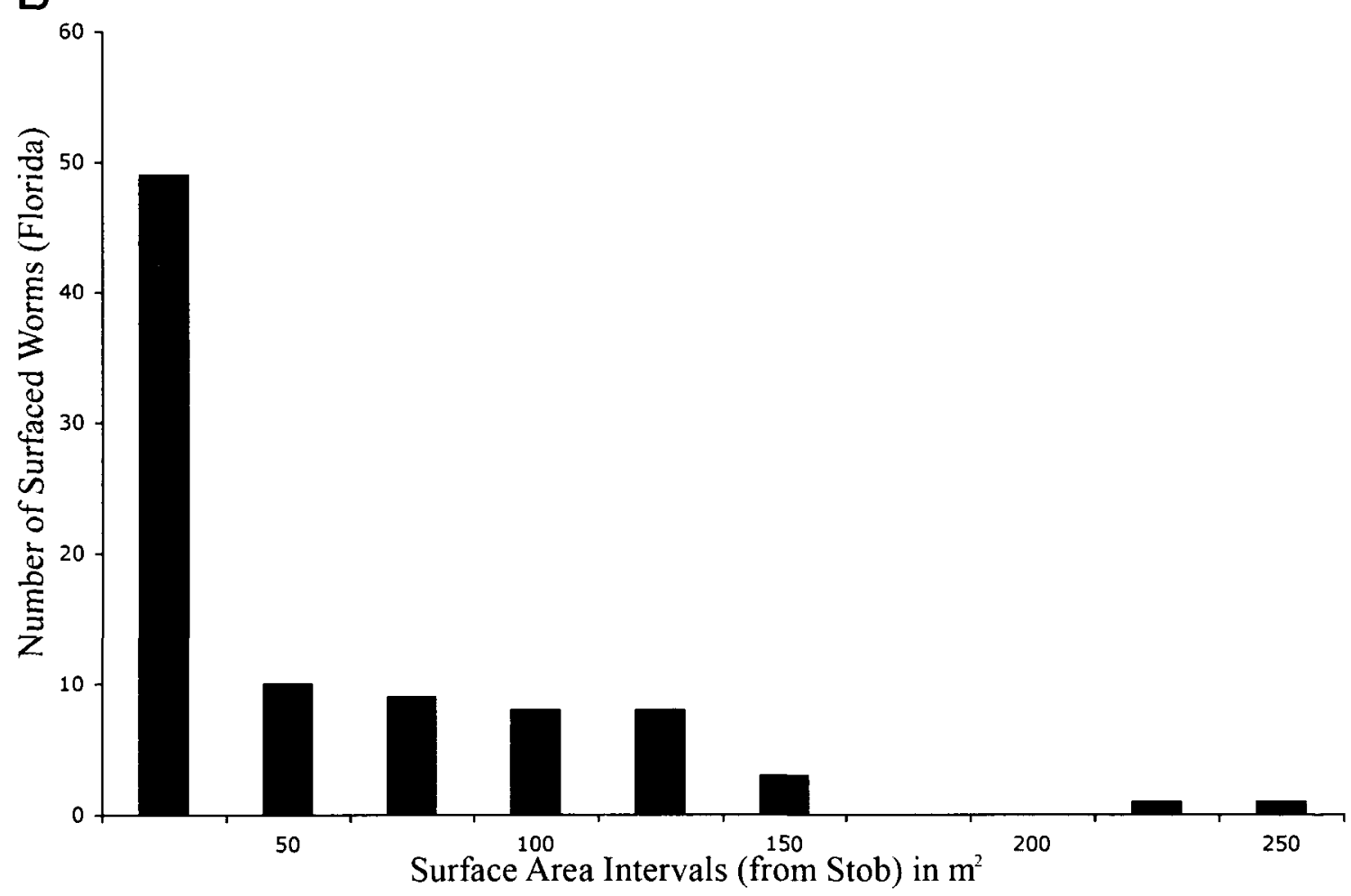




\subsubsection{Earthworm Responses to Vibration in the Ottawa Region of Canada}

Various earthworm species could be made to surface in the Ottawa area using soil vibration created by either the stob and rooper or the pitchfork, although the effective distance of these techniques was much shorter than that observed in Florida. There were also significant differences between the efficacies of these two techniques in making earthworms surface out of the soil, as the pitchfork was significantly more effective in eliciting earthworm emergence from the soil than the stob and rooper, while the stob and rooper were in turn only minimally more effective than the control conditions.

\section{Temporal and Frequency Characteristics}

Vibrations recorded using geophones demonstrated that soil vibrations were present throughout the area of soil within which earthworms had emerged. A pair of geophones was normally placed in a linear array so that each sensor was 100 and $200 \mathrm{~cm}$ away from the vibration source respectively, and vibrations from both the stob and pitchfork were easily recorded within these distances.

The two stimulus types did differ in the temporal pattern of vibrations they produced. The stob produced pulsed vibrations with fairly consistent rhythms, pulse rates, and amplitudes, which were similar to the vibrations produced by the stob and rooper in Florida (Fig 2.17 A). Stob pulses were typically $0.663 \pm 0.137 \mathrm{sec}$ long $(\mathrm{n}=30)$ with $0.750 \pm 0.217 \mathrm{sec}$ intervals between pulses $(n=30)$. In contrast, the pulses of each pitchfork "twang" were temporally longer and began with higher amplitudes that steadily decreased over time for each "pulse" (Fig 2.17 B). 
Figure 2.17 Stob vs. Pitchfork Soil Vibrations in Ontario

(A, D) Waveforms of stob and rooper (A) and pitchfork (D) vibrations respectively, recorded with $4.5 \mathrm{~Hz}$ geophones $2 \mathrm{~m}$ away from the vibration source (scale bar is $2 \mathrm{sec}$.) $(\mathrm{B}, \mathrm{E})$ Spectrograms corresponding to A and D. (C, F) Power spectra corresponding to A and $\mathrm{D}$. Lowest power spectra indicate the background noise levels. 
Stob

A
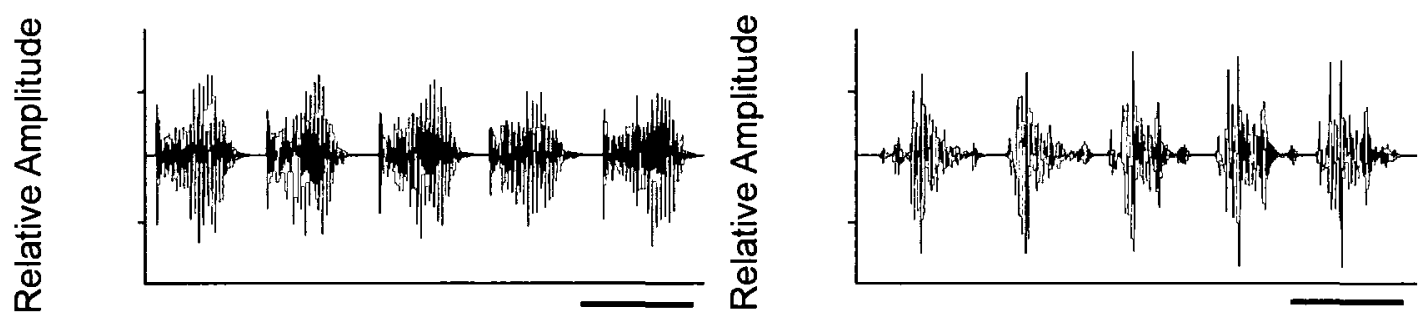

B

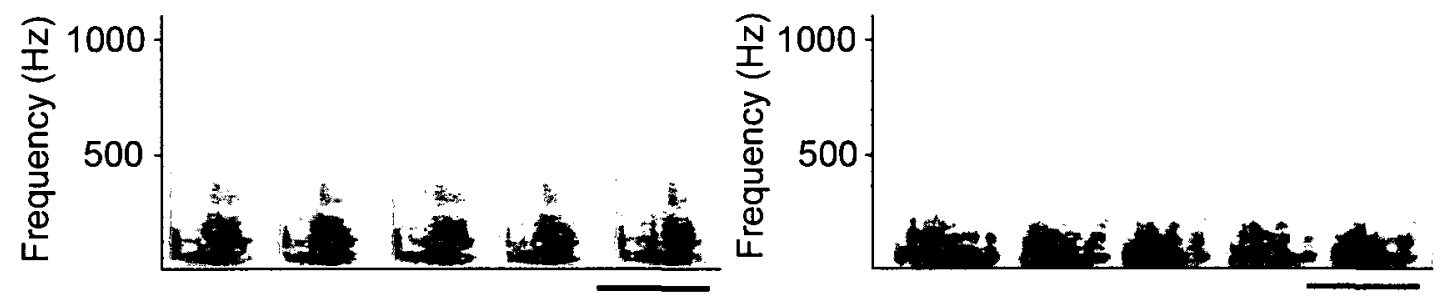

C
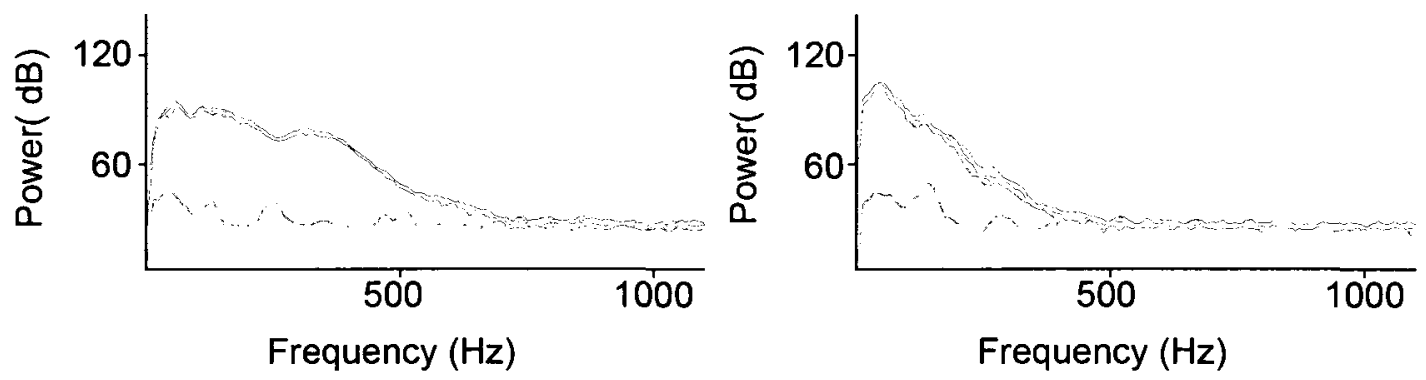
This was due to the nature of pitchfork vibration, since the pitchfork would begin moving with a hard pull, and would then bounce back and forth while slowing down and eventually stopping. Each pitchfork pulse was also followed by a much smaller pulse created when the experimenter's hand grabbed the pitchfork in preparation for the next pulse. The main pulse created by the pitchfork was typically $0.885 \pm 0.128 \mathrm{sec}$ long $(\mathrm{n}=$ 30 ), with an interval of $0.502 \pm 0.168 \mathrm{sec}$ between pulses $(\mathrm{n}=30$, and this interval includes the small pulse created by the experimenter's hand).

Both the stob and pitchfork produced broadband vibrations in the soil, with relatively lower frequencies dominating the spectrum in both cases. The most prominent frequencies produced by the stob technique were all below $500 \mathrm{~Hz}$ (Fig. 12.17 B), and these low frequencies remained at high amplitude levels throughout the duration of the stimulus (i.e. throughout each stob scrape). Less prominent higher frequency components (up to 2 to $2.5 \mathrm{kHz}$ ) are visible more erratically in the stob vibrations. The pitchfork produced a similar type of vibration in the soil, with the dominant frequencies still falling below $500 \mathrm{~Hz}$ (Fig. $12.17 \mathrm{~B}$ ), and limited erratic high frequencies up to $1.5 \mathrm{kHz}$. However, the pitchfork stimulus was much more variable across time during each twang, because the first half of each twang was much more intense than the latter half, which was to be expected given the nature of the production of vibration using a pitchfork. During the latter half of each pitchfork twang all frequencies (high and low) diminish substantially, but low frequencies below $500 \mathrm{~Hz}$ continue to dominate the frequency spectrum. Peak power was found around $72 \pm 24 \mathrm{~Hz}$ for the stob $(\mathrm{n}=20)$ and $66 \pm 14 \mathrm{~Hz}$ the pitchfork $(n=20)$ (Fig. 12.17 C). 
The stob and pitchfork vibrations were both measureable within the radius of all geophones. Changes in stimulus characteristics were observed between the two sensor distances used. At one meter away from the stob, vibrations contained frequencies up to 2 or $2.5 \mathrm{kHz}$ with the dominant frequencies being $500 \mathrm{~Hz}$ and below (Fig. $2.18 \mathrm{~A}$ ), while at 2 meters most frequencies above 400 to $500 \mathrm{~Hz}$ disappeared (Fig. $2.18 \mathrm{~B}$ ). The pitchfork had similar frequency components at one meter, although the higher frequencies only went up to about 1 or $1.5 \mathrm{kHz}$ (Fig. $2.18 \mathrm{C}$ ), and these higher frequencies decayed almost completely at 2 meters (Fig. 2.18 D). The relatively higher frequencies were more prominent at both distances in the stob recordings than those of the pitchfork, although in all cases low frequencies were consistently dominant.

When the rooper and stob produced soil vibration the surface of the soil could be visibly seen vibrating in the immediate vicinity of the stob, but the soil only showed a small amount of visible horizontal displacement in a small radius around the stob. The pitchfork also created visible vibration on the soil surface, but it also resulted in a much greater horizontal displacement of soil than the stob. When the pitchfork was rocked back and forth, the soil in front of and behind the pitchfork would be forced to move suddenly, rapidly, and with considerable force in the same directional plane as the pitchfork movement. This repeated displacement of the soil was sufficient to loosen the soil considerably during the trial. In fact, by the end of some trials the soil would be too loose to use the pitchfork properly. The stob and rooper did not disturb and loosen the soil in the same manner. 
Figure 2.18 Attenuation of Soil Vibrations in Stob and Pitchfork Trials

A) Oscillograms of stob and rooper soil vibrations recorded with geophones at 1 and $2 \mathrm{~m}$ distances. B) Corresponding spectrograms for the same vibrations (frequencies in $\mathrm{Hz}$ ). C) Relative amplitude decay of stob vibrations, measured from five pulses during a single trial. D) Oscillograms of pitchfork soil vibrations recorded with geophones at 1 and $2 \mathrm{~m}$ distances (frequencies in $\mathrm{Hz}$ ). E) Corresponding spectrograms for the same vibrations. F) Relative amplitude decay of pitchfork vibrations, measured from five pulses during a single trial. With both vibration sources, higher frequencies (above 400 to $500 \mathrm{~Hz}$ ) attenuate considerably between the 1 and $2 \mathrm{~m}$ distances. Scale bars are all $0.5 \mathrm{sec}$. 
Fig. 2.18

Stob
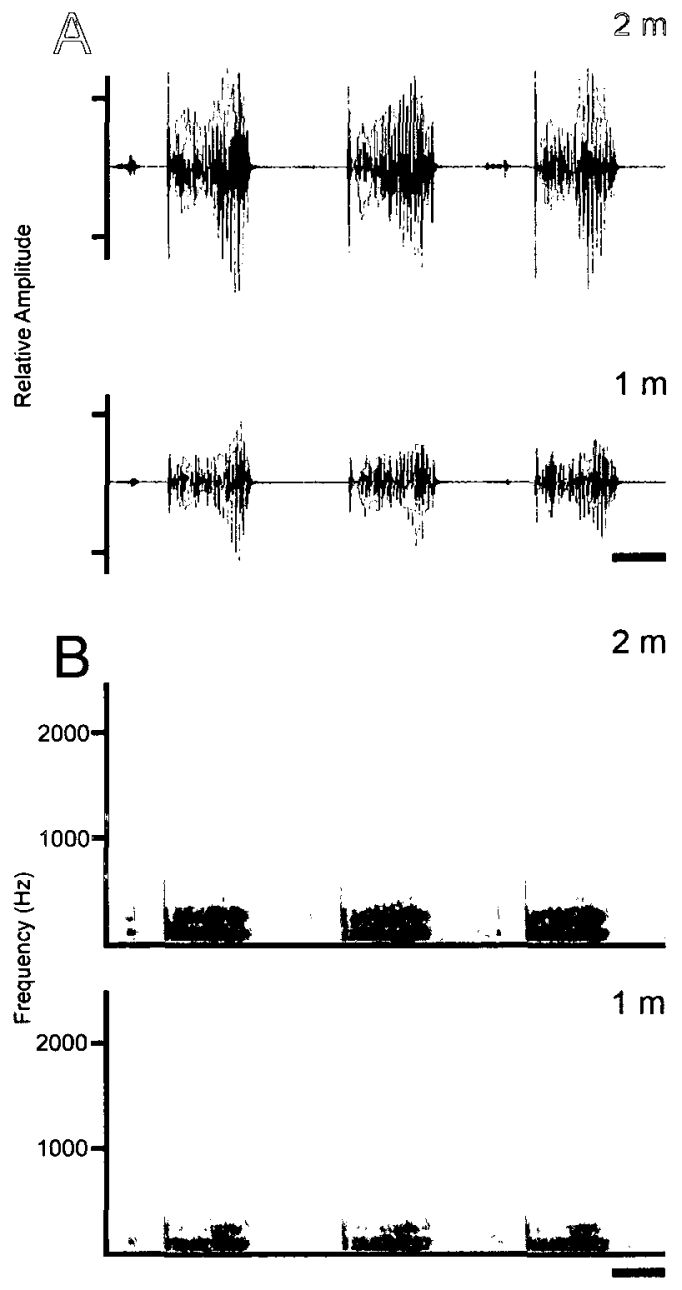

C

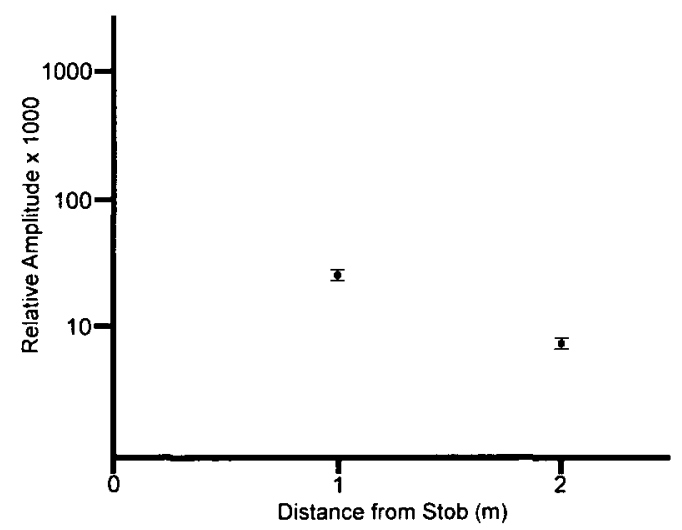

Pitchfork
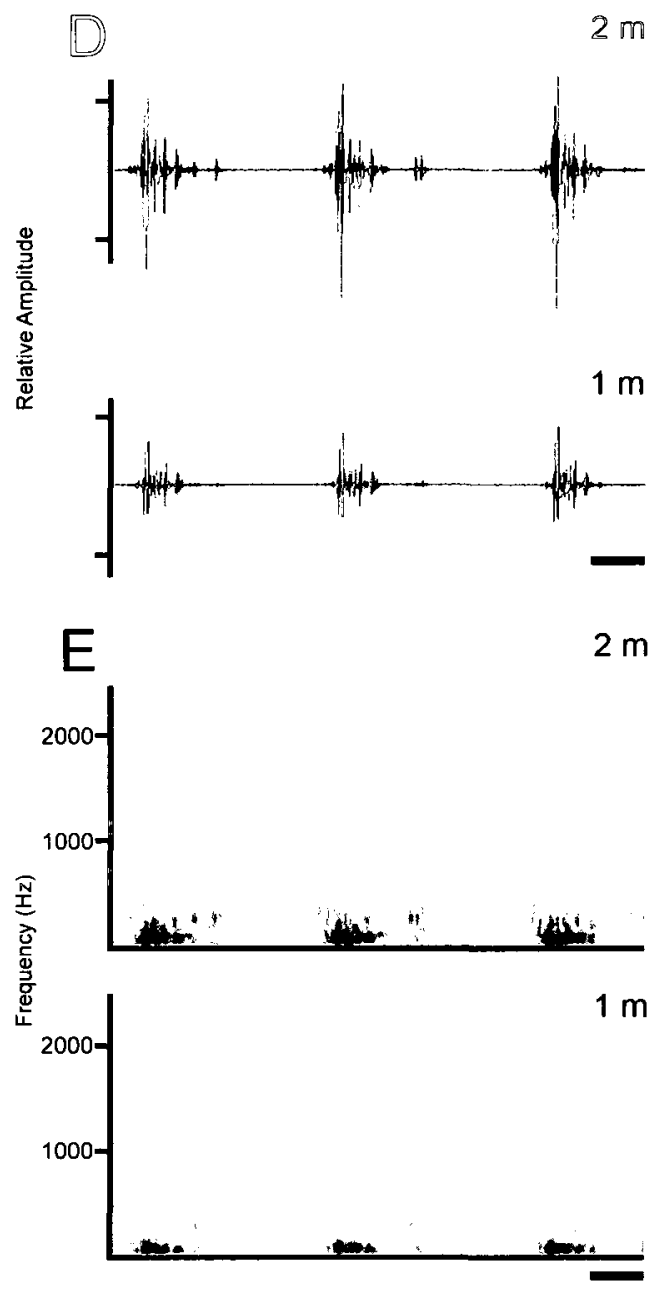

F

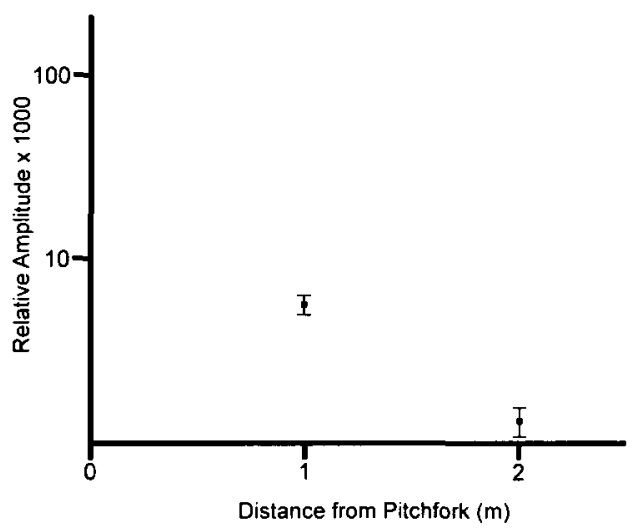




\section{Earthworm Emergence}

Earthworms were observed surfacing during both the stob and pitchfork trials, but the pitchfork proved to be a more effective method of eliciting surfacing responses. The pitchfork caused the first initial worm to begin emerging anywhere from 7 to 147 seconds following the onset of vibration, although the average emergence latency for the first surfacing earthworm was $72 \pm 40$ seconds $(n=23)$. In addition to the latency of the first emerging worm, earthworms emerged in general from the soil between 7 and 369 seconds after the onset of vibration production, with an average emergence latency of 123 \pm 86 seconds $(n=67)$, and worms continued emerging for as long as 4 minutes and 50 seconds during the duration of the vibration stimuli. Earthworms observed surfacing typically emerged from their burrows very rapidly (typically taking one or two seconds to completely exit their burrow) and would often writhe, contract their bodies, and/or thrash about from side to side immediately after exiting their burrows. Once they had emerged out of the ground, most worms would move quickly across the soil surface using a typical peristaltic motion. There did not appear to be any directionality to these movements, although this was not quantitatively examined. The majority of worms remained on the soil surface until picked up, and worms that had completely emerged from the soil rarely re-entered the soil afterwards. Earthworms that were touched or disturbed while partially emerged would immediately retreat back into their burrows.

The distances between worm emergence sites and the vibration source were measured, and despite the fact that both the stob and pitchfork techniques produced soil vibrations within a $2 \mathrm{~m}$ radius of the vibration source, no earthworms were ever observed surfacing more than one meter away from the vibration source (Fig. 2.19). Analysis of 
Figure 2.19 Earthworm Emergence During Pitchfork Trials in Ontario

Composite map indicating the locations of surfaced earthworms (circles) during 19 superimposed trials using the pitchfork in Ontario. The rectangle in the center indicates the orientation of the pitchfork (which was vibrated in a vertical plane with respect to the map). Scale bar is $25 \mathrm{~cm}$. 
Fig. 2.19

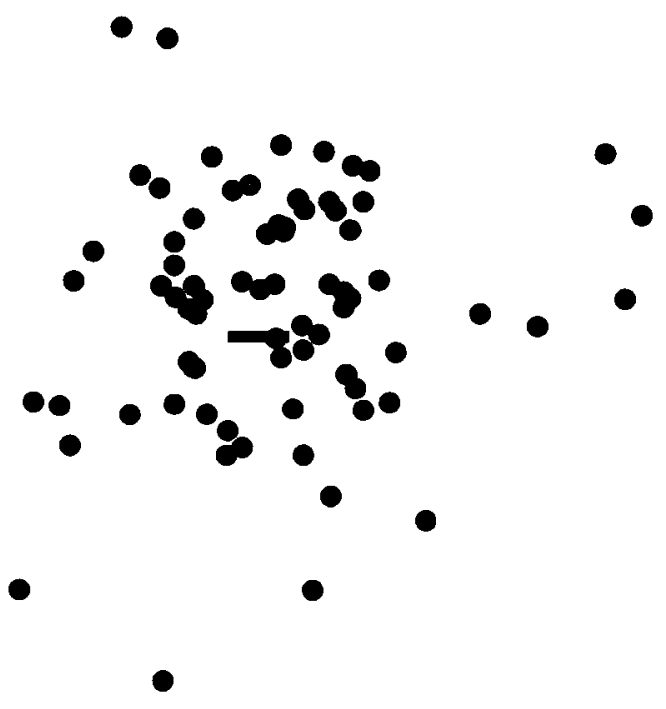

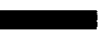


the number of worms emerging in the direction of pitchfork motion (in front of and behind the pitchfork) versus those that emerged perpendicularly to that direction indicated that there was no significant difference in the directionality of earthworm emergence (paired one-tailed t-test, $\mathrm{p}=0.44$, using the same procedure used for the Florida data). Only three earthworms in total were found surfacing during stob trials, and these were found 45,65 , and $84 \mathrm{~cm}$ away from the stob (Fig. 2.20). In contrast, earthworms were observed emerging anywhere between 1 to $97 \mathrm{~cm}$ away from the vibration source during the pitchfork trials, with the majority of earthworms found surfacing between 15 and $35 \mathrm{~cm}$ away from the pitchfork (Fig. 2.21). Very few worms surfaced very close to the pitchfork ( 0 to $15 \mathrm{~cm}$ away), and after reaching a peak in emergence in the 15 to $35 \mathrm{~cm}$ range, the number of worms emerging decreased as distance from the vibration source (pitchfork) increased (Fig. 2.21).

\section{Control Conditions vs Earthworm Emergence}

Very few earthworms were observed during the control conditions used for all trials, where the soil surface of each prepared trial site was observed for 5 minutes before the vibration stimuli were delivered. Worms were rarely observed on the soil surface before the stimulus, with only 2 worms observed on the surface prior to the stob trials ( $\mathrm{n}$ $=15$ ), and 4 found prior to the pitchfork trials $(n=28)$ (Fig. 2.22). Earthworms were never found on the soil surface after stimulus delivery for any trial type $(n=43)$, and this was true even on days when it was raining. The 2 earthworms found on the surface prior to the stob trials were found at the same time during the same trial, and were located very close to one another (about $7 \mathrm{~cm}$ apart) on a wet and lightly rainy day. Both organisms 
Figure 2.20 Sliding Window Analysis of Earthworm Emergence over Distance During Stob/Rooper Trials in Ontario

A) Graph indicates the number of worms surfacing as a function of distance from the stob, using data collected from 15 trials. Data is plotted using sliding window comparisons, using $10 \mathrm{~cm}$ windows with $5 \mathrm{~cm}$ increments. B) Number of worms surfacing as a function of surface area around the stob, using data collected from 15 trials. Data is plotted using sliding window comparisons, using $1 \mathrm{~m}^{2}$ windows with 0.5 $\mathrm{m}^{2}$ increments. 
Fig. 2.20
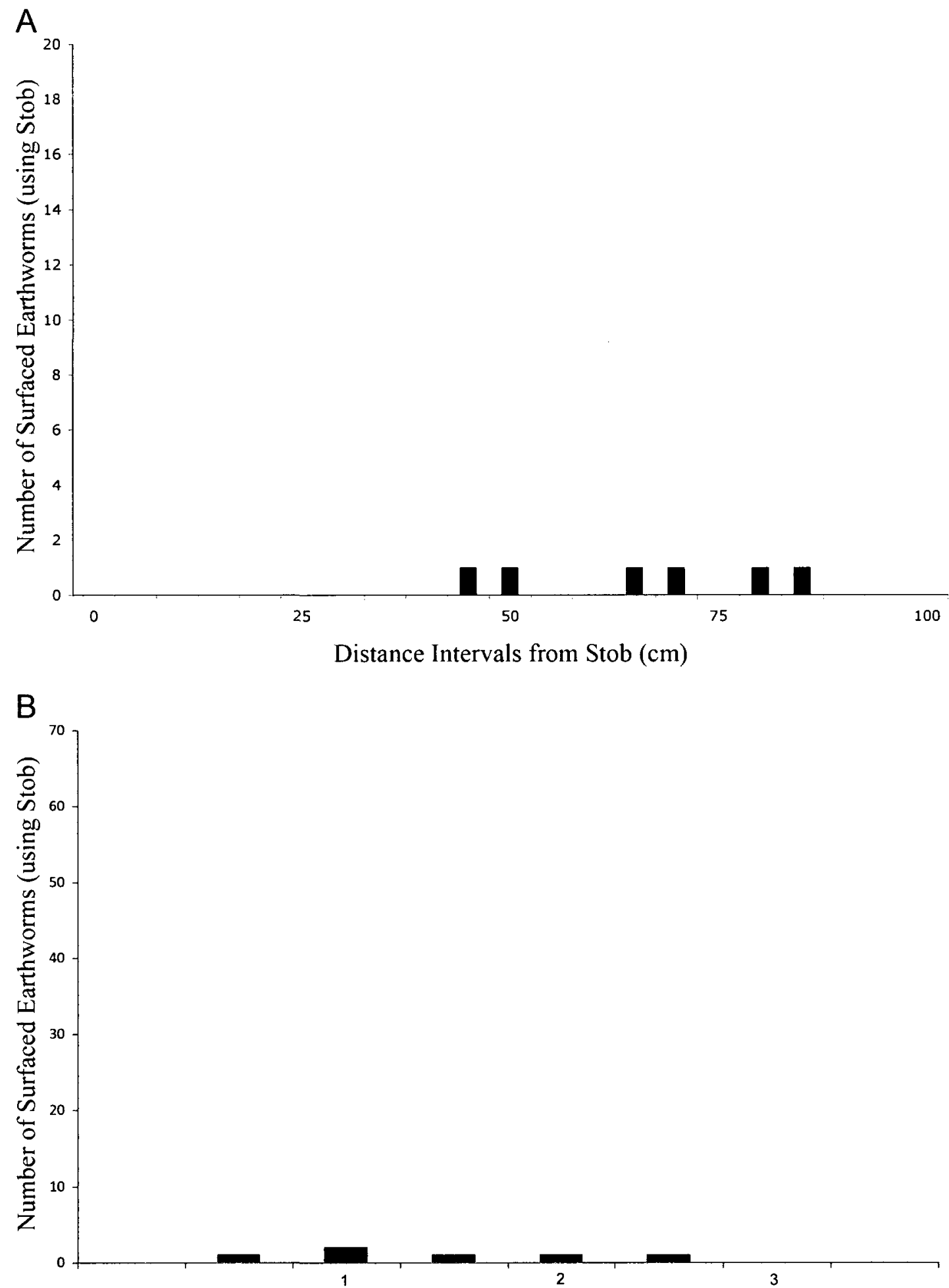

Surface Area Intervals from Stob $\left(\mathrm{m}^{2}\right)$ 
Figure 2.21 Sliding Window Analysis of Earthworm Emergence over Distance During Pitchfork Trials in Ontario

A) Graph indicates the number of worms surfacing as a function of distance from the pitchfork, using data collected from 27 trials. Data is plotted using sliding window comparisons, using $10 \mathrm{~cm}$ windows with $5 \mathrm{~cm}$ increments. B) Number of worms surfacing as a function of surface area around the pitchfork, using data collected from 27 trials. Data is plotted using sliding window comparisons, using $1 \mathrm{~m}^{2}$ windows with 0.5 $\mathrm{m}^{2}$ increments. 
Fig. 2.21

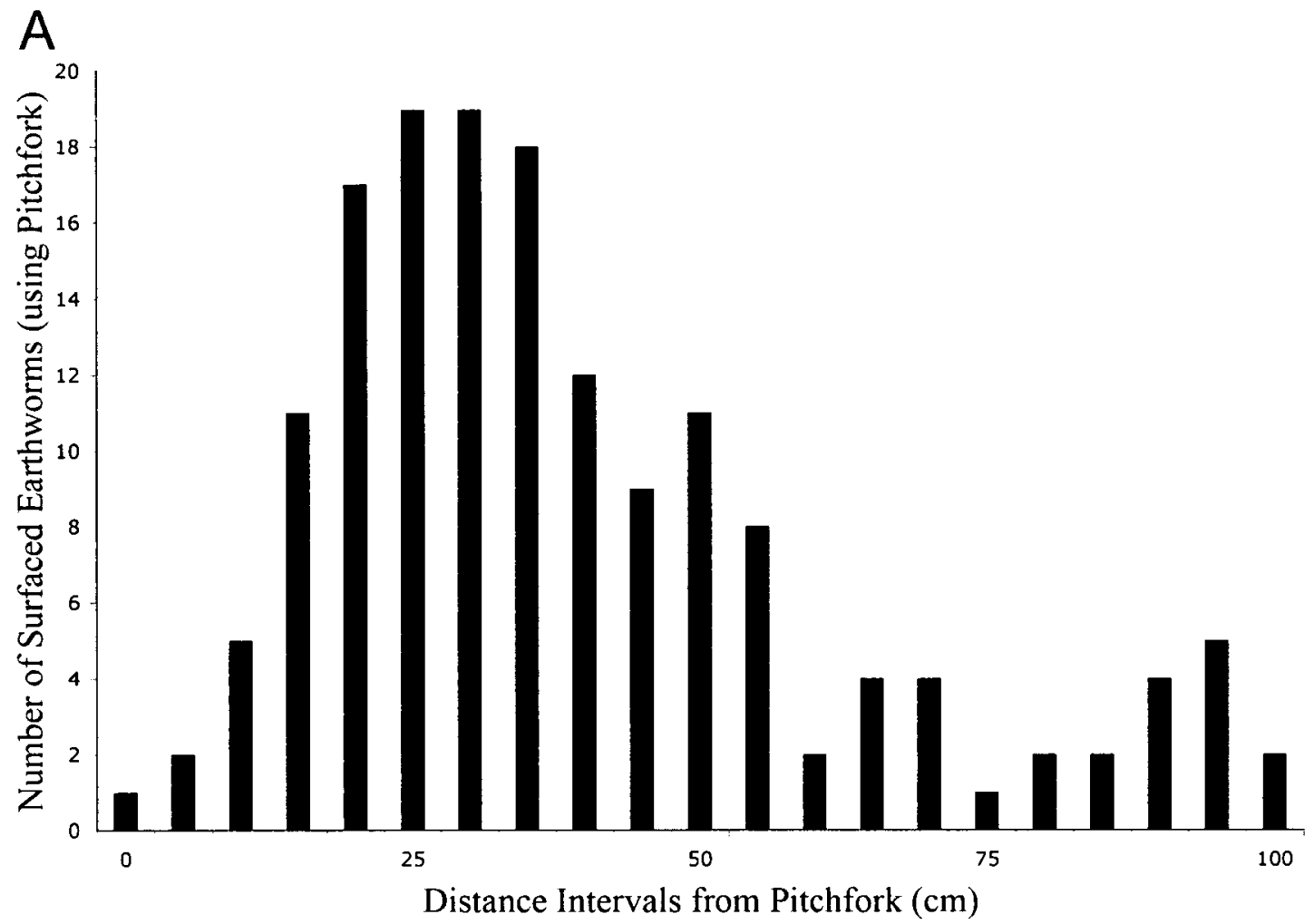

B

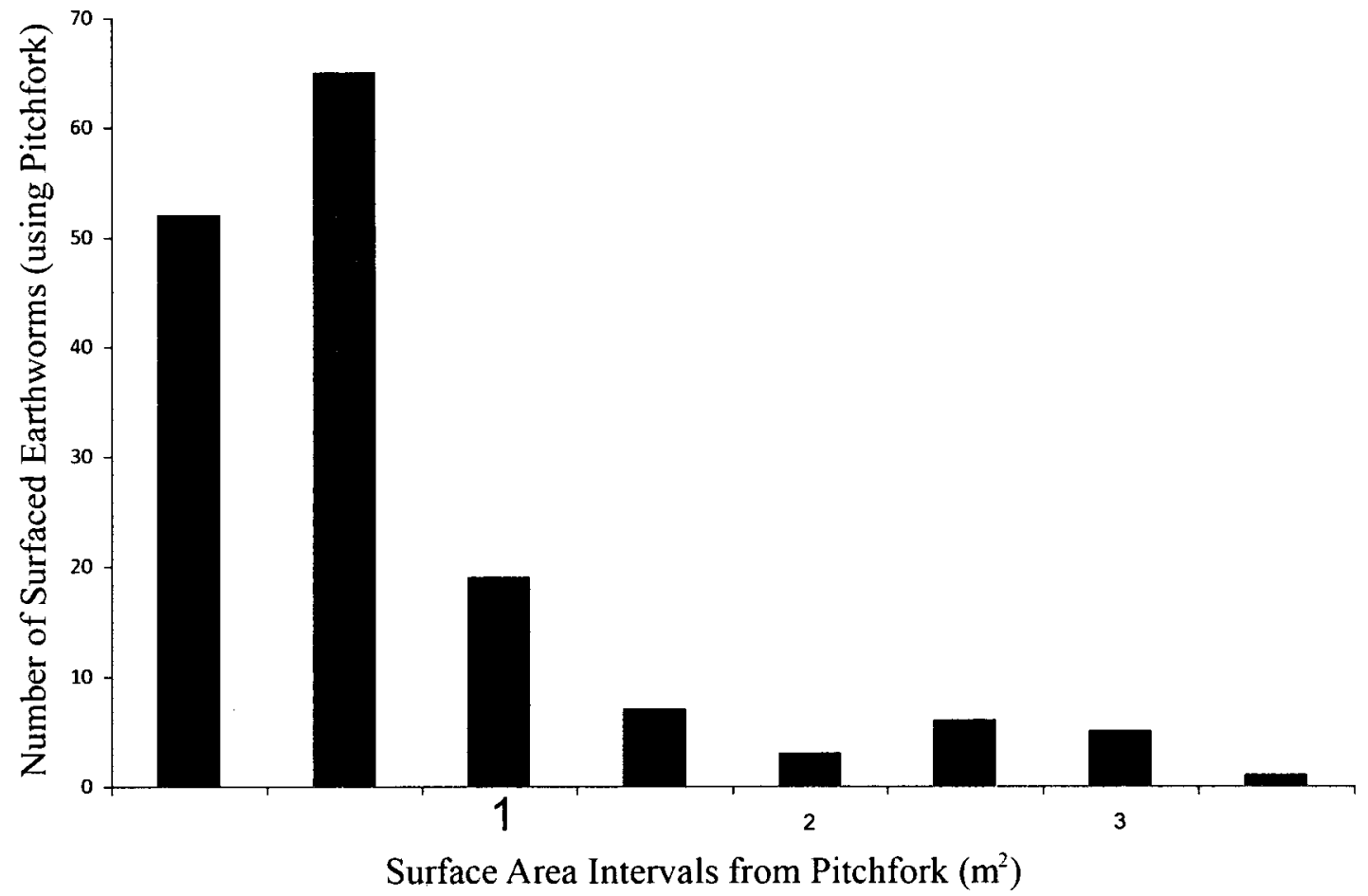


Figure 2.22 Earthworm Emergence and Abundance Comparisons for the Stob and Pitchfork Trials in Ontario

Graph indicates earthworms observed on the soil surface before, during, and after vibration trials, as well as the number of earthworms found in the soil sample taken after the trial was completed. Note that significantly more earthworms emerged during the pitchfork trials than the stob trials. 
Fig. 2.22

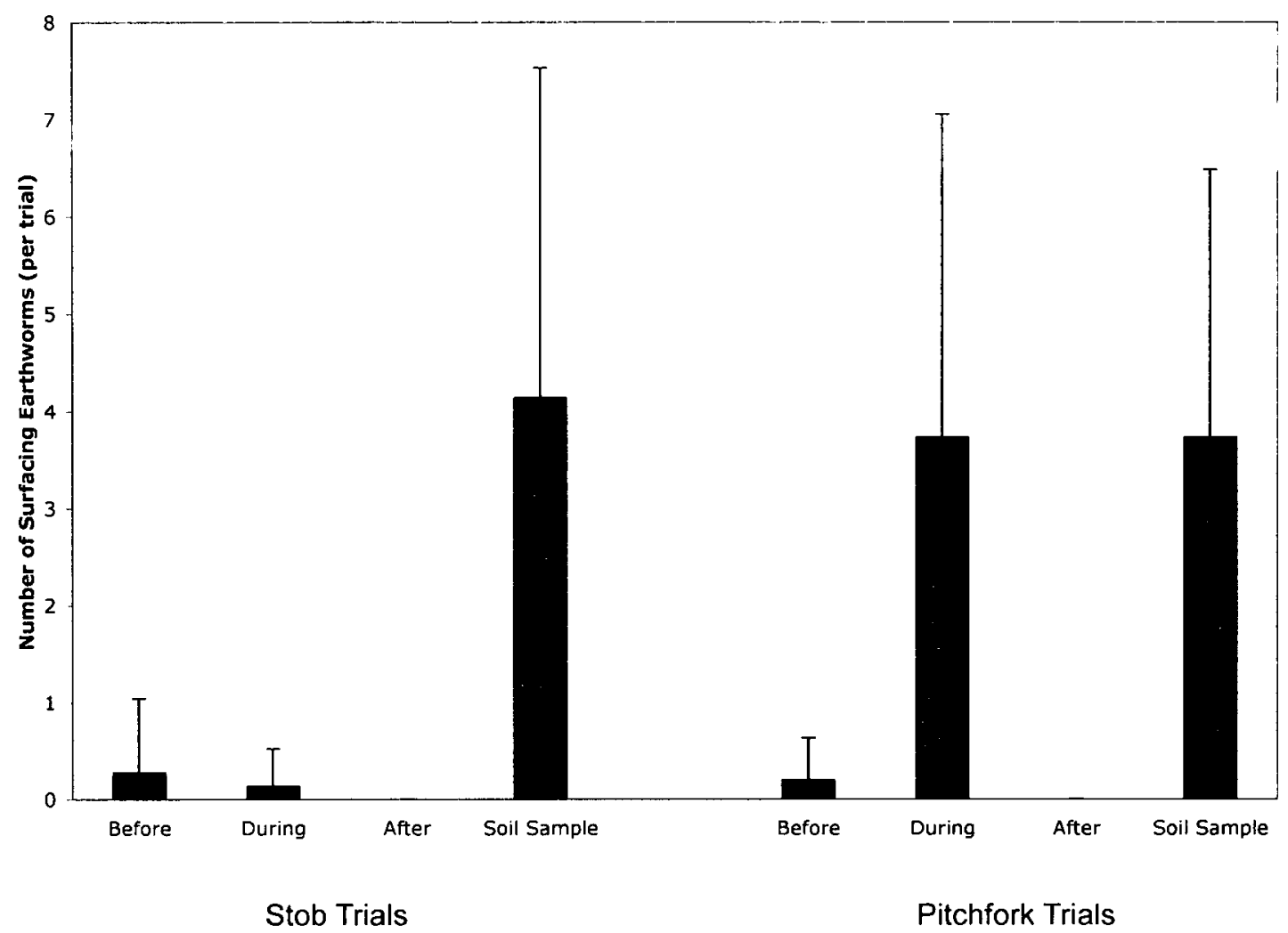


were moving across the soil surface in roughly the same direction when found. The earthworms found on the surface prior to the pitchfork trials were all found under leaf litter and were possibly foraging, as they were active and responsive to disturbance.

The prevalence of earthworms on the soil surface before and after trials was quite consistent between both trial types. The average number of worms on the surface prior to the vibration stimulus was 0.13 for stob trials $(n=15)$ and 0.14 for pitchfork trials $(n=$ 28 ), while 0 worms were found on the surface after both trial types ( $n=15$ and 28 for the stob and pitchfork respectively). The number of earthworms found remaining within the soil samples taken after the vibration tests were completed was also very similar between both trial types, with an average of $3.27(n=15)$ worms observed within the soil after the stob trials and $3.25(\mathrm{n}=28)$ found after pitchfork trials.

Although the control conditions and soil samples showed very consistent numbers of earthworms between trial types, the two types of vibration tests produced very different results in terms of the number of earthworms that surfaced during the vibrational test phase of each trial. The stob and rooper only caused 3 worms to surface over 15 trials, resulting in an average of 0.2 earthworms surfacing per trial, while the pitchfork technique caused 76 earthworms to surface over 28 trials, resulting in an average of 2.7 worms surfacing per trial (Fig. 2.21). Statistical analysis of these results indicates that the effectiveness of the pitchfork technique was statistically significant (paired, one-tailed t-test, $\mathrm{p}=4.5 \times 10^{-5}$ ), while the effectiveness of the stob was not statistically significant (paired, one-tailed t-test, $\mathrm{p}=0.36$ ). 


\section{Breakdown of Emergence Data Based on Site Types}

The data from the Ontario experiments does demonstrate the effectiveness of the pitchfork in eliciting surfacing responses, but a detailed analysis of earthworm emergence in both the stob and pitchfork trials must take into account the fact that two different types of trial sites were used for these trials. One set of trials was performed at specific sites that were reused for subsequent trials (for both the stob and pitchfork), while the second set of trials was performed at sites that were freshly prepared prior to each trial (for both techniques) and were never reused. The previously presented data consisted of pooled data from both the "old" and "fresh" trial sites (Fig. 2.21 A). However, these two trial types possessed slightly different experimental conditions and gave slightly different experimental results. Because the old sites had vegetation and ground cover removed from the area for a prolonged period of time (lasting a total of about 6 weeks), these sites were subjected to much more physical soil disturbance over time (due to the repeated tests performed there), and the soil surface also became much drier than normal. In contrast the fresh sites were subjected to much less disturbance because they had never been used for prior trials and were only minimally disturbed and recently cleared of vegetation and ground cover. The soil at the fresh sites was also moister than that of the old sites. Earthworm abundance at the old and previously used trial sites was also typically lower than that of freshly prepared sites, and this was true for all sample types including the control and experimental conditions, as well as the soil samples. For example, the average number of earthworms found in each soil sample from the old sites was $2.35(n=17)$, while fresh sites contained a higher average of 3.70 worms per soil sample $(n=27)$. 
Regardless of the differences in earthworm abundance between the old and fresh trial sites, the pitchfork technique proved to be more effective at eliciting the surfacing responses of earthworms in both types of experimental categories. Among old trial sites, the stob made an average of 0.25 earthworms emerge to the surface per trial $(n=8)$, versus 0.556 earthworms emerging per pitchfork trial $(n=9)$, and this difference in effectiveness is even more apparent when examining the data from the fresh sites, where an average of 0.143 worms emerged per trial during stob tests $(n=7)$, and an average of 3.74 worms emerged per trial during pitchfork tests $(n=19)($ Fig. 2.21). Data for these findings is summarized in Table 2.3.

\section{Variability in Earthworm Emergence}

It should be noted that despite the fact that the pitchfork was considerably more effective than the stob in eliciting surfacing responses, both techniques showed a considerable amount of variability in their effectiveness at making earthworms surface. The stob technique was typically completely ineffective, as the majority of stob trials did not result in any worms coming to the surface, and only one surfacing worm was ever found in each "successful" stob trial. Furthermore, only some of these specimens showed typical surfacing behaviour (which consisted of rapid peristaltic surfacing motions). Two of the worms that had "surfaced" during the stob tests were sickly and fairly unresponsive and may have emerged purely by chance. In contrast, the pitchfork was usually (but not always) effective in making earthworms emerge from the soil, and nearly all the worms observed surfacing during pitchfork trials displayed vigorous locomotory and contractile behaviours. The greatest number of earthworms to emerge during a single pitchfork trial 
Table 2.3 Earthworm Abundance Data for Fresh and Old Trial Sites

Table presents the average number of earthworms found per trial in each sample type, for both stob and pitchfork vibration methods. The "before" sample was taken by monitoring the soil surface for 5 minutes prior to the vibration test, the "during" sample was taken by monitoring the soil surface during 5 minutes of vibration production, the "after" sample was taken by monitoring the soil surface for 4 minutes after the vibration test, and the "soil" sample was taken from a $20 \times 20 \times 20 \mathrm{~cm}$ soil volume dug up after all other samples were taken.

\begin{tabular}{|c|c|c|c|c|}
\hline & & Fresh Trial Sites & & \\
\hline & Before & During & After & Soil \\
\hline Stob & $0.29 \pm 0.76$ & $0.14 \pm 0.38$ & $0.0 \pm 0.0$ & $4.1 \pm 3.4$ \\
\hline Pitchfork & $0.21 \pm 0.42$ & $3.7 \pm 3.3$ & $0.0 \pm 0.0$ & $3.7 \pm 2.8$ \\
\hline & Bef & $\begin{array}{l}\text { Old Trial Sites } \\
\text { During }\end{array}$ & After & Soil \\
\hline & $=0.0$ & $0.25 \pm 0.46$ & $0.0 \pm 0.0$ & $2.5 \pm 3.0$ \\
\hline Ditchfork & $0.0 \pm 0.0$ & $0.56 \pm 0.73$ & $0.0 \pm 0.0$ & $2.2 \pm 2.7$ \\
\hline
\end{tabular}


was 12 , followed by two trials where 9 worms emerged each time. When analyzing all trials, it was found that $84.2 \%$ of pitchfork trials $(n=28)$ resulted in at least one or more earthworms emerging from the soil during the production of vibration, while in contrast earthworms were observed emerging in only $14.3 \%$ of stob trials $(n=15)$.

\section{Species Composition}

The earthworms that emerged due to vibration stimuli were comprised of a wide range of ages and species. Juveniles, aclitellate adults, and reproductively mature clitellate adults were found in all sample groups. The only 2 species that emerged during the stob trials were Aporrectodea tuberculata and Octolasion tyrtaeum. There were four species that emerged during the pitchfork trials: Aporrectodea tuberculata, Aporrectodea rosea (formerly known as Eisenia rosea), Lumbricus rubellus, and Lumbricus terrestris. The most common species present (based on adult clitellate specimens) were Aporrectodea tuberculata and Lumbricus rubellus. Some earthworms were almost always found remaining in the soil after each trial was complete, even if the trial resulted in many worms surfacing.

The exact same species that emerged during trials were also found in the soil samples taken after the vibration trials were completed. Earthworms were nearly always present within the soil following a vibration trial, even after trials that successfully elicited the emergence response in a large number of specimens. The soil samples taken after the trials showed considerable variability in the number of worms found in each sample, although the average number of worms found in each sample were quite consistent between trial types $(3.25$ worms for pitchfork trials $(n=28)$ and 3.26 for stob 
trials $(n=15))$. While some of the worms found within soil samples were located freely in the soil itself, many of these worms were closely associated with the root systems of plants, and would often be found within quite dense clumps of roots and soil. It should be noted that many of these worms (especially those found within root clumps) appeared to be quite inactive compared to earthworms that had surfaced. Many of these rootassociated worms reacted very minimally to being handled, picked up, and otherwise disturbed, while in contrast the surfacing worms demonstrated very strong physical reactions to being handled. These surfaced worms would typically thrash and contract very vigorously when touched or picked up, and some specimens even demonstrated autotomy when handled.

\section{Environmental Conditions}

The environmental conditions were fairly varied between the different trials. Weather conditions included hot and sunny days, cloudy but bright days, and days with light to moderate rainfall. Soil humidity varied as well, but none of the trial sites had soil that was either completely dry or heavily saturated with water, even on the rainy days. All of the sites had soil that was relatively acidic, with a range of measured $\mathrm{pH}$ values between 4 and 6 . Soil composition was usually uniform within each location, and nearly all sites had soil types that were classified as silty loam according to the OPAL soil classification scheme. The only exceptions to this were the Mongrain property, Pinhey forest, and Nesbitt locations. Only the Mongrain property had multiple soil types in the same location, where the upper layer of soil was a silty clay loam, and the deeper soil was composed of a sandy loam. Pinhey Forest had a slightly more sandy composition than 
other sites, while the Nesbitt property had a more clay-like composition compared to the typical sites. It should be noted that the Pinhey Forest property was the only trial site that displayed evidence of mole activity, as burrows were clearly visible in the area.

Environmental conditions for all trials are summarized in Table 2.4.

\subsection{Discussion}

The results of the experiments in Florida and Ontario support the hypothesis that seismic vibrations are eliciting surfacing responses in various earthworm species. The collected data from these trials gives rise to five prominent questions/topics that I will address in this discussion:

1) Do earthworms really respond to soil vibration?

2) Why is the stob effective in Florida but not in Ontario?

3) Why do Ontario earthworms respond to the pitchfork and not the stob?

4) Why do earthworms surface in response to vibration?

5) Conclusions and future directions for research

\section{Do Earthworms Really Respond to Soil Vibrations?}

The results of these experiments do demonstrate that two common methods of vibration mediated earthworm harvesting can be very effective in making earthworms surface out of the soil, although these methods can have very differential effects in different geographic areas. Research conducted in Florida demonstrated that the low frequency seismic vibrations generated by the stob and rooper soil vibration technique were very effective in making earthworms from the Diplocardia genus surface out of the 


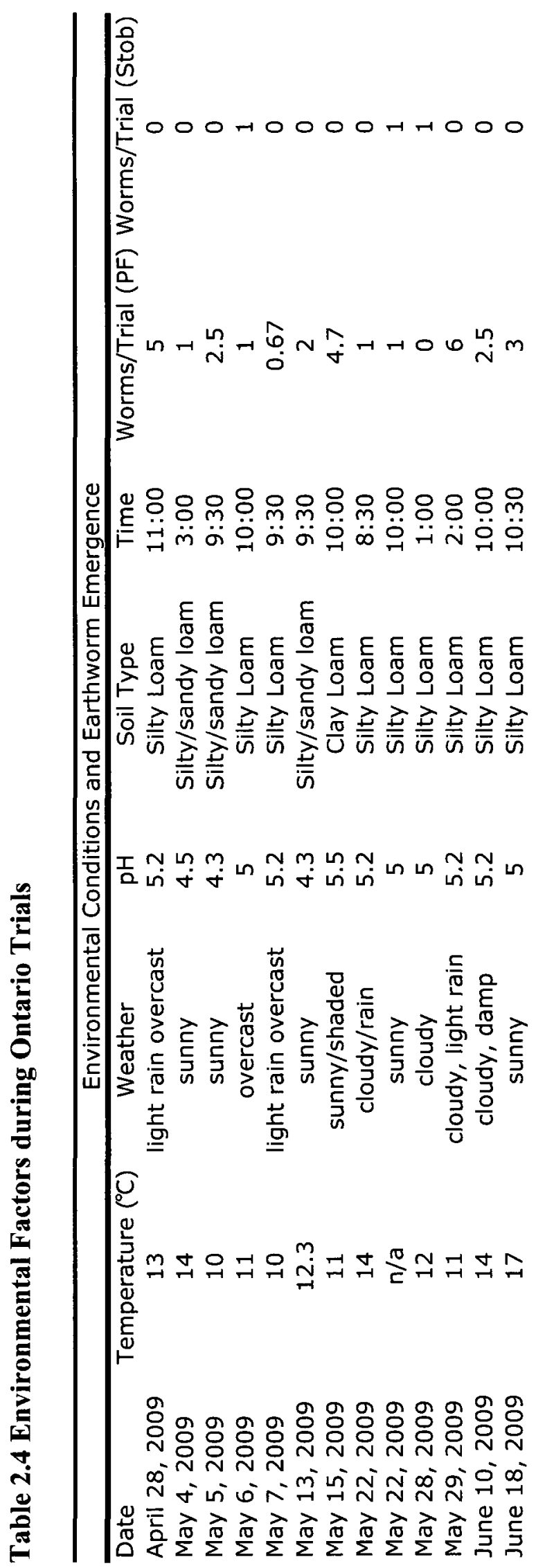


soil. This was demonstrated by my research (Mitra et al., 2009) as well as research being conducted simultaneously in the same geographic area by Catania (2008). These two papers were actually published within one day of each other, but since Catania (2008) was an online publication, it is listed with an earlier publication date than Mitra et al. (2009). Both of these papers used stob and rooper techniques to elicit earthworm emergence, while demonstrating the relationship between the number of surfacing earthworms and vibrational amplitude. In contrast, the same stob and rooper technique was only minimally effective when used in the Ottawa region of Canada, while the pitchfork vibration technique (which also produced low frequency seismic vibrations) proved to be very effective in eliciting surfacing responses among multiple Ontario earthworm species. In the cases of both the Floridian stob technique and Ontario pitchfork technique, worms emerged from their burrows within a few seconds or minutes following the onset of vibrations, the number of worms surfacing was positively correlated to the intensity of the vibrations, and the number of surfacing worms was negatively correlated to the distance from the vibration source. Furthermore, soil vibrations were measured and were found throughout and beyond the area of the trials in both locations. These observations, along with the fact that the number of earthworms emerging during vibration stimuli (in both locations) were significantly greater than those observed during any of the control conditions does demonstrate the role of seismic vibrations in the surfacing behaviours of earthworms.

There are two patterns in the emergence of earthworms from both Florida and Ontario that deserve some further analysis. While the stob trials in Florida and the pitchfork trials in Ontario clearly show that the number of surfacing worms decreases as 
distance from the vibration source increases, both data sets show two peculiarities: 1) a low level of emergence very close to the vibration source, and 2) a slight increase in emergence further away from the vibration source (see Fig. 2.16 and 2.20). The low levels of worm emergence near the vibration source are particularly obvious in the Ontario pitchfork trials (although it is also apparent in the Florida stob trials). While the largest number of worms surfaced between 20 and $35 \mathrm{~cm}$, very few worms surfaced in the immediate vicinity of 0 to $15 \mathrm{~cm}$ away from the pitchfork. Once the peak emergence distances were reached, the number of earthworms emerging decreased steadily, with a very small increase in emergence near the furthest distance (about $1 \mathrm{~m}$ ). This small increase in emergence is also apparent in the Florida data, about $5 \mathrm{~m}$ away from the stob. The fact that fewer worms emerged close to the vibration source might be explained by the possibility that the stimulus was so strong at this distance that the earthworms responded to the stimulus in a different way rather than surfacing, although it's also possible that the stimulus simply saturated and overwhelmed their receptors so that they showed diminished or even extinguished responses. As for the marginal increase in worms near the end, this may simply be an artifact of random variation. However, both the Florida emergence data and the Ottawa pitchfork data show a similar small increase in worm emergence at a further distance, following the overall reduction in earthworm emergence with distance. Although these might both be explained by random variation as well, it is possible that they may be the result of some type of resonance in the vibrational stimulus. Based on the likely speeds of vibration propagation through the soil (adapted from Oelze et al., 2002), the likely frequency range that could produce such resonance 
would be between 133 and $213 \mathrm{~Hz}$, and this frequency range includes some of the most powerful components of the vibrations produced by both the stob and pitchfork.

It must be noted that species such as Aporrectodea tuberculata and Lumbricus rubellus were often found to have both responsive and unresponsive specimens during the same trial. Why might these differences in responsiveness exist in the same species at the same times and trial sites? This could be attributed to differences in responsiveness or vibration sensitivity among individual earthworms of the same species. It might also be a function of the activity levels of the earthworms, as many types of earthworms can enter temporary periods of inactivity and dormancy (Reynolds, 1977, Edwards and Bohlen, 1996). Many of the specimens found in soil samples following trials were observed to be much less active and less responsive to disturbance than the specimens that surfaced. These less active earthworms often showed little to no response to tactile stimuli as the soil was disturbed or even when they were touched directly by hand. This is in contrast to the worms that surfaced, which reacted immediately and vigorously to touch and disturbance. These apparent differences in responsiveness might have occurred because some of the worms that remained in the soil were in a state of dormancy or diapause. However, periods of dormancy (sometimes referred to as aestivation, diapause, and even hibernation, depending on the circumstances) are regulated by environmental factors, although some earthworm species will undergo an obligatory diapause that is independent of environmental conditions (Edwards and Bohlen, 1996). The typical factors that result in non-obligatory dormancy are temperature and humidity, as many earthworms will become dormant if the temperature gets too high or low, and/or if conditions become too dry (Reynolds, 1977; Edwards and Bohlen, 1996). However, these 
types of extreme conditions were not present at most trials sites, making diapause unlikely for most of these worms. Similarly, while worms will coil themselves into a tight ball when they enter diapause (Reynolds, 1977; Edwards and Bohlen, 1996), none of the collected specimens were observed in such a state. However, it is possible that the disturbance caused by digging up the soil sample caused worms that might have been in diapause to uncoil.

One simple explanation for the unresponsive specimens that belonged to species that otherwise responded to the pitchfork is that there may have been physical factors that interfered in their ability to surface. The specimens found in the soil samples were often found within dense clumps of entangled roots, which may have provided a physical impediment to their surfacing behaviour, or may have dampened the vibrational or compression stimuli. If the surfacing response is indeed an escape response to burrowing predators, it's also possible that worms in the soil might surface until they reach a dense root clump, after which they might remain in the root clump as this could afford some protection against predators without incurring the risks of surfacing above the soil. However, there is no evidence that hiding in root clumps is protective against fossorial predators. Another physical factor that might explain why some specimens did not surface is the fact that they might have been more deeply burrowed than other specimens, and if they were responding to the vibrations by surfacing, they simply might not have had enough time to reach the surface before the soil sample was taken.

Although the practice of "grunting" or "charming" earthworms either for leisure or for harvesting fish-bait is well known in regions such as England and the Southern USA, there are very few documented accounts of worms responding to vibrations. A few 
authors have briefly described or commented upon the worm grunting technique as a means of collecting Diplocardia mississipiensis, D. floridana, or Pheretima diffringens (Hendrix et al., 1994; Vail, 1972; Edwards and Bohlen, 1996), but these sources did not directly examine the nature of the worm emergence phenomena itself. As noted previously, it has also been reported that other mechanical disturbances, such as digging, power motors, and even walking, can cause worms to emerge (Darwin, 1881; Kaufmann, 1989; Edwards and Bohlen, 1996), and interestingly, some animals have also been observed to employ similar techniques to capture worms. Wood turtles (Clemmys insculpta) stomp their front feet at a rate of about once per second (which is similar to the grunting rate), which induces earthworms to surface (Kaufmann, 1986; 1989), and different birds have been noted to "paddle" the earth with their feet or peck hard on a rock to force earthworms to the surface (Darwin, 1881; Tinbergen, 1960; Edwards and Bohlen, 1996). However, while in all of these reports it is implied that seismic vibrations cause the worms to surface, the vibrations were never recorded or examined. My research, along with that of Catania (2008), is the first to characterize the vibrations involved in such responses. Geophone recordings made by Catania (2008) found that the stob and rooper created vibration pulses that lasted an average of $610 \mathrm{~ms}$, with peak energy found around $80 \mathrm{~Hz}$.

Other reports of vibration-mediated behavioural responses mainly describe rapid escape reflexes, which do not resemble the locomotory response observed during our trials. This includes the observations made by Charles Darwin (1881) of how Lumbricus terrestris rapidly retreated into its soil burrow when presented with a vibration, and those of Herz et al. (1967) which similarly described the unconditioned response of $L$. 
terrestris to a 'mild vibratory stimulation' as 'an initial sharp contraction which appears to habituate upon repeated presentations'. These do not appear to resemble the surfacing responses of earthworms observed in nature. However, Herz et al. (1967) also demonstrated that when the vibration stimulus is 'more intense' the worm extends the anterior portion of its body. Perhaps this latter response more closely reflects the response to worm grunting, as it may involve the body extension movements used by earthworms during their peristaltic method of locomotion. In any case, the research conducted in Florida and Canada is novel, and Mitra et al. (2009) is one of only two published studies that demonstrate the relationship between seismic vibrations and earthworm emergence in Florida (in addition to Catania, 2008), while the data collected on the vibration responses of Ontario earthworms is the first of its kind. Research conducted in these two regions does clearly show that seismic vibrations can induce locomotory responses in earthworms, but this research also gives rise to a number of unanswered questions.

\section{Why is the Stob Effective in Florida but not in Ontario?}

One obvious question that arises from these results is why the stob and rooper technique shows such variability in its effectiveness between Florida and Ottawa, while the pitchfork readily elicits the surfacing responses of earthworms in the Ottawa area (the pitchfork technique has yet to be properly tested in Florida, although preliminary work suggests it may work (Catania, 2008). There are various possibilities that may explain why this is the case, one of which might be that the earthworm species in the Ottawa area simply possess a reduced or different responsiveness and/or sensitivity to soil vibration compared to the earthworms found in Florida. The difference in species composition of 
the earthworms found in the habitats of these two regions was very significant. The only responsive species found in Florida during recent research was Diplocardia mississipiensis (Catania, 2008; Mitra et al., 2009), although the related species Diplocardia floridana is reported to respond to worm grunting as well (Edwards and Bohlen, 1996). In contrast, the two species that surfaced during stob vibrations in Ontario were Aporrectodea tuberculata, and Octolasion tyrtaeum, with Aporrectodea tuberculata showing a more robust response (based on visual observation, but using a sample size of only one due to the stob's limited effectiveness). Soil sampling in Ontario indicated that a variety of species proved unresponsive to the vibrations made using the stob and rooper.

A difference in sensitivity and/or responsiveness across these species is quite possible, since the primary components of the soil vibrations recorded from all three trial types (the stob in Florida, the stob in Ottawa, and the pitchfork in Ottawa) were all extremely similar. The dominant frequencies were always found to be in the range of 0 to $500 \mathrm{~Hz}$, with a peak near $100 \mathrm{~Hz}$. These similarities in frequency composition also diminish the likelihood of differential effects caused by different worm grunters, since two different individuals performed the worm grunting in Florida and Ontario. Although it's possible that there are differences in the soil properties of the two test regions (Florida and Ottawa) that may affect the propagation of subterranean vibration, the recordings of stob vibrations made in various field sites (with various soil compositions) are quite consistent in their characteristics, and this again indicates that the vibration stimuli used in Ottawa are nearly identical to those used in Florida, at least within the $1 \mathrm{~m}$ radius within which worms were observed to emerge in Ontario. Similarly, the stob technique was consistently ineffective in a wide range of trial sites in Ontario, which also 
suggests that differences in soil properties were not interfering with the vibration stimulus. One possible explanation for differences in sensitivity and responsiveness between species may be different selection pressures that underlie the surfacing responses of earthworms from Florida and Ontario, and this will be discussed in subsequent sections.

\section{Why do Earthworms Respond to the Pitchfork and not the Stob in Ontario?}

While the stob and rooper was only minimally effective at all Ontario trial sites, the pitchfork was generally very effective at the same sites. As mentioned previously, the reduced effectiveness of the stob might be the result of the differential species composition of the Ontario earthworms (compared to those of Florida), as well as possible differences in their sensitivity and/or responsiveness to vibrational stimuli. However, the pitchfork did prove to be very successful at eliciting surfacing behaviours in various local earthworm species belonging to multiple genera. These species occupied a range of life styles and burrowing behaviours. The most common species that emerged during the pitchfork stimulus were Aporrectodea tuberculata, Aporrectodea rosea (also known as Eisenia rosea), and Lumbricus rubellus. These species are quite common in Ontario, and are epigeic species that are often found in leaf litter and do not typically burrow very deeply in the soil (Reynolds, 1977; Edwards and Bohlen, 1996). However, specimens of Lumbricus terrestris also emerged a number of times during pitchfork trials, and this species is a particularly deeply burrowing anecic earthworm. Despite this, these specimens displayed particularly vigorous movements and body thrashing when they emerged. 
In addition to the possible differences in vibration sensitivities between various earthworm species, there are other possible explanations for differential surfacing behaviours that must be considered as well. One explanation for the differential effectiveness of the stob and pitchfork techniques is the difference in temporal structure between the stob and pitchfork stimuli. While they share a similar frequency composition, these two vibration production methods create very different patterns and rhythms of vibration. While both stimulus types are pulsed and occur at fairly regular intervals, the stob creates vibrations that typically increase slightly in amplitude over the duration of each pulse, although these pulses nevertheless remain more consistent in intensity and frequency composition over the time interval of each pulse than the pulses created by the pitchfork. In contrast, each pitchfork pulse is more erratic and attenuates in intensity and frequency range over time, and is also comprised of many smaller subpulses that are created by the back and forth motion of the pitchfork. It is possible that the earthworms of Ontario respond differently to these characteristics of the stimuli, and if so, this could be the result of differential selection pressures if the worms are surfacing in an attempt to avoid fossorial predators, since the types of burrowing predators would be different in Florida and Ontario.

However, regardless of the differences in amplitude and temporal structure of these stimuli, it is clear that the earthworms of Ottawa do respond very differently to soil vibrations than the earthworms of Florida, even if both groups of organisms ultimately do end up responding with similar surfacing behaviours. Perhaps a more likely explanation for the differences in the two earthworm harvesting methods is that the pitchfork technique may not be acting through a purely vibrational mechanism, and may instead act 
through a tactile or compressional mechanism. This is suggested by visual observations of the pitchfork, which created much more robust physical disturbances in the soil than the stob. When the rooper and stob produced vibration, the surface of the soil could be seen vibrating in the immediate vicinity of the stob, but otherwise showed only a small amount of visible horizontal displacement. The pitchfork also created visible vibrations on the soil surface, but resulted in a much greater horizontal displacement of soil than the stob, causing the soil in front of and behind the pitchfork to move suddenly, rapidly, and with considerable force. This should create outward pressure waves of horizontal displacement in the soil, and these compression waves could create a stimulus that the earthworms could detect and respond to. As a result, it's possible that the earthworms of Ontario are not surfacing because of a response to soil vibration per se, but because of a tactile or compressional response to the displacement and/or compression of soil. This hypothesis has not been properly tested, but informal work by Catania (2008) did show that soil compression by hand could elicit surfacing behaviour in Diplocardia sp., although that author did not provide any details about exactly how this was tested. The possible role of soil compression is also supported by the fact that the pitchfork has a much smaller effective range than the stob technique, since all of the earthworms that emerged using the pitchfork technique surfaced within only one meter of the pitchfork. This is in stark contrast to the effective distance of the stob, which resulted in worms emerging as far as $8.7 \mathrm{~m}$ from the vibration source. Catania (2008) also claims that the pitchfork technique has the same effective radius of less than one meter, although it is unclear if this was determined through direct observation and experimentation. Further research should be undertaken to explore vibrational versus compressional stimuli in the 
soil to see exactly what types of differential effects these two types of stimuli have on various earthworm species.

\section{Why do Earthworms Surface in Response to Soil Vibration?}

Of course, the major question posed by all of this research is why are these earthworms surfacing in the first place? In and of itself, surfacing out of the soil can be very dangerous for earthworms, especially during the daytime. Surfaced earthworms are very vulnerable to predation, dessication, and harmful solar and UV radiation (Edwards and Bohlen, 1996). One hypothesis is that the vibrations resemble those caused by rain, and the worms emerge from the soil to avoid drowning (Kaufmann, 1986), low oxygen levels (Minnich, 1977), or to enhance dispersal (Butt and Nuutinen, 2005). A second hypothesis, first proposed by Darwin (1881) in response to indirect reports of worms surfacing in response to vibrations, and then by Tinbergen (1960) in relation to gull paddling, is that earthworms are responding to vibrations caused by the burrowing of predatory moles.

\section{Rain Hypothesis}

Preliminary recordings of light rainfall show that most energy falls below $500 \mathrm{~Hz}$ (Mitra, unpublished data), corresponding to the same frequency range as grunting. However, although I did not directly test rainfall stimulus on earthworms, it was observed that during my trials in the Ottawa area very few earthworms surfaced spontaneously or were already found on the soil surface during rainy trials (in fact only two worms were ever found on the soil surface on a rainy day). Similarly, work by Catania (2008) showed 
that few worms emerged in Florida in response to actual or simulated rainfall, and those that did demonstrated a long emergence latency that was greater than 15 minutes, which is considerably longer than the emergence latencies observed in any of the vibration mediated earthworm surfacing experiments. Research conducted on the Asian earthworm Amynthas gracilis produced similar results, as Chuang and Chen (2008) found that this species always surfaced when placed in waterlogged soil, but did so even more slowly than the earthworms of Florida, with an average emergence latency of 10 hours.

However, this same research also demonstrated that the earthworm species Pontoscolex corethrurus does not emerge from waterlogged soil at all, possibly due to a higher tolerance to low oxygen conditions found in waterlogged soil (Chuang and Chen, 2008). Although responses to rainfall and water saturated soil vary between different earthworm species, the results of these studies do suggest that rainfall does indeed elicit surfacing responses in earthworms (which is hardly surprising), but in a very different way than vibration, since rain and moisture in general appear to cause fewer worms to surface (at least for North American earthworms), and does so much more slowly than vibrational stimuli. It seems likely that rainfall elicits surfacing behaviour not through a vibrational stimulus, but perhaps through increased moisture levels in the soil. In any case, the precise mechanisms behind rainfall related surfacing in earthworms has not been determined, and this topic warrants further investigation through future research.

\section{Mole Predation Hypothesis}

Moles are significant predators of earthworms (Edwards and Bohlen, 1996), and evidence for mole tunneling was observed at our trial sites in Florida and to a very 
limited extent in Ontario. Digging and foraging moles of the species Scalopus aquaticus were found to produce a wide range of subterranean frequencies below $1 \mathrm{kHz}$ that peaked at $200 \mathrm{~Hz}$ (Catania, 2008), which falls within the frequency range of worm grunting and worm charming. Other fossorial mammals that produce soil-borne vibrations (for orientation or communication purposes) create vibrations that also fall within the frequency range of worm grunting/charming stimuli (Mason and Narins, 2001), and since other vertebrates and invertebrates have been reported to use seismic cues to detect predators (Mason and Narins, 2001; Cocroft and Rodriquez, 2005), the mole hypothesis seems worthy of further testing.

Recent research directly examining the mole predation hypothesis does show support for this idea. When burrowed Diplocardia sp. worms were exposed to burrowing moles in a laboratory setting, they showed significantly more emergence than during control conditions (Catania, 2008), and when these same worms were subjected to either simulated rainfall, actual rainfall, or burrowing moles, significantly more earthworms were found to emerge in the presence of moles than in either types of rainfall. This same research also noted that nearly half of all outdoor trial sites in Florida had mole tunnels within a $5 \mathrm{~m}$ distance. These experiments were done using the Eastern American mole Scalopus aquaticus, which is endemic to Florida and is known to feed on earthworms (Catania, 2008).

The results from the Ottawa experiments can also provide preliminary support for the predator escape hypothesis. Although the earthworm species in the Ottawa area were generally unresponsive to the stob vibrations, the pitchfork produced vibrations in the same low frequency range as digging moles, and if the earthworms were responding more 
to tactile stimuli and/or soil compression (instead of vibration) created by the pitchfork, this could still be a manifestation of predator avoidance. The limbs of animals that are actively digging and burrowing could generate soil compression through their movements, particularly during the main power-stroke of digging. Although such compression would likely have a smaller effective range than the vibrations produced by digging, it may nevertheless be a valuable sensory cue that some earthworms could detect to avoid being eaten. While falling rain might also generate soil compression in a downward direction, one would expect this stimulus to be milder than that of an actively digging predator. The fact that the pitchfork has a very small effective radius compared to the stob lends support to the hypothesis that the pitchfork makes worms surface due to soil compression, and not vibration. As stated earlier, all earthworms that emerged during my pitchfork trials did so within a one-meter radius of the pitchfork, and the same result (a shorter emergence radius) is implied in Catania (2008), although his research did not directly examine the pitchfork phenomena.

Although further work must be done to examine the nature of rainfall versus predation with respect to earthworm emergence in Ontario, if the earthworms are surfacing to avoid fossorial predators, it is important to consider the primary predators of earthworms in Ontario. Catania focused on moles, and moles are present in the Ottawa area. However, the only trial site that showed any evidence of mole activity was Pinhey Forest. Mole burrows and tunnels were visible at multiple locations within this area, but these were never found at any of the other trial sites. Incidentally, Pinhey Forest contained one of the lowest earthworm densities according to my sampling, since only one earthworm was found at that site. It is possible that this low earthworm density was 
partially caused by predation from moles, and it is interesting to note that the only worm found in Pinhey forest was collected because it responded to the pitchfork stimulus by surfacing. Moles appeared to be more common in the Florida trial sites than in Ontario (although this has not been quantitatively examined), and if this is the case, it may explain why the Florida worms are more sensitive to predatory vibration stimuli compared to the Ontario earthworms, as they may be experiencing a much greater predation pressure.

There are various details regarding the adaptive significance of earthworm surfacing responses that have yet to be clarified, but the evidence accumulated so far does show strong support for the mole predation hypothesis. Despite the fact that surfacing responses in earthworms from Florida and Ontario might possibly be mediated by different stimuli, the two responses are nevertheless quite robust. This is interesting to consider given the fact that surfacing is in and of itself a very dangerous behaviour for an earthworm. Despite the fact that surfaced earthworms are very vulnerable to desiccation, harmful radiation, and predation (even earthworms that are simply near the soil surface are much more vulnerable to predation than those that are deeply burrowed: Edwards and Bohlen, 1996), these worms still surface into a dangerous environment when subjected to vibrations or soil compression, and this is true even for deeply burrowing species such as Lumbricus terrestris, which would otherwise be afforded protection within their deep burrows. This is quite significant, as it strongly implies that the negative consequences of surfacing behaviours are outweighed by the greater dangers of remaining within the soil when vibrational or tactile cues indicating the proximity of an underground predator are 
detected. In this case, the danger presented by emerging onto the soil surface may the lesser of two "evils".

\section{Conclusions and Future Directions for Research}

I conclude that earthworms of various species in Florida and Ontario can be induced to surface in response to seismic vibrations, although in the case of Ontario earthworms this may be a response to either soil vibration or soil compression. Based on the available evidence, it is proposed that these vibrations are mimicking those of rain or predatory fossorial mammals, and based on playback, laboratory, and field studies conducted so far, the evidence appears to provide more support for the fossorial predator hypothesis (at least with respect to Diplocardia sp.). There are, however, many aspects of this phenomena that have yet to be fully explored, and further research must be conducted to formally test various parameters of surfacing behaviours in greater detail. Experiments should be conducted in different geographic regions to test the responsiveness of different earthworm species to worm grunting and worm charming stimuli. Further field work should similarly be conducted in England, since worm grunting and charming techniques have not been scientifically tested in England despite the fact that worm charming is relatively common there, and while the species reported to respond to worm grunting in Florida are almost exclusively Diplocardia mississippiensis or D. floridana (Vail, 1972; Hendrix et al., 1994, Catania, 2008; Mitra et al., 2009), and various species have responded in Ontario, no studies have been conducted in England to examine what species show similar responses there. Furthermore, the pitchfork worm charming method has not been formally tested in Florida with the Diplocardia worms, 
and it would be very interesting to see exactly how these worms respond to a different seismic harvesting method.

Perhaps the biggest untested hypothesis regarding these phenomena is whether or not earthworms are truly using two different methods of detecting fossorial predators. Further experimentation is necessary to properly determine if soil vibration and/or soil compression stimuli are both being detected and used by earthworms with respect to different worm harvesting methods and different earthworm species. While soil vibration has been measured for both the stob and pitchfork methods, soil compression has not. Directly measuring the soil displacement and soil compression generated by these two techniques (perhaps using an accelerometer in conjunction with other methods) would help clarify the roles these two stimuli may have in the escape responses of earthworms, as would an experimental methodology that uses a purely compression based mechanism to attempt to elicit surfacing responses in earthworms. These types of investigations should initially be conducted on the earthworms of Florida and Ontario, since quite a bit of relevant data has already been collected on the earthworm species of these regions.

Another important avenue of research here is examining exactly how earthworms detect seismic cues, and how these sensory signals are translated into locomotion and escape responses. Although the next chapter will deal with preliminary examinations of possible sensory receptors for such stimuli, future work on Diplocardia and other earthworm species should adopt a neuroethological approach to elucidate the behavioural and physiological responses to vibrations that the worms would be exposed to in their natural environment. These types of experiments should shed light on exactly how the nervous system in earthworms is responding to seismic cues. 
Furthermore, additional experiments may want to consider what predators besides moles might be eliciting surfacing responses in earthworms. Many different animal groups prey on earthworms, including insects, birds, amphibians, reptiles, and mammals, some of which feed preferentially on earthworms (Edwards and Bohlen, 1996). Many of these animals are primarily surface predators (e.g. birds), but it is burrowing and digging predators that are of interest with respect to earthworm emergence responses. There are a variety of burrowing animals that are known to feed on worms, including smaller arthropods such as ants, beetles, and beetle larvae, as well as larger organisms such as moles and shrews (Edwards and Bohlen, 1996; Catania, 2008), and it is possible that some of these organisms can elicit surfacing responses in earthworms. It is also possible that different predators in Florida versus Ontario have created different selection pressures that have resulted in the evolution of the two different surfacing mechanisms in earthworms of these regions. There have been some recordings of burrowing activity in animals that prey on earthworms. While the Eastern American mole and other fossorial mammals produce soil-borne vibrations either by digging or for orientation and communication purposes that fall into the same low frequency range as worm grunting and charming (Mason and Narins, 2001; Cocroft and Rodriguez, 2005; Catania, 2008), smaller organisms such as beetle grubs produce digging vibrations in the range of 300 to $600 \mathrm{~Hz}$, while ants can produce subterranean clicking noises at a frequency of about 125 $\mathrm{Hz}$ (Mankin et al., 1998). All of these animal-produced subterranean vibrations do fall within the dominant low frequency range of the vibration spectrums recorded from the stob and pitchfork vibration stimuli. As a result, earthworms that are sensitive to these low frequencies may be able to detect and avoid multiple underground predators. 
However, predator avoidance through surfacing may only work against certain types of predatory animals, such as those that only forage below the ground. For example, any subterranean predator that forages both below and above the ground may still have an opportunity to consume an earthworm if it tries to escape by surfacing, although it should be noted that the Eastern American mole, which is a common earthworm predator, is only known to forage below the soil (Catania, 2008). It is also possible that some predators might even be able to track surfacing earthworms if they can detect and follow the vibrations made by the moving worms themselves. Recordings of earthworm movements within the soil indicate that they also produce low frequency vibrations, between 300 to $600 \mathrm{~Hz}$ (Mankin et al., 1998), and these may be detectable by some organisms. There are many unexplored intricacies regarding the relationships between predators and surfacing earthworms, and these all provide many new avenues of potential research.

Despite the fact that there are an estimated 7000 species of earthworm worldwide (Hendrix et al., 2008), surprisingly little is known about the behaviour and life history traits of any one species. This research has begun to reveal some of the relationships between fossorial prey and fossorial predators that appear to be present in a variety of earthworm species in various geographic areas. Discovering such novel and previously unexamined behaviours in an organism as common and prevalent as the earthworm demonstrates just how rich a repertoire of unknown behavioural adaptations organisms can have, even when the organisms are otherwise very familiar to us, and even when humans and other animals have been exploiting these behaviours for their own benefit for quite some time. 


\section{Chapter 3}

Anatomy: Nervous system and Sensory Organs 


\subsection{Introduction:}

The experiments from the previous section along with work done by Catania (2008) describe how various earthworm species in different geographic areas respond to soil disturbance by surfacing out of the soil. This response appears to be mediated by a combination of tactile and vibration sensitivity, but the mechanisms behind this response are unknown. The receptors that transduce vibrational and tactile stimuli into nerve signals are unknown, and the way in which these organisms are translating such nerve signals into locomotory responses is also unknown. This section will begin to explore what, if any specialized sensory organs earthworms might possess, and what components of the nervous system might be involved in surfacing responses.

This introduction will begin by reviewing literature on the gross anatomy of the nervous system in earthworms. Structure and function of the primary components of the earthworm nervous system will be examined with respect to tactile and vibration reception as well as motor functions. Finally, receptors for tactile and vibration stimuli will be considered, and the literature will be briefly reviewed with respect to vibration and mechanoreceptors in invertebrates and annelids related to earthworms. This information will be used to conduct preliminary anatomical studies using earthworms from Florida and Ontario in an effort to shed light on how these organisms may be producing their surfacing responses to soil disturbance.

Earthworms have often been used as model species by biologists to demonstrate various anatomical and physiological features, and although many aspects of the earthworms' external and internal anatomy are fairly well studied, many specific anatomical and physiological functions in these organisms remain unclear (Edwards and 
Bohlen, 1996). This is particularly true when considering vibration reception in earthworms, as the receptors and neural pathways involved are completely unknown. The anatomy of the nervous system in earthworms has been described fairly thoroughly in common species such as Lumbricus terrestris, and although the main components and structures of the nervous system have been characterized along with some of their functions (Bullock and Horridge, 1965; Mill, 1982), there are still many uncertainties regarding the functions of many of the smaller and more specific structures. The nervous systems of less common earthworm species have not been as fully characterized, and the anatomy of the nervous system of the Diplocardia genus has not been characterized at all. Similarly, while some work has been done to examine surface receptors that may detect tactile and vibration stimulus in some species of earthworm (Langdon, 1895; Bullock and Horridge, 1965; Gardner, 1976; Mill, 1982), these features have not been described in Diplocardia worms. I aim to characterize the gross anatomy of the nervous system in Diplocardia spp., while comparing this anatomy to that of more well studied earthworms. An emphasis will be placed on characterizing the gross morphology of the nervous system in Diplocardia spp. to aid future researchers in conducting physiological experiment related to vibration reception and surfacing responses. Similarly, an attempt will be made to examine external anatomy for any possible receptors in Diplocardia that may be involved in vibration reception. Although external sense organs that may respond to tactile stimuli have been found in some earthworm species (Mill, 1982), sense organs specific to vibration have not been described, and no descriptions of any external sense organs have been made in Diplocardia spp. Electron microscopy will be used to look for such organs in Diplocardia, as well as one Ontario species of earthworm that showed 
surfacing responses to vibration: Lumbricus rubellus. As a result, the specific objectives of my anatomical work on earthworms include:

1) Using dissection to characterize the primary anatomical components of the nervous system in Diplocardia earthworms

2) Using electron microscopy to look for any external sense organs in Diplocardia mississipiensis and Lumbricus rubellus

3) Comparing these findings to the literature in a preliminary effort to understand what parts of the nervous system and what receptor structures might support future research regarding the surfacing responses of earthworms

\subsubsection{Central Nervous system}

The segmental body plan of all earthworms is reflected in both their external and internal anatomy, which includes the arrangement of their nervous systems. The earthworm body is visibly segmented with external grooves whose positions correspond to internal septa that divide the body internally, and many organ systems of the earthworm demonstrate an anatomical pattern that is repeated virtually identically in all segments (Edwards and Bohlen, 1996). The earthworm body plan also displays bilateral symmetry that is also reflected in external and internal anatomy. The arrangement of the nervous system in Lumbricus terrestris is bilaterally symmetrical and is also virtually identical in all segments except for the most anterior and posterior segments (Hess, 1925). The ventral nerve cord is the most prominent structure in the nervous system and extends through most of the length of the body, beginning at the $4^{\text {th }}$ anterior segment and ending in the last posterior segment. This nerve cord is located beneath the digestive 
tract, close to the ventral coelomic wall. The anterior end of the ventral nerve cord connects to a subesophageal ganglion (nomenclature adapted from Hess, 1925), which bifurcates into two connectives that pass anteriorly and dorsally around both lateral sides of the esophagus and crop (Fig. 3.1). These connectives (referred to as the circumesophageal or circumpharyngeal connectives) meet on the dorsal side of the pharynx in the $3^{\text {rd }}$ segment to form a bilobed cerebral ganglion, or "brain" (Hess, 1925; Edwards and Bohlen, 1996).

From the $5^{\text {th }}$ anterior segment onwards the ventral nerve cord swells into segmental ganglia in every segment. The ventral nerve cord itself contains various cell bodies, nerve fibers, and interneurons, including three large giant fibers. These are located in the dorsal side of the ventral nerve cord, and are comprised of a median giant fiber with two lateral giant fibers (one on either side of the median giant fiber), all of which run the entire length of the nerve cord (Mill, 1982; Edwards and Bohlen, 1996). The median giant fiber is thicker in the anterior portions of the organism, while the lateral giant fibers are thickest in the posterior portions of the organism (Mill, 1982). Similarly, mechanical stimulation to the anterior 40 segments of the worm appears to excite the median giant fiber, while the stimulation of the posterior segments excites the lateral giant fibers (Bullock and Horridge, 1965).

\subsubsection{Peripheral Nervous System}

Each of the segmental ganglia in the ventral nerve cord has three pairs of nerve trunks that extend out laterally from both sides of the nerve cord (Hess, 1925). Of these three segmental nerve pairs, the first and anterior most pair is separated from the others 
Figure 3.1 Diagram of the Central Nervous System of the Earthworm Lumbricus terrestris

(A) Dorsal view (adapted from Hess 1925). To avoid confusion, terminal branches of some paired nerves have been omitted from one side or the other in segments 1 and 2 . $\boldsymbol{C} \boldsymbol{G}$, cerebral ganglion; $\boldsymbol{C P C}$, circumpharyngeal connective; $\boldsymbol{S} \boldsymbol{G}$, subesophageal ganglion; $A$, nerve pair emerging from the lateral area of the cerebral ganglion, passing anteriorly to the prostomium; $\boldsymbol{B}$, nerve pair from the middle region of the circumpharyngeal connective, passing into segment $1 ; \boldsymbol{A} \boldsymbol{N}$, dorsal ramus of anterior segmental nerve (a.k.a. 1st segmental nerve); $\boldsymbol{M N}$, dorsal ramus of median segmental nerve (a.k.a. 2nd segmental nerve); $\boldsymbol{P N}$, dorsal ramus of posterior segmental nerve (a.k.a. 3rd segmental nerve); VNC, ventral nerve cord. (B) Lateral view (adapted from Hess 1925). M, mouth opening. All other labels are the same as in part (A). 
Fig. 3.1
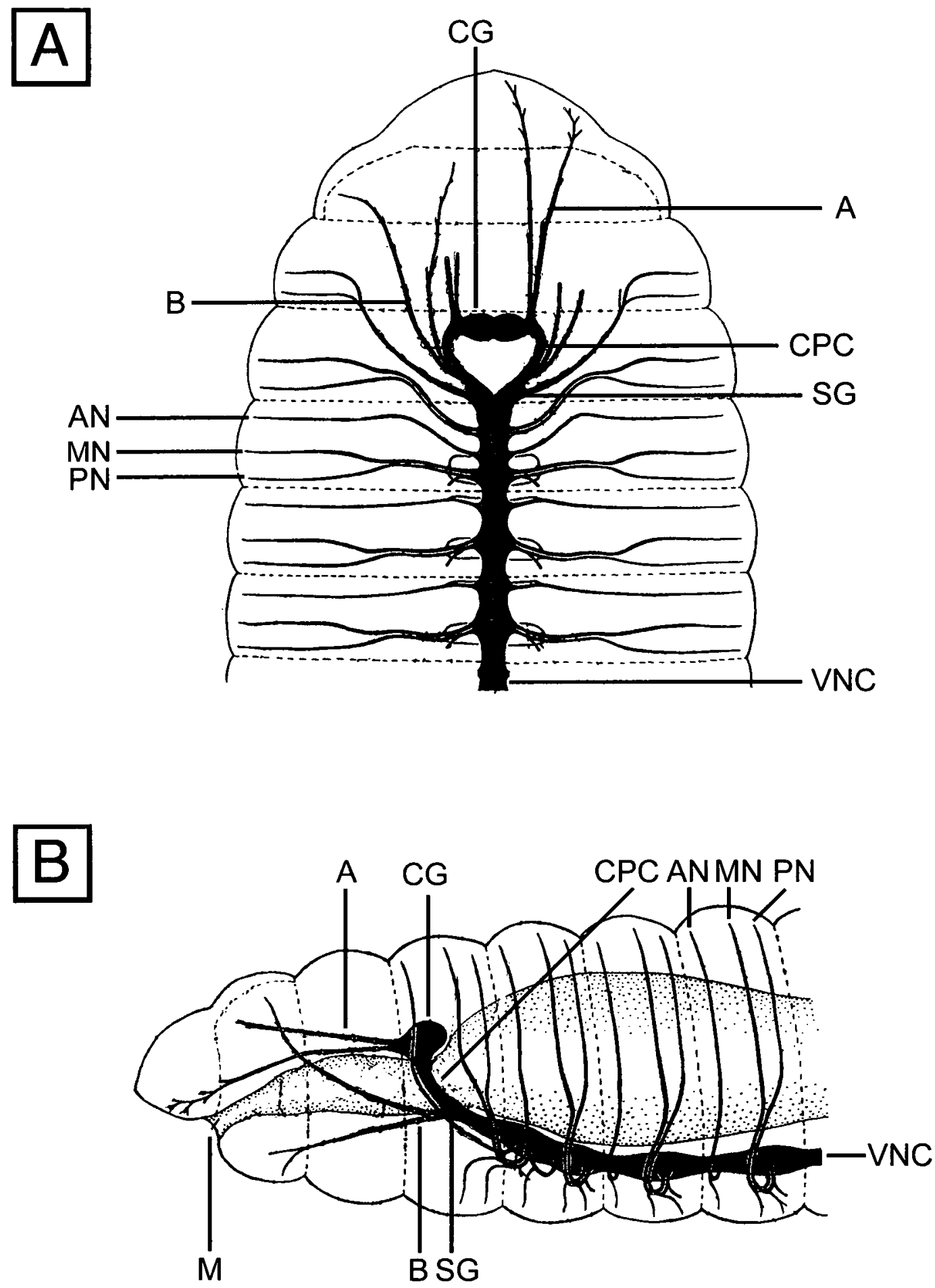
and emerges just in front of the segmental ganglia, while segmental nerve pairs 2 and 3 are very close to one another and are located at the posterior end of the segment (Fig. 3.1). All three pairs of segmental nerves extend from beneath the ventral surface of the ventral nerve cord before continuing to extend laterally into strands of longitudinal muscle and eventually circular muscle before dividing into various smaller nerve fibers (Hess, 1925; Edwards and Bohlen, 1996). The longitudinal muscles extend through most of the body between the anterior and posterior ends of the organism. Sensory input is mostly segmental, with limited overlap between adjacent segments. This means that sensory input from a particular segment primarily sent to nerves and neurons within that same segment. Tactile input occurs via segmental nerves I and III (Mill, 1982), while proprioception uses all three segmental nerves. Motor output is also mostly segmental and uses all three segmental nerves. The arrangement of the three segmental nerve pairs is identical in all but the most anterior and posterior segments. The 3 most anterior segments contain the circumpharyngeal connectives as well as the subesophageal and cerebral ganglia, and there are many different nerve branches that arise form these structures. In fact these anterior-most segments are more richly supplied with nerves than any other segments (Hess, 1925). The last few posterior segments of the earthworm show the same overall 3 nerve pair arrangement of lateral segmental nerves observed in most other segments, but the length of these branches decreases along with the size of the segments themselves as one nears the last most posterior caudal segment. The caudal segment itself usually possesses six pairs of small nerves, but there is often considerable irregularity in the arrangement and numbers of these nerve pairs (Hess, 1925). 


\subsubsection{Surface Receptors in the Earthworm}

There are a variety of mechanoreceptors/vibration receptors that have been found in invertebrates. Insects possess a variety of receptor types that are capable of transducing substrate vibration. These include campaniform sensilla and leg scolopidia, as well as subgenual organs, joint chordotonal organs, and mechanoreceptors such as the Johnston's organs found in antennae (Cokl and Virant-Doberlet, 2003; Virant-Doberlet and Cokl, 2004). However, the possible vibration receptors in closer relatives of the earthworm are less diverse. Various relatives of the earthworm such as polychaete worms as well as leeches use vibration sensitivity as an important sensory modality, often used for detecting predators or prey (Shaffer, 1979; Kristan et al., 1982; Brodfuehrer and Friesen, 1984). These types of organisms typically contain various types of sensory "buds" or sensilla, which are typically round shaped organs that are often ciliated, and are found on the body surface. Organisms including polychaetes and clitellates (both closely related to earthworms) possess such structures. The polychaete lugworm Arenicola marina possesses many epidermal papillae that contain ciliated sensory buds (Jouin et al., 1985). Similarly, the clitellate worm Branchiobdella pentodonta possesses similar sense buttons that are both uniciliated and multiciliated (Farnesi et al., 1982). Two types of sensory buds (in this case ciliated ad non-ciliated) have been also observed in the freshwater oligochaete Limnodrilus hoffmeisteri, which is an even closer relative of the earthworm (Molnar et al., 2006). These are often arranged in rows near the chetae of this organism, although they can also be found randomly on the body surface, and similar organs have been described in other freshwater oligochaetes (Yanez et al., 2006). Structures very similar to these sensory "buds" have also been described in the leech, and these have 
been studied enough to be implicated in vibration reception (Brodfuehrer and Friesen, 1984). The leech is an aquatic annelid closely related to the earthworm (both organisms belong to the class Clitellata), and as such it is highly sensitive to water-borne vibrations. Leeches possess a number of oval or round ciliated sensory sensilla throughout their body wall (Derosa and Friesen, 1981). These sensilla are quite sensitive to water vibration, a stimulus which elicits locomotion responses in the leech in the form of swimming (Brodfuehrer and Friesen, 1984). Water waves have been shown to elicit this locomotory response in whole organisms as well as physiological preparations, and this response is not elicited by the touch receptors alone (Brodfuehrer and Friesen, 1984). These sensillae appear to transduce near-field water vibration, and this type of stimulation results in compound action potentials in the segmental nerves as well as spikes in the dorsal posterior nerve cord of the organism. These signals travel both anteriorly and posteriorly in the organism (Brodfuehrer and Friesen, 1984). There are three types of ciliated cells within these sensory sensilla, and based on morphological comparisons it seems the uniciliate receptor cells are the mostly likely candidates for vibration receptors in these sensilla (Philips and Friesen, 1982).

There are two features of the earthworm anatomy that are believed to be involved in tactile reception. There are sensory neurons with branched free nerve endings that are found in the body wall, and these are thought to be tactile or mechanoreceptors (Langdon, 1895; Bullock and Horridge, 1965; Mill, 1982). There are also distinct sensory cell bumps that are found on the surface of the earthworm body that contain multiciliate sensory cells that extend their cilia through the outer cuticle of the body. These closely resemble the sensory buds previously described in other annelids, and are widely 
distributed across the body surface and are thought to be involved in tactile and possibly chemoreceptive sensation (Langdon, 1895; Knapp and Mill, 1971; Gardner, 1976; Mill, 1982). These sensory buds are also described in Bullock and Horridge (1965), and are said to have 16 to 45 sensory nerve cells with few or no supporting cells. Each bud has a bundle of axons going into a subepithelial nerve plexus. The sensory buds are found in all segments, and are present in 3 rows with 300 to 1000 buds per segment. They are more numerous in the prostomium and anal segments, with the upper lip having the greatest concentration (Langdon, 1895). Hesse found 686 of these organs in a single square millimeter of the prostomium (Bullock and Horridge, 1965). A review by Mill (1982) also describes these sensory buds and indicates that these organs are concentrated in two bands that encircle the worm in each segment, while Edwards and Bohlen (1996) state that they are more common on the ventral rather than dorsal surface. The organs are also said to surround each nephridial pore. Each sense organ usually contains many multiciliate sensory cells but they may contain a few uniciliate sensory cells as well. Each multiciliate sensory cell contains one or two rows of cilia which protrude outside the body wall, and is flattened in one transverse plane (Knapp and Mill, 1971; Mill, 1982). Although they are typically found together in a sensory bud, the multiciliate sensory cells can sometimes be found isolated in the body surface. There are some other solitary sensory cells that have been described, but these are thought to be proprioceptive, chemoreceptive, and non-specific in nature (Bullock and Horridge, 1965).

No vibration specific receptor has been described in any earthworm species. Earthworms can detect tactile stimuli over their entire body surface (Laverack, 1960), and tactile stimulation has been shown to produce activity in the segmental nerves (Laverack, 
1960; Mill and Knapp, 1967). The large number of sensory buds observed on the body surface of earthworms combined with their tactile sensitivity makes them a good candidate for vibration reception in Diplocardia spp. as well as Lumbricus rubellus, unless they possess a more specific vibration receptor. This is particularly true since similar sensory buds in leeches have been shown to be vibration sensitive (Brodfuehrer and Friesen, 1984). Their relatively large size may allow for direct stimulation of these organs, which could be an avenue of future research. As a result, an attempt will be made to locate and characterize these receptors in Diplocardia mississippiensis and Lumbricus rubellus, while searching for any novel type of vibration receptor as well.

\subsection{Materials and Methods}

Whole specimens of Diplocardia spp. were collected by worm grunting in the Apalachicola National Forest and brought back from Florida in April 2008. These were preserved in $70 \%$ isopropyl alcohol, which is not an ideal preservative but was the only preservative available in the field at the time of collection. Further specimens (preserved in formalin) were also sent to me by mail by Dr. Mac Callaham. All specimens were identified in the field as being Diplocardia mississippiensis by Dr. Mac Callaham. The specimens of Lumbricus rubellus used for external anatomy were obtained in the Ottawa area by Ombor Mitra using the pitchfork worm "charming" technique. These were sacrificed by immersion in 70\% ethanol solution and were then preserved in a $15 \%$ formalin solution (both solutions were in distilled water).

Neural anatomy was characterized by dissection and observation using an optical dissection microscope. Images were taken using an axiocam MRc 5 digital camera (by 
Zeiss) and AxioVision software (v. 4.6.3.0) that was used in conjunction with the dissecting microscope, and composite images were made using Photoshop software (CS3). All dissections were done using a dorsal incision that ran longitudinally down the dorsal mid-line of the specimen. Parts of the segmental septa were cut through this incision so that the integument of the earthworm could be spread laterally on both sides and pinned open. The segmental septa were then fully cut, which allowed for the removal of all of the internal organs (including the digestive system, circulatory system, and reproductive system). As these were carefully removed from the specimen, this exposed the nervous system and ventral body wall and allowed for images to be taken. The pharynx had to be removed much more gradually and carefully, as the circumpharyngeal connectives pass around it, and the cerebral ganglia rest on top and in front of it. Nerves were physically traced with a small hook and were usually examined unstained, although Janus Green B (Yack, 1993) was occasionally used in an effort to stain the nervous system.

External anatomy was also examined using an optical dissection scope, but detailed anatomy and sensory organs were observed using a scanning electron microscope (VEGA-II XMU variable pressure SEM, Tescan, PA, USA). Specimens used with the electron microscope were dehydrated by a series of increasing ethanol concentrations $(70,80,90,100 \%)$ for 15 minutes in each solution, before undergoing two final one-hour dehydrations in pure hexamethyldisilizane (Rumph and Turner, 1998). Following this procedure the specimens were mounted onto glass microscope slides before being gold-palladium sputter coated with a Hummer VII sputtering system (Anatech Ltd, Alexandria, VA). 


\subsection{Results}

\subsubsection{Internal Anatomy of the Nervous System}

The primary features of the nervous system were characterized using optical microscopy in the Diplocardia specimens. As discussed in the introduction, the cephalic ganglia, circumpharyngeal connectives, ventral nerve cord, and all three segmental nerve branches have all been previously characterized in other earthworms, and all of these features were readily visible with Diplocardia species. Some of the smaller nerves in the cephalic segments were also identified, but my focus was on the primary nervous structures of the body (i.e. the ventral nerve cord and its immediate nerve roots). The ventral nerve cord and its ganglia were quite prominent, as were the segmental nerve branches that project out laterally from the ventral nerve cord and "disappear" into long tracts of longitudinal muscle (which extend through nearly the full length of the body). Although the segmental nerves give rise to small epidermal nerves and rami, these were too small to be visible.

The main components of the nervous system in Diplocardia mississipiensis appear to be identical to that of Lumbricus terrestris as described by Hess (1925). The ventral nerve cord (VNC) travels down nearly the full longitudinal length of the organism, and is the most prominent structure of the nervous system. The VNC terminates into paired subpharyngeal ganglia in the anterior segments of the organism before splitting into two large circumpharyngeal connectives that travel laterally and dorsally around the pharynx before terminating in the cerebral ganglia (Fig. 3.2). Two sets of paired nerve roots were found extending anteriorly from beneath the 
Figure 3.2 Cephalic Region of the Nervous System in Diplocardia mississipiensis Optical image of the dorsal view of the nervous system, stained with Janus Green B. CG, cerebral ganglion; CPC, circumpharyngeal connective; $\mathbf{S G}$, subpesophageal ganglion; VNC, anterior end of the ventral nerve cord. Scale bar is $1 \mathrm{~mm}$. 
Fig. 3.2

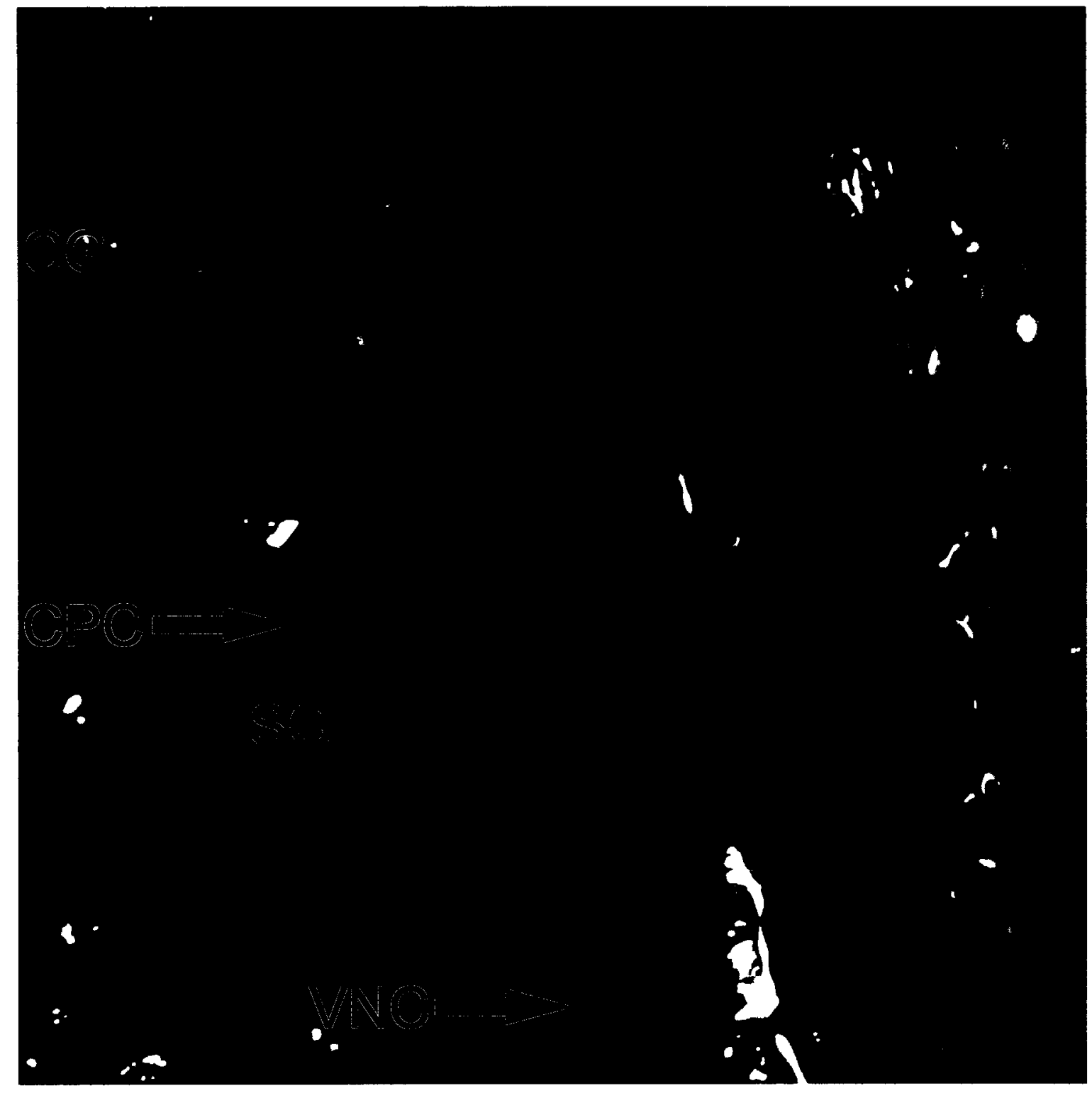


subpharyngeal ganglia (Fig. 3.3), and two more sets of paired nerve roots were found extending anteriorly from the circumpharyngeal connectives as well (Fig. 3.3). The ventral nerve cord is similar in size and proportion to that of Lumbricus terrestris and shows similar ganglionic swellings that are repeated in each segment (except in the most anterior and posterior segments). The segmental nerves were observed to branch outwards and laterally from the ventral nerve cord in the same arrangement observed in Lumbricus terrestris: there are three segmental nerve pairs, the first of which emerges from the anterior end of the segmental ganglia while the second and third pairs emerge very close together near the posterior end of the segmental ganglia. This pattern is repeated in all but the most anterior and posterior segments, and an image of this arrangement is presented in figure 3.3. These segmental nerve pairs disappeared as they extended laterally into tracts of longitudinal muscle that concealed their paths.

None of the small nerves or rami were visible in the specimens used, and this may have been the result of poor preservation. Staining with Janus Green B was only partially helpful in identifying the anatomy of the nervous system. This was because Janus Green B did not fully stain the nervous tissues themselves, while also staining various nonnervous tissues (particularly the intersegmental septa), making its usefulness rather limited. Nevertheless, the arrangement of the primary components of the nervous system in Diplocardia mississipiensis does appear to be identical to that of Lumbricus terrestris. These primary components include the cephalic ganglia, the circumpharyngeal connectives, the ventral nerve cord and its ganglia, and all three segmental nerves branches. Although the fine structure of the nervous system was not examined, no 
Figure 3.3 Schematic of the Central Nervous System of Diplocardia mississipiensis (A) Dorsal view. $\boldsymbol{C G}$, cerebral ganglion; $\boldsymbol{C P C}$, circumpharyngeal connective; $\boldsymbol{S} \boldsymbol{G}$, subpesophageal ganglion; $\boldsymbol{A}$, nerve pair emerging from the lateral area of the cerebral ganglion, passing laterally and anteriorly towards the prostomium; $\boldsymbol{B}$, nerve from beneath the middle region of the circumpharyngeal connective, passing into segment $1 ; A N$, dorsal ramus of anterior segmental nerve (a.k.a. 1st segmental nerve); $\boldsymbol{M N}$, dorsal ramus of median segmental nerve (a.k.a. 2nd segmental nerve); $\boldsymbol{P N}$, dorsal ramus of posterior segmental nerve (a.k.a. 3rd segmental nerve); SGG, segmental ganglia; VNC, ventral nerve cord. Scale bar is $1 \mathrm{~mm}$. (B) Lateral view. Labels are the same as in part A). Scale bar is $1 \mathrm{~mm}$. 
Fig. 3.3

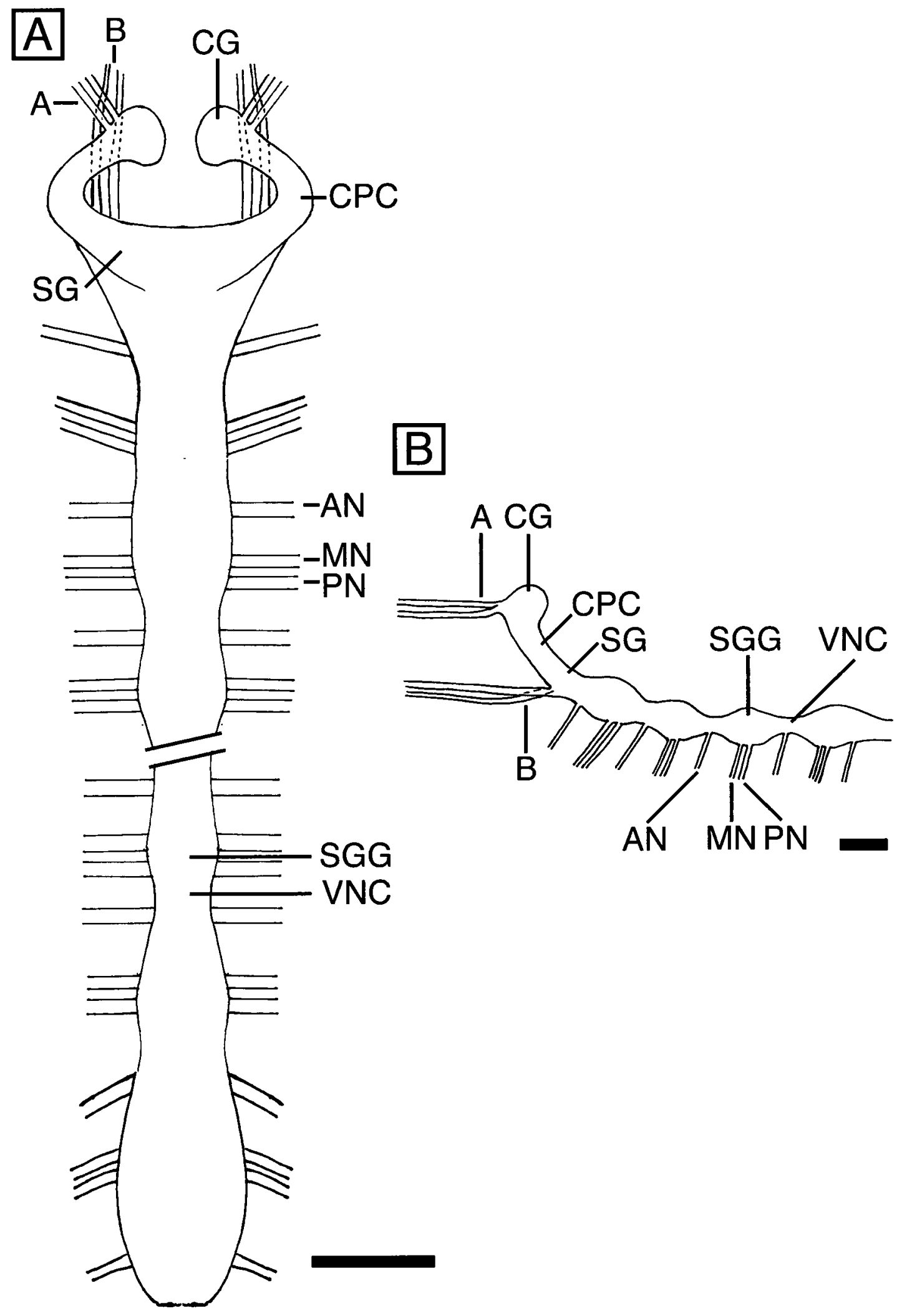


significant differences were found in the anatomy and organization of the primary nervous structures between Diplocardia mississipiensis and Lumbricus terrestris.

\subsubsection{External anatomy}

Few discernible structures were visible on the surface of Diplocardia. Although the anterior, posterior, dorsal, and ventral surfaces were examined, only paired rows of chetae and one row of pores were observed on the body surface. No sensory organs were found at all on the body surface (Fig. 3.4 A, D), and the surface of the integument was riddled with irregular holes (Fig. 3.4 B, C). This suggested that the integument had deteriorated, and that the specimen itself may have been degraded. The body surface around the chetae was carefully examined as well, but no sensory bud-like structures were visible in these areas (Fig. 3.4 E).

The specimen of Lumbricus rubellus used for electron microscopy was better preserved and provided better images than the Diplocardia specimen. Sensory organs were readily visible in the anterior and posterior regions of this organism. These consisted of round, oval, or rectangular structures that were distinct from the surrounding integument (Fig. 3.5). Sometimes they were positioned in a "pit" or depression, but this was not always the case. These structures were more dense on the anterior end of the specimen, but were also numerous on the posterior segments, and were typically organized into rows (Fig. 3.5 B, C). Organs on the posterior segments appeared to have a more ordered arrangement and were positioned in rows, although there were still some "randomly" positioned organs in this area, while sensory organs in the anterior portion of the organism appeared to have a more random distribution. Comparisons of these 
Figure 3.4 Body surface of Diplocardia.

A) Dorsal view of whole organism, indicating areas where magnified images were taken. B) Anterior portion of organism (scale bar $=2 \mathrm{~mm}$ ). C) Closeup of second segment, with the first and third segments in frame. Damage to the integument is clearly visible. Scale bar $=200 \mu \mathrm{m}$. D) Dorso-lateral view of middle segments, showing a row of paired chetae. Scale bar $=2 \mathrm{~mm}$. E) Closeup of body surface near chetae. Scale bar $=100 \mu \mathrm{m}$. 

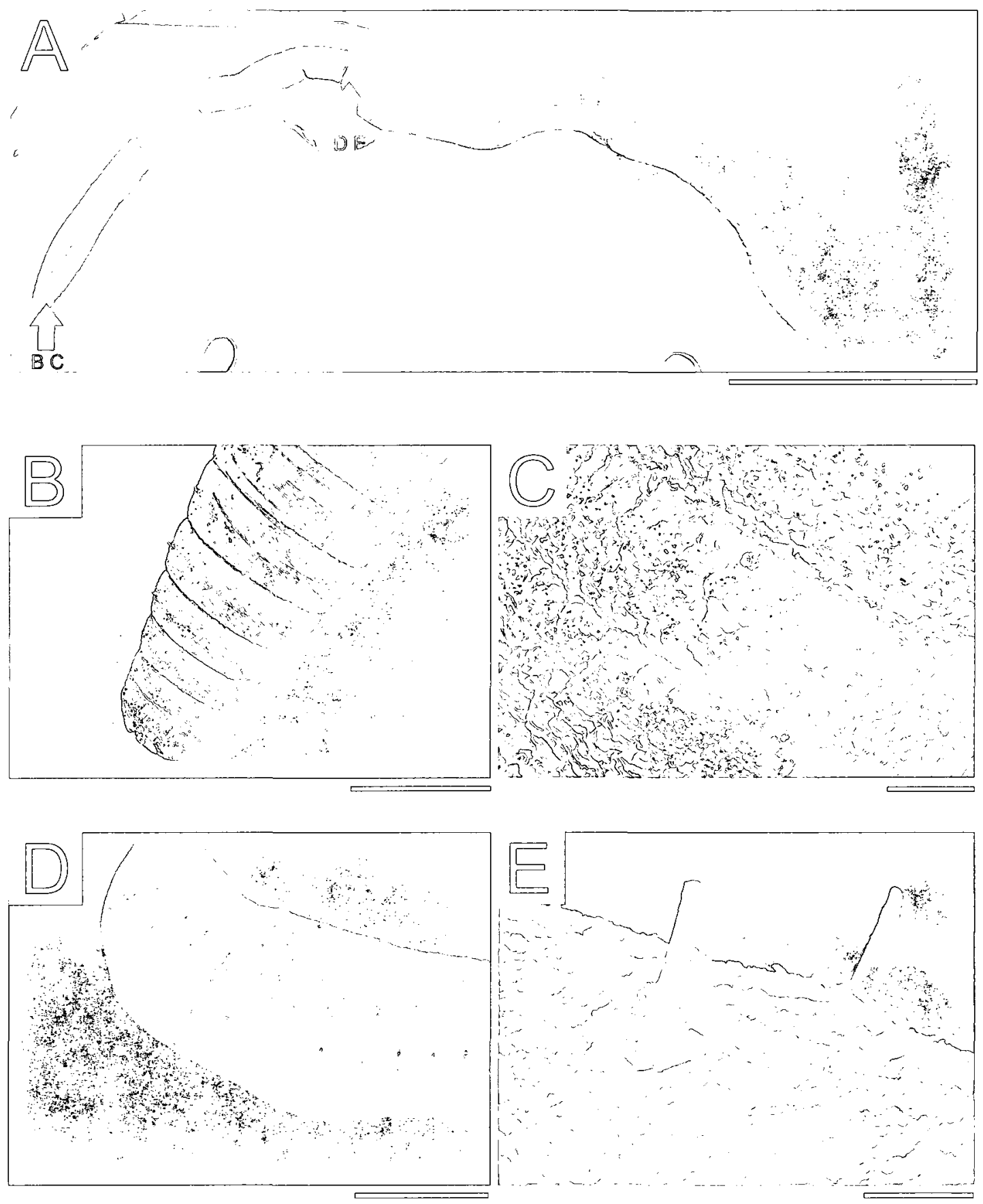
Figure 3.5 Arrangement of Sensory Organs in Lumbricus rubellus

A) Dorsal view of whole organism, indicating areas where magnified images were taken. B) Rows of sensory organs in the anterior segments. One sense organ is marked with the arrow. Scale bar $=200 \mu \mathrm{m}$ D) Rows of sensory organs are formed into more distinct bands around the posterior segments, although randomly arranged sensory organs are still present. One sense organ is marked with the arrow. Scale bar $=500 \mu \mathrm{m} \mathrm{D)} \mathrm{Anterior}$ segment: sensory organs are dense, but show a less distinct morphology and a less ordered arrangement. Sensory organ is marked with an arrow. Scale bar $=100 \mu \mathrm{m} \mathrm{E}$ ) Posterior segment: fewer sensory organs are present, but they are more distinct and ordered in their arrangement. Sensory organ is marked with an arrow. Scale bar $=100$ $\mu \mathrm{m}$. F) Isolated sense organ and surrounding area of integument. Scale bar $=20 \mu \mathrm{m} . \mathrm{G}$ ) Closeup of one sense organ. Note the cilia-like structures in the center region of the organ. Scale bar $=10 \mu \mathrm{m}$. 
Fig.g. 3.5

$\mathbb{A}$
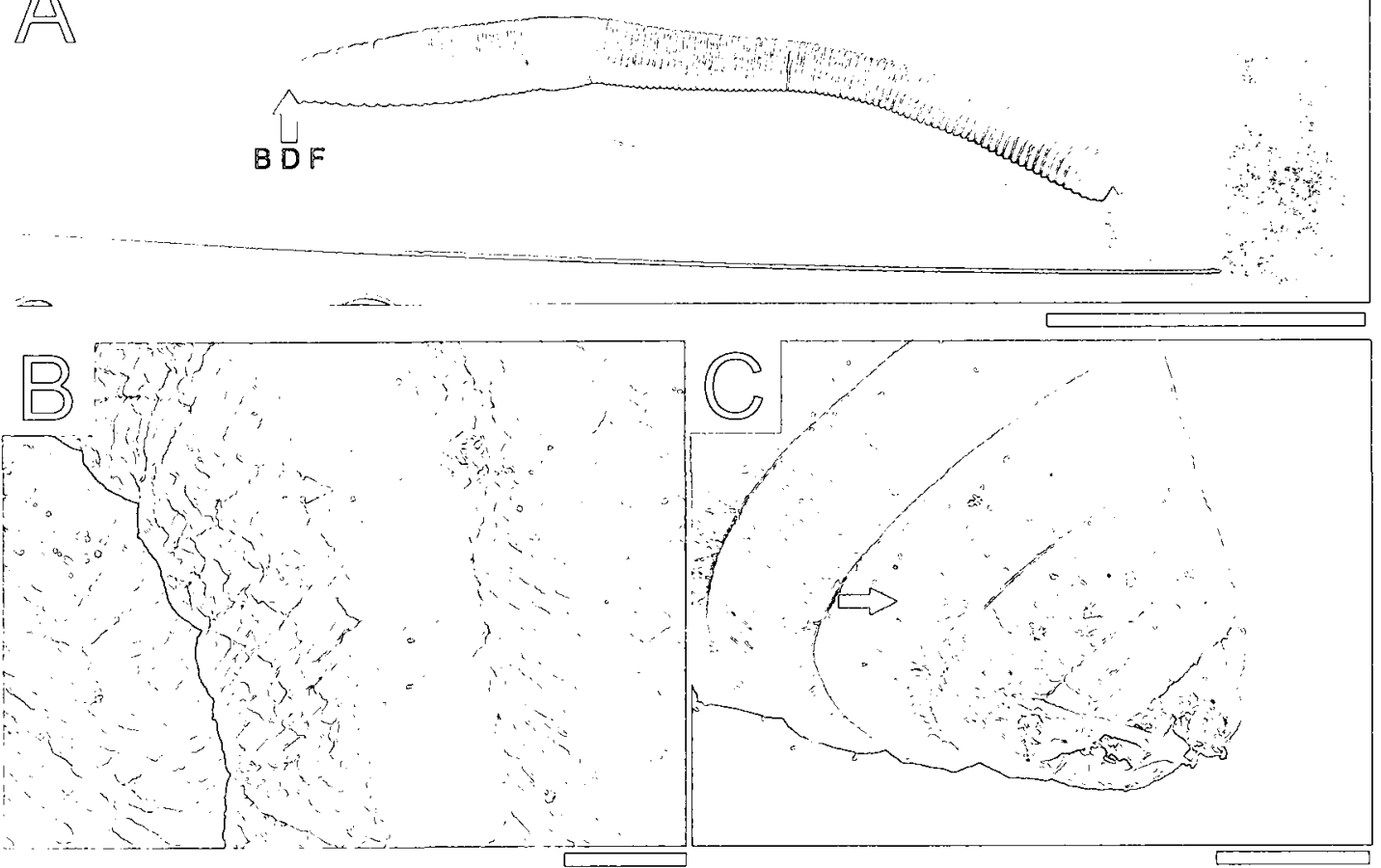

(D)

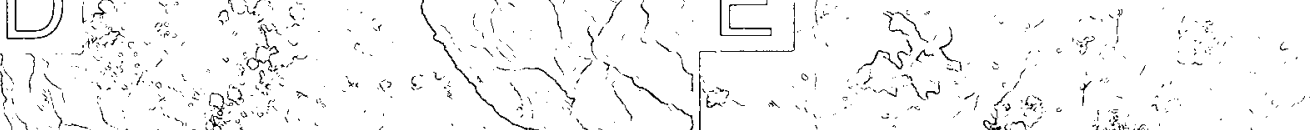

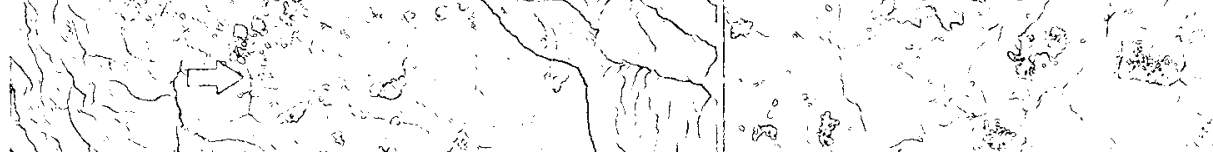
S1 3 (1)

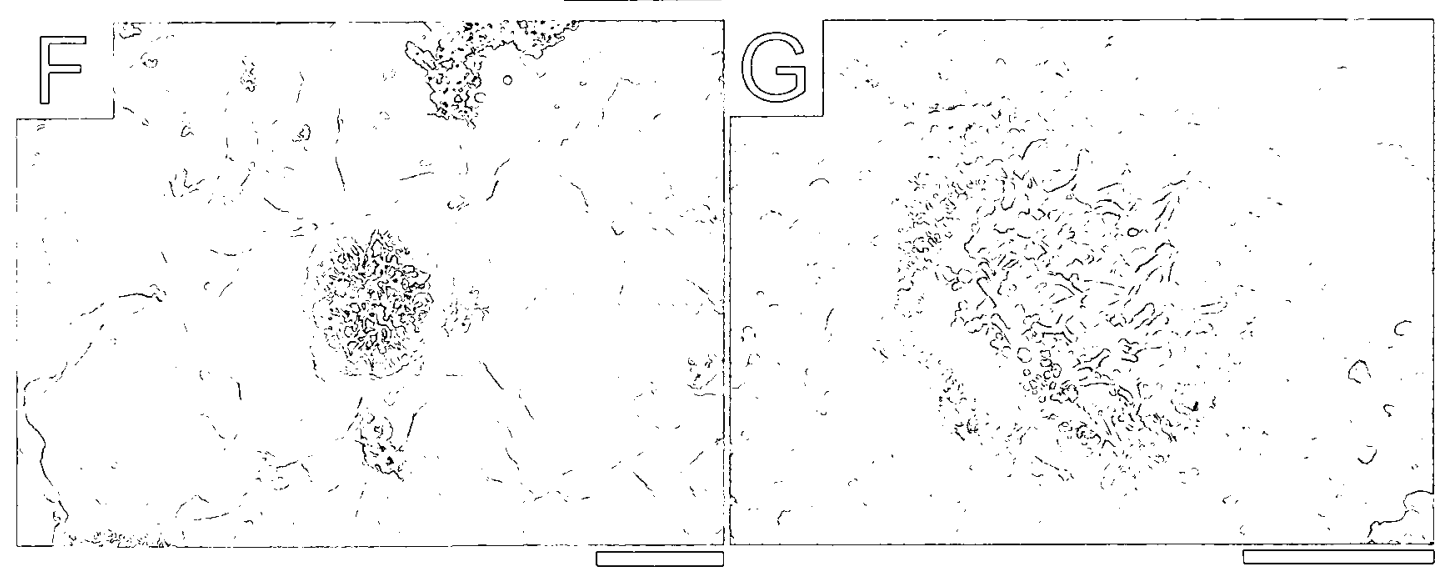


arrangements are presented in Figure 3.5 D and E. These structures were more common on the ventral surface than the dorsal surface, and no organs were found in the middle segments at all. These organs appeared to be heavily ciliated, with cilia observed in the center portion of these organs while smaller protrusions were visible around the central area of cilia (Fig. 3.5 F, G).

\subsection{Discussion}

The similar arrangement between the ganglia and main nerve roots of the nervous systems in Lumbricus terrestris and Diplocardia mississipiensis is rather interesting to note due to the fact that these two species belong to different superfamilies within the class Oligochaeta. There are various superfamilies of earthworms, and Lumbricus terrestris belongs to the superfamily Lumbricoidea while Diplocardia mississipiensis belongs to the superfamily Megascolecidea (Blakemore, 2006). Since these two species are relatively distantly related as far as earthworms go, a considerable amount of evolutionary conservation is implied by the anatomical similarities between the nervous systems of these two earthworm species. This conservation of form may also suggest conservation in function, although this has not been experimentally demonstrated. Since some of the functions of specific components of the nervous system of Lumbricus terrestris have been demonstrated, it seems possible that the same or at least similar functions would occur in the equivalent structures of the nervous system in Diplocardia. These possible parallels should help set the stage for future anatomical and physiological work that may help elucidate exactly how earthworms are detecting and responding to substrate vibration, or more precisely, how vibration stimuli are transduced into action 
potentials in the nervous system which then elicit activity in the nervous system that causes locomotion as a behavioural response in the organism.

Research using various earthworm species (including Lumbricus terrestris and Allolobophora longa) has demonstrated that the segmental nerves all respond to tactile stimuli. (Laverack, 1960; Mill and Knapp, 1967; Mill, 1982). While vibrational stimuli have not been accurately traced in the nervous system of any earthworm, it is possible that they might share the same pathways as tactile stimuli. If so, this would make the $1^{\text {st }}$ and $3^{\text {rd }}$ segmental nerve branches the most likely candidates for the transmission of vibration stimuli to the ventral nerve cord, and future electrophysiological experiments should seek to examine the activity in these nerve branches in response to vibration stimuli. While it is unclear exactly how the ventral nerve cord processes tactile and/or vibrational signals, Bullock and Horridge (1965) state that tactile stimulation of the anterior 40 segments appears to excite the median giant fiber of the ventral nerve cord, while tactile stimulation to the posterior segments of the body excites the lateral giant fibers of the ventral nerve cord. With respect to surfacing responses, vibration stimuli coming in to the ventral nerve cord must eventually stimulate locomotory activity in the nervous system. Motor output, like sensory input, is mostly segmental in the earthworm, but unlike tactile input the motor output signals appear to use all three segmental nerves (Mill, 1982), suggesting that vibration signals received from the entire body surface (during worm grunting) gets transmitted to most if not all segmental ganglia of the VNC via the first and third segmental nerves of each segment, before motor output is sent out from the VNC by all three segmental nerves. This may imply localized processing in the segmental ganglia with respect to translating vibrational input stimuli into motor output 
signals, although it is entirely possible that the vibration stimuli signals are sent to the cephalic ganglia for processing before motor output signals are sent to the muscles. Further physiological experimentation will be required to determine if peripheral or central processing is involved in the behavioural responses of earthworms to vibration, although in either case the segmental nerves will almost certainly play a crucial role.

Although the behavioural response to vibrations observed in surfacing earthworms appears to be similar to normal locomotion, it is also possible that this response is related to the rapid escape response of earthworms as well. While normal locomotion in an earthworm consists of rhythmic peristaltic muscle contractions over time, the escape response in earthworms is a sudden stereotyped and rapid behaviour where the anterior and/or posterior end of a worm rapidly withdraws (bilaterally shortens) in response to threatening stimuli such as touch or substrate vibration (Drewes, 1997). Although locomotion and the rapid escape response are normally unrelated behaviours, it is possible that there is some overlap between these activities during the surfacing response to vibration, since surfacing earthworms often display sudden movements of the body that include contractions and side to side thrashing (personal observations). However, the majority of earthworm behaviour during surfacing responses appears to consist of "normal" peristaltic locomotion.

How exactly is the surfacing response elicited? It's possible that this particular response may arise because of the type of stimulus perceived by the organism, since different types of predators may create physical stimuli with different spatial and temporal characteristics. Some predatory stimuli (a pecking bird, for example) would create tactile stimulus of short duration, localized near a specific part of the earthworm 
body closest to the pecking, and might be repeated a number of times. In contrast, stimulus from a predator like a digging mole would be relatively continuous over time (due to the repetitive and constant digging motion of moles) and would likely stimulate most if not all of the earthworm body (since most or all of the volume of soil around the earthworm would vibrate from the digging). These different scenarios should result in different patterns of activity in the nervous systems of the worms. In the pecking bird scenario, tactile and/or vibrational receptors in only a few segments would be strongly stimulated, creating afferent impulses in the segmental nerves of those segments, which would then result in a rapid escape response or locomotion via the ventral nerve cord (involving either the medial giant fibers or the lateral giant fibers, depending on which segments were stimulated). Meanwhile, the vibrations produced by a digging mole would likely cause tactile and vibration receptors to be stimulated over most or all of the earthworm body wall, creating afferent impulses in nearly all segmental nerves of the body, which should in turn result in the stimulation of both the medial and lateral giant fibers of the ventral nerve cord. It's possible that such a large influx of afferent sensory information produces the specific response in the nervous system of the earthworm that elicits surfacing behaviour in response to soil vibration, suggesting that the volume and saturation of incoming nerve activity might be what differentiates the stimulus of soil vibration from other types of tactile and predatory stimuli. Of course, this is speculative, but this idea might be tested experimentally by stimulating multiple segmental nerves simultaneously, or by stimulating both the medial and lateral giant VNC fibers at once. The resulting nervous system activity and organismal behaviour could then be contrasted to that observed by stimulating the segmental nerves of only one or two segments, or by 
stimulating only one of the giant fiber systems. It should be noted that stimulation of segmental nerves in prior experimentation did not elicit locomotion (Bullock and Horridge, 1965), but it is possible that stimulation of many segmental nerves at once might be required to elicit such a response. It is thought that small motor-neurons are likely important in generating peristaltic motion, and it has been suggested that sensory cells probably make direct contact with these neurons (Bullock and Horridge, 1965).

The precise details of how vibration stimuli are translated into locomotory responses have yet to be elucidated, but the data collected up to this point does set the stage for electro-physiological work to be carried out in the near future in an attempt to answer this question. Questions about whether or not this response is processed peripherally or centrally, if the response is related to locomotion or rapid escape responses, and just what components of the segmental nerves and giant fiber systems are involved in this response remain to be answered by subsequent research.

\section{Sensory Organs}

The sensory organs found in Lumbricus rubellus do match with the descriptions of these organs from the literature (Langdon, 1895; Bullock and Horridge, 1965; Mill, 1982; Edwards and Bohlen, 1996). Although none of these organs were found in Diplocardia, it is almost certain that this is a result of poorly preserved specimens. In contrast, the sense organs of Lumbricus rubellus were easily visible over much of the body surface of the organism. This wide distribution may be important if this organ is indeed involved in vibration reception. Although these sensory buds have not been directly stimulated to examine exactly what types of stimuli they are sensitive to, 
morphological comparisons with closely related organisms do support the idea that they may be vibration sensitive. The overall morphology of these structures is very similar to the equivalent structures in related annelids, including clitellates, leeches, polychaetes, and other oligochaetes (Derosa and Friesen, 1981; Farnesi et al., 1982; Jouin et al., 1985; Molnar et al., 2006). The similarities between these structures are fairly specific, especially with respect to their overall organization and morphology, as well as the fact that many of these buds are ciliated. The most detailed work on these receptors has been conducted in the leech, where ciliated sensory buds have been shown to be vibration sensitive, and importantly, have also been shown to induce locomotion in response to water vibration stimuli (Brodfuehrer and Friesen, 1984). Although these sensory buds contain different types of ciliated receptor cells, the uniciliate cells have been most implicated as vibration receptors (Philips and Friesen, 1982), and uniciliate cells are also present in the equivalent sensory organs of earthworms. These morphological comparisons make the sensory buds observed in earthworms a very likely candidate for vibration reception, although further work will need to be done to directly confirm this.

Further work must also be done using properly preserved specimens to fully examine the surface receptors of Diplocardia, as this has yet to be accomplished, and it would be important to compare the sensory organs between Diplocardia and Lumbricus rubellus. If these organs are responding to different types of soil disturbance (vibration versus compression), there may anatomical differences in the structures of these organs, as well as differences in their numbers, distribution, and sensitivities. Although these organs are fairly small it might be possible for future experimentation to try and stimulate these structures directly in an attempt to further investigate possible differences in their 
reception of tactile and vibrational stimuli. This could be coupled with electrophysiological recordings from the epithelial and segmental nerves that connect to these organs in an effort to understand what role (if any) these organs may have in the surfacing responses of different earthworms. My work did not examine the free nerve endings that are present in the epidermal layers of earthworms, and it is possible that these may be involved in the reception of soil vibration and/or soil compression as well. A combination of physiology experiments and more detailed anatomical investigation will be necessary to clarify the precise roles of these structures with respect to vibration and tactile sensitivity in earthworms. 


\section{Chapter 4}

\section{General Discussion}


The experiments described in this thesis have demonstrated that a variety of earthworm species in different geographic areas can be made to emerge from the soil when subjected to soil vibration and/or mechanical disturbance to the soil. Two common vibration mediated earthworm harvesting methods were tested, and while they may both be effective at eliciting surfacing behaviour among the earthworms of Florida (Catania, 2008; Mitra, 2009), the significant differences in their efficacy among the earthworms of Ontario implies that they may not be operating via the same mechanisms.

The evidence accumulated so far suggests that the pitchfork method may be eliciting behavioural responses in earthworms via soil compression, while the stob and rooper technique may be using seismic vibrations. This evidence is preliminary, however, and consists of differences in effectiveness between the two techniques when used in Ontario, differences in the effective distances of the two techniques, as well as visual observation of soil disturbance using both methods. As a result, this evidence is limited and is not completely conclusive, and further experimentation will need to be done to completely demonstrate the suggested difference in the mechanism of action of these two earthworm-harvesting methods.

The two primary hypotheses (rainfall and predatory moles) regarding the possible adaptive significance of these surfacing responses have been tentatively examined, and the evidence so far does lend support to the idea that the worms are surfacing in an attempt to escape fossorial predators. This hypothesis must be explored further in order to completely understand the relationships between such predators and earthworms. For example, the distribution of moles in Ontario and England have yet to be examined, and the roles of other fossorial predators (both vertebrate and invertebrate) have not been 
examined either. Further research using live moles is recommended to examine this phenomenon in more detail.

Animals are always evolving novel ways to interpret their environment through their senses, especially when it comes to sensory modalities which provide cues that assist in predator avoidance. It is very interesting that earthworms may have evolved two different methods of manifesting the same type of escape response (sensitivity to soil vibration vs. soil compression), and it is similarly very interesting that humans as well as some animals have learned to exploit this escape response, by using the rare predator effect. A number of questions remain to be answered, while this research also opens up doors for asking new questions.

For example, further work will need to be done to properly demonstrate the differential stimuli and effects of soil compression versus seismic vibration with respect to these phenomena. Are moles the only subterranean predators that earthworms are attempting to avoid? And are moles or other underground predators evolving any counter-strategies against surfacing behaviours? Can any of the predators detect and follow the vibrations of escaping earthworms? How do worms of other areas (e.g. Britain) respond? Finally, there is much work that can be done to understand how these responses are working physiologically. How exactly does sensory stimulation get translated into locomotion responses? What specific components and pathways of the nervous system are involved? Are the cerebral ganglia involved, or is this response peripherally processed? The likely receptors have been identified, so how might they be tested? Are the Diplocardia worms using the same receptors and physiological response pathways as the earthworms of Ottawa? And how might the earthworm species of Ottawa 
and Florida compare to those that respond elsewhere, such as the earthworms of Britain? Do they possess similar receptors?

Many organisms experience a very different sensory world compared to the one we "live" in and experience. This research offers a glimpse into one of these worlds, a world that has been exploited by both humans and animals for some time now, but a world that has only now been examined scientifically, despite lying right underneath our very feet. To uncover a novel predator-prey relationship in an organism as common and as significant as the earthworm opens up the doors to a variety of multi-disciplinary research projects that can shed more light on this fascinating underground phenomenon. 


\section{References:}

Baroni-Urbani, C., Buser, M.W. and Schilling, E. (1988). Substrate vibration during recruitment in ant social organization. Insectes Sociaux. 35, 241-250.

Blakemore, R. J. (2006). A Series of Searchable Texts on Earthworm Biodiversity, Ecology and Systematics from Various Regions of the World - 2nd Edition and Supplement (2006). General Eds: N. Kaneko \& M.T. Ito. COE Soil Ecology Research Group, Yokohama National University, Japan. CD-ROM Publication. Online: http://bioeco.eis.ynu.ac.jp/eng/database/earthworm/ [accessed Nov 30th, 2007].

Brodfuehrer P. D. and Friesen O. W. (1984). A sensory system initiating swimming activity in the medicinal leech. Journal of Experimental Biology. 108, 341-355.

Brownell, P. H. (1977). Compressional and surface waves in sand used by desert scorpions to locate prey. Science. 197, 479-48.

Bullock, T. H. and Horridge, G. A. (1965). Structure and Function in the Nervous System of Invertebrates. W.H. Freeman and Company, San Francisco and London.

Butt, K. R. and Nuutinen, V. (2005). The dawn of the dew worm. Biologist. 52, 218223.

Callaham, M. A. Jr. and Hendrix, P. F. (1998). Impact of earthworms (Diplocardia: Megascolecidae) on cycling and uptake of nitrogen in coastal plain forest soils from northwest Florida, USA. Applied Soil Ecology. 9, 233-239.

Catania, K. C. (2008). Worm grunting, fiddling, and charming - humans unknowingly mimic a predator to harvest bait. PLOS ONE. 3(10), art. no. e3472.

Chuang, S. C. and Chen, J. H. (2008). Role of diurnal rhythm of oxygen consumption in emergence from soil at night after heavy rain by earthworms. Invertebrate Biology. 127, 80-86.

Cocroft R. B. and Rodríguez R. L. (2005). The behavioral ecology of insect vibrational communication. BioScience. 55, 323-334.

Cokl A. and Virant-Doberlet M. (2003). Communication with substrate-borne signals in small plant-dwelling insects. Annual Review of Entomology. 48, 29-50.

Collier, H. O. J. (1939). Central nervous activity in the earthworm. I. Responses to tension and to tactile stimulation. Journal of Experimental Biology. 16, 286-299.

Darwin, C. (1881). The Formation of Vegetable Mould Through the Action of Worms with Observation on Their Habits. London: Murray. 
Derosa S. Y. and Friesen O. W. (1981). Morphology of leech sensilla: observations with the scanning electron microscope. Biological Bulletin. 160, 383-393.

Drewes, C. D. (1997). Sublethal effects of environmental toxicants on Oligochaete escape reflexes. American Zoologist. 37, 346-353.

Edwards, C. A. and Bohlen, P. J. (1996). Biology and Ecology of Earthworms, 3rd edn. London: Chapman \& Hall.

Elias, D. O., Lee, N., Hebets, E. A., Mason, A. C. (2006). Seismic signal production in a wolf spider: parallel versus serial multi-component signals. Journal of Experimental Biology. 209, 1074-1084.

Farnesi, R. M., Marinelli, M., Tei, S., Vagnetti, D. (1982). Ultrastructural aspects of mechano- and chemoreceptors in Branchiobdella pentodonta (Annelida, Oligochaeta). Journal of Morphology. 173, 237-245.

Gardner, C. R. (1976). The neuronal control of locomotion in the earthworm. Biologial Reviews. 51, 25-52.

Hendrix, P. F., Callaham, M. A. Jr., Kirn, L. (1994). Ecology of neartic earthworms in the southern USA. II. Effects of bait harvesting on Diplocardia (Oligochaeta, Megascolecidae) populations in Apalachicola National Forest, North Florida. Megadrilogica. 5, 73-76.

Hendrix, P. F., Callaham, M. A., Drake, J. M., Huang, C. Y., James, S. W., Snyder, B. A., Zhang, W. X. (2008). Pandora's box contained bait: the global problem of introduced earthworms. Annual Review of Ecology, Evolution, and Systematics. 39, 593 613.

Herz, M. J., Peeke, H. V. S., Wyers, E. J. (1967). Classical conditioning of the extension response in the earthworm. Physiology and Behaviour. 2, 409-411.

Hess, W.N. (1925). Nervous system of the earthworm Lumbricus terrestris. Journal of Morphology and Physiology. 40, 235-259.

Hill, P. S. M. (2001). Vibration as a communication channel: a synopsis. American Zoologist. 41, 1133-1134.

Hill, P. S. M. (2008). Vibrational Communication in Animals. Harvard University Press, Cambridge, Massachusetts.

Hill, P. S. M. and Shadley, J. R. (2001). Talking back: sending soil vibration signals to lekking prairie mole cricket males. American Zoologist. 41, 1200-1214. 
Jouin, C., Tchernigovtzeff C., Baucher M. F., Toulmond A. (1985). Fine structure of probable mechano- and chemoreceptors in the caudal epidermis of the lugworm Arenicola marina (Annelida, Polychaeta). Zoomorphology. 105, 76-82.

Kaufmann, J. H. (1986). Stomping for earthworms by wood turtles, Clemmys insculpta: a newly discovered foraging technique. Copeia. 4, 1001-1004.

Kaufmann, J. H. (1989). The wood turtle stomp. Natural History. 8, 8-11.

Knapp, M. G. and Mill, P. J. (1971). The fine structure of ciliated sensory cells in the epidermis of the earthworm Lumbricus terrestris. Tissue and Cell. 3, 623-636.

Kristan, W. B. Jr, McGirr, S. J., Simpson, G. V. (1982). Behavioural and mechanosensory neurone responses to skin stimulation in leeches. Journal of Experimental Biology. 96, 143-160.

Langdon, F. E. (1895). The sense organs of Lumbricus agricola Hoffm. Journal of Morphology. 11, 193-234.

Laverack, M. S. (1960). Tactile and chemical perception in earthworms - I. Responses to touch, sodium chloride, quinine, and sugars. Comparative Biochemistry and Physiology. 1, 155-163.

Mankin, R. W., Crocker R. L., Flanders K. L., Shapiro J. P. (1998). Acoustic detection and identification of insects in soil. Journal of the Acoustical Society of America. 103, 2826-2826.

Mason, M. J. and Narins, P.M. (2001). Seismic signal use by fossorial mammals. American Zoologist. 41, 1171-1184.

Mill, P. J. (1982). Recent developments in earthworm neurobiology. Comparative Biochemistry and Physiology. 73, 641-661.

Mill, P. J. and Knapp, M. F. (1967). Efferent sensory impulses and the innervation of tactile receptors in Allolobophora longa Ude and Lumbricus terrestris Linn. Comparative Biochemistry and Physiology. 23, 263-276.

Minnich, J. (1977). The Earthworm Book. Emmaus, Rodale Press.

Mitra O., Callaham M. A., Smith M. L., Yack J. E. (2009). Grunting for worms: seismic vibrations cause Diplocardia earthworms to emerge from the soil. Biology Letters. 5, 16-19.

Molnar, L., Kiszler, G., Pollak, E. (2006). Identification and pattern of primary sensory cells in the body wall epithelium of the tubificid worm, Limnodrilus hoffmeisteri.

Hydrobiologia. 564, 45-50. 
Oelze M. L., O'Brien W. D., Darmody R. G. (2002). Measurement of attenuation and speed of sound in soils. Soil Science Society of America. 66, 788-796.

O'Gara, B. A., Murray, P. M., Hoyt, E. M., Leigh-Logan, T., Smeaton, M. B. (2006). The vitamin $\mathrm{E}$ analog trolox reduces copper toxicity in the annelid Lumbriculus variegatus but is also toxic on its own. Neurotoxicology. 27, 604-614.

Peeke, H. V., Herz, M. J., Wyers, E. J. (1965). Amount of training, intermittent reinforcement and resistance to extinction of conditioned withdrawal responses in the earthworm (Lumbricus terrestris). Animal Behavior. 13, 566-570.

Philips C. E. and Friesen O. W. (1982). Ultrastructure of the water-movement-sensitive sensilla in the medicinal leech. Journal of Neurobiology. 13, 473-486.

Quirici, V. and Costa, F. G. (2005). Seismic communication during courtship in two burrowing tarantula spiders: an experimental study on Eupalaestrus weijenberghi and Acanthoscurria suina. The Journal of Arachnology. 33, 159-166.

Ratner, S. C. and Miller, K. R. (1959). Classical conditioning in earthworms, Lumbricus terrestris. Journal of Comparative Physiology and Psychology. 52, 102-105.

Reynolds, J. W. (1977). The Earthworms (Lumbricidae and Sparganophilidae) of Ontario. Royal Ontario Museum, Life Sciences, Miscellaneous Publications, Toronto.

Rosengaus, R. B., Jordan, C., Lefebvre, M. L., Traniello, J. F. A. (1999). Pathogen alarm behavior in a termite: a new form of communication in social insects.

Naturwissenschaften. 86, 544-548.

Rumph, J. A. and Turner, W. J. (1998). Alternative to critical point drying for softbodied insect larvae. Annals of the Entomological Society of America. 91, 693-699.

Shaffer, P. L. (1979). The feeding biology of Podarke pugettensis (Polychaeta: Hesionidae). Biological Bulletin. 156, 343-355.

Thanthianga, C. and Mitchell, R. (1987). Vibrations mediate prudent resource exploitation by competing larvae of the bruchid bean weevil Callosobruchus maculates. Entomologia Experimentalis et Applicata. 44, 15-22.

Tinbergen, N. (1960). The Herring Gull's World. A Study of the Social Behaviour of Birds. New York: Basic Books.

Vail, V. A. (1972). Natural history and reproduction in Diplocardia mississippiensis (Oligochaeta). Bulletin of Tall Timbers Research Station. 11, 1-39. 
Virant-Doberlet M. and Cokl A. (2004). Vibrational communication in insects. Neotropical Entomology. 33, 121-134.

Wallwork, J.A., (1983). Earthworm Biology. Edward Arnold (Publishers) Ltd., London.

Watanabe. H., Takaya, T., Shimoi, T., Ogawa, H., Kitamura, Y., Oka, K. (2005).

Influence of mRNA and protein synthesis inhibitors on the long-term memory acquisition of classically conditioned earthworms. Neurobiology of Learning and Memory. 83, 151-157.

Yack, J. E. (1993) Janus Green B as a rapid, vital stain for peripheral nerves and chordotonal organs in insects. Journal of Neuroscience Methods. 49, 17-22.

Yanez, E., Cuadrado, S., Martinez-Ansemil. (2006). External sense organs in freshwater Oligochaetes (Annelida, Clitellata) revealed by scanning electron microscopy. Journal of Morphology. 267, 198-207. 


\section{Appendix}

Table of Ontario Stob and Rooper Emergence Results.

The "before" column indicates earthworms observed on the soil surface for 5 minutes prior to vibration production, the "during" column indicates worms observed surfacing during vibration production, the "after/surface" column indicates worms observed on the surface for 5 minutes after vibration production ceased, and the "after/in soil" column indicates worms collected in a $20 \times 20 \times 20 \mathrm{~cm}$ soil sample directly in front of the vibration source.

\begin{tabular}{|c|c|c|c|c|c|}
\hline \multirow[t]{2}{*}{ site } & \multicolumn{3}{|c|}{ STOB } & & \multirow[b]{2}{*}{$\begin{array}{l}\text { After (in } \\
\text { soil) }\end{array}$} \\
\hline & Before & During & $\begin{array}{l}\text { After } \\
\text { (surface) }\end{array}$ & & \\
\hline April 28 Herbert Corners & & 2 & 0 & 0 & 3 \\
\hline May 4 Pinhey Forest & & 0 & 0 & 0 & 0 \\
\hline May 5 Mongrain Property & & 0 & 0 & 0 & 4 \\
\hline May 6 Mer Bleu & & 0 & 1 & 0 & 11 \\
\hline May 7 Herbert Corners & & 0 & 0 & 0 & 3 \\
\hline May 13 Mongrain Property & & 0 & 0 & 0 & 0 \\
\hline May 15 Nesbitt & & 0 & 0 & 0 & 3 \\
\hline May 22 Mer Bleu & & 0 & 0 & 0 & 9 \\
\hline May 22 Herbert Corners & & 0 & 1 & 0 & 1 \\
\hline May 28 Mer Bleu & & 0 & 1 & 0 & 4 \\
\hline May 29 Herbert Corners & & 0 & 0 & 0 & 2 \\
\hline \multirow[t]{2}{*}{ June 10 Herbert Corners } & & 0 & 0 & 0 & 1 \\
\hline & & 0 & 0 & 0 & 3 \\
\hline \multirow{2}{*}{ June 18 Mer Bleu } & & 0 & 0 & 0 & 0 \\
\hline & & 0 & 0 & 0 & 5 \\
\hline
\end{tabular}




\section{Table of Ontario Stob and Rooper Emergence Results.}

The "before" column indicates earthworms observed on the soil surface for 5 minutes prior to vibration production, the "during" column indicates worms observed surfacing during vibration production, the "after/surface" column indicates worms observed on the surface for 5 minutes after vibration production ceased, and the "after/in soil" column indicates worms collected in a $20 \times 20 \times 20 \mathrm{~cm}$ soil sample directly in front of the vibration source.

\begin{tabular}{|c|c|c|c|c|c|c|}
\hline \multirow[t]{2}{*}{ site } & \multicolumn{5}{|c|}{ PITCHFORK } & \multirow[b]{2}{*}{$\begin{array}{l}\text { After (in } \\
\text { soil) }\end{array}$} \\
\hline & Before & & During & $\begin{array}{l}\text { After } \\
\text { (surface) }\end{array}$ & & \\
\hline \multirow[t]{3}{*}{ April 28 Herbert Corners } & & 0 & 3 & & 0 & 3 \\
\hline & & 0 & 3 & & 0 & 2 \\
\hline & & 0 & 9 & & 0 & 3 \\
\hline May 4 Pinhey Forest & & 0 & 1 & & 0 & 0 \\
\hline \multirow[t]{2}{*}{ May 5 Mongrain Property } & & 0 & 5 & & 0 & 5 \\
\hline & & 0 & 0 & & 0 & 4 \\
\hline \multirow[t]{2}{*}{ May 6 Mer Bleu } & & 0 & 0 & & 0 & 1 \\
\hline & & 0 & 2 & & 0 & 10 \\
\hline \multirow[t]{3}{*}{ May 7 Herbert Corners } & & 0 & 1 & & 0 & 3 \\
\hline & & 0 & 0 & & 0 & 6 \\
\hline & & 0 & 1 & & 0 & 6 \\
\hline \multirow[t]{2}{*}{ May 13 Mongrain Property } & & 0 & 0 & & 0 & 1 \\
\hline & & 1 & 4 & & 0 & 4 \\
\hline \multirow[t]{3}{*}{ May 15 Nesbitt } & & 0 & 2 & & 0 & 9 \\
\hline & & 0 & 9 & & 0 & 6 \\
\hline & & 0 & 3 & & 0 & 3 \\
\hline \multirow[t]{2}{*}{ May 22 Mer Bleu } & & 0 & 2 & & 0 & 9 \\
\hline & & 0 & 0 & & 0 & 1 \\
\hline May 22 Herbert Corners & & 0 & 0 & & 0 & 1 \\
\hline \multirow[t]{2}{*}{ May 28 Mer Bleu } & & 0 & 0 & & 0 & 2 \\
\hline & & 0 & 2 & & 0 & 1 \\
\hline \multirow[t]{3}{*}{ May 29 Herbert Corners } & & 0 & 1 & & 0 & 0 \\
\hline & & 1 & 5 & & 0 & 0 \\
\hline & & 1 & 12 & & 0 & 2 \\
\hline \multirow[t]{2}{*}{ June 10 Herbert Corners } & & 0 & 0 & & 0 & 2 \\
\hline & & 1 & 5 & & 0 & 3 \\
\hline \multirow[t]{2}{*}{ June 18 Mer Bleu } & & 0 & 1 & & 0 & 1 \\
\hline & & 0 & 5 & & 0 & 3 \\
\hline
\end{tabular}

